\title{
Repeated patterns in the evolution of size in island plants
}

\author{
by \\ Matthew Biddick
}

\begin{abstract}
A thesis submitted to
Victoria University of Wellington

in fulfilment of the requirements for the degree of Doctor of Philosophy in Ecology and Biodiversity
\end{abstract}

Victoria University of Wellington

August 2020 
This thesis was conducted under the supervision of:

Prof. Kevin C. Burns (Primary Supervisor)

Victoria University of Wellington

Wellington, New Zealand 


\section{Summary}

For reasons not fully understood, animals often evolve predictably on islands. For example, radiations of large, flightless birds are a common element of many island biotas. However, our understanding of how plants evolve on islands is comparatively poor. Further, an investigation into the evolution of island plants could help resolve unanswered questions about island animals. This thesis investigates insular size changes in a range of plant functional traits.

First (Chapter 2), I explored size changes in 9 species of vines that have colonized islands from the New Zealand and Australian mainland. I asked whether leaf-stem allometry prohibits leaves and stems from evolving independently from one another. Island populations consistently produced larger leaves than did mainland populations. Moreover, changes in leaf size were not associated with concomitant changes in stem size, suggesting that trait allometry does not govern trait evolution on islands.

Next (Chapter 3), I asked whether plants obey the infamous island rule, a putative trend in island evolution wherein small animals become large on islands and large animals become small. I demonstrate that plant stature and leaf area obey the island rule, and seed size does not. My findings illustrate that the island rule is more pervasive than previously considered, but that support for its predictions vary among plant functional traits.

Third (Chapter 4), I demonstrate that the island rule results from evolutionary drift along bounded trait domains. The island rule has long been hypothesized to result from a suite of selective pressures. Applying my model to island plants, I show that evolutionary drift is the most parsimonious explanation for the island rule pattern.

Finally (Chapter 5), to explore insular patterns in leaf size evolution, I conducted a large-scale, macroevolutionary analysis of leaf size on 98 of New Zealand's offshore islands. Leaf gigantism was emblematic of island populations, and was most prominent in taxa with variable leaf morphologies on the mainland. Further, leaf gigantism was greatest in populations inhabiting old, distant islands, suggesting that time since divergence is a direct predictor of morphological differentiation between mainland and island populations.

Overall, this thesis reveals novel patterns, and helps disentangle the distinct roles of natural selection and drift, in the evolution of plant form and function on islands. Finally, this thesis illustrates how investigating the changes in plant traits can help identify the evolutionary mechanisms operating on islands. 
"To do science is to search for repeated patterns,

not simply to accumulate facts."

- Robert MacArthur 


\section{Acknowledgements}

There are a great many people to thank for where and who I am today. I will start from the beginning...

I will never forget the day this whole journey began. Overwhelmed with the hustle and bustle of the city, my mind stale from regurgitating biological facts on demand with no apparent context, I had left university and was working a dead-end job at a tourism operator. It offered the "New Zealand off-road experience" to any naïve tourist with few hundred dollars to waste. One day, while working underneath a mud-covered, beat-up old Suzuki Jimny, I began asking my mechanic colleague what the purpose and function of each part under the vehicle was, in a bid to keep my mind from turning to formless jelly meat. After explaining (probably reluctantly) each and every part of the vehicle, he turned me to me asked me: "why are you here?". "What do you mean, why am I here?", I said. "Well, you're clearly an intellectual. You're not going to be happy here. You should be at university". A few weeks later, I was fired.

Ben - the mechanic - had planted a seed. It didn't take long until that seed germinated and grew into something that I couldn't ignore. I didn't enjoy university my first 3 years. Like high school, my worth was determined by some arbitrary test questions that had no immediate utility to me or impact on my life. I did, however, really enjoy a field trip to Nelson Lakes. It was led by a strange character with an annoying American accent. Less annoying was his teaching style and genuine enthusiasm for the things he was discussing. He seemed like someone I could work with. So, despite many warnings from other academics who won't be named, I pulled out my laptop and sent an email. In that email, I explained that I was coming back to university, and that I wanted to give it $110 \%$. I was sick of dragging my feet everywhere I went, never really seeing the true extent of my potential. The next day I got a reply. "Great. Come to my office on Monday and let's chat". And the rest really is history.

$\mathrm{KC}$, you took me under your wing and gave me every opportunity you could. You were hard on me, sometimes harder than I thought I could handle. But you were fair. You were, quite literally, the first person to truly believe in me and commit to fostering my potential. You didn't know me for from a bar of soap. I was just some mildly intelligent kid with a bad attitude and crap work ethic. But, for some unknown reason, you saw something and gave me a chance. And for that I will never be able to thank you enough. Before I met you, I had never so much as received a certificate of attendance. No awards. No A-grades. No trophies. Nothing. Some 
years later, I have achieved infinitely more than I thought was even possible. More valuable than the achievements, though, is the independence and ridiculous work ethic you taught me. For this I am beyond grateful (by the way, I am so glad I ignored the warnings - I will defend your supervision for as long as I remain in academia). Thank you.

If $\mathrm{KC}$ was my coach, my mother was my cheerleader. Mum, I have no words to explain how grateful I am for your support. But of course you can clearly see the words below this sentence, so that was a lie. Not a single bit of this would have been possible without you. You picked me up when I was down, cheered from the side-line when I was scrapping to get my first paper out, and helped me celebrate my success when it all finally paid off. You sent me money when I had none. You reminded me that I could always come home if it all didn't work out. You assured me that you would always be there to catch me if I fell. I have said it a thousand times, and I'll say it again: if I ever win Lotto, I'm making sure you never have to work another day in your life. You are a genuine and kind soul, and an even kinder Mother. Don't dwell on the mistakes. I love you and I am grateful for everything you have done for me and our family.

The same goes for the rest of my family and friends. Josh, you have always been a guiding force in my life - I couldn't have asked for a better role model. Stay exactly the way you are. Tracey, thank you for always cheering me on and accepting me exactly the way I am. You guys have always supported me and helped me celebrate my success. I am so happy for you both with the arrival of Bailey. She's already so amazing and I can't wait to watch her grow into a down-to-earth character like her mum and dad. To the boys, cheers for the endless entertainment and banter on the group chat over the last 8 years. That chat has kept me simultaneous sane and connected to you guys, even while living $500 \mathrm{~km}$ away. Not many people are lucky enough to have mates as genuine and as reliable and you lot, so cheers for always being there.

Zu guter Letzt, Julia. Seit dem Tag, an dem wir uns trafen, hast Du mich tief berührt. Ich kenne keine einzige Person, die so ist wie Du. Du bist bescheiden, ehrlich, aufrichtig, fürsorglich, liebevoll, stark, einfühlsam, unterstützend und von innen und außen unfassbar schön. Mein Leben war nie mehr das Gleiche, seit ich dich getroffen habe, und ich würde es für nichts ändern. Du hast mich in schwierigen Zeiten unterstützt, mir geholfen die guten Zeiten zu feiern, und mir die Perspektive gegeben, die ich brauchte als ich unten war. Worte können nicht beschreiben, wie glücklich ich bin, dich zu haben. Ich habe echt Glück gehabt. Mein Schatz, Ich liebe dich und ich werde immer deine Speckmaus sein. 


\section{Publications from this thesis}

Biddick M, Hutton I, Burns KC (2018). Independent evolution of allometric traits: a test of the allometric constraint hypothesis in island vines. Biological Journal of the Linnean Society 126(1): 203-211.

- Author contribution: MB collected data, performed analyses and wrote the manuscript. IH collected data and assisted with manuscript preparation. KCB collected data and assisted with manuscript preparation.

Biddick M, Hendriks A, Burns KC (2019). Plants obey (and disobey) the island rule. Proceedings of the National Academy of Sciences 116(36): 17632-17634.

- Author contribution: MB conceived the idea, collected data, performed analyses and wrote the manuscript. AH collected data. KCB conceived the idea and assisted with writing of the manuscript.

Biddick M, Burns KC (2019). Reply to Brian and Walker-Hale: Support for the island rule does not hide morphological disparity in insular plants. Proceedings of the National Academy of Sciences.

- Author contribution: MB and KCB wrote the manuscript together.

Biddick M, Burns KC (in review). The island rule is predicted by evolutionary drift. Ecology Letters.

- Author contribution: MB conceived the idea, wrote all simulation code, performed analyses, and wrote the manuscript. KCB conceived the idea and assisting with writing the manuscript.

Biddick M, Burns KC (in review). Trait variability and the predictable evolution of large leaves in island plants. Journal of Biogeography.

- Author contribution: MB conceived the idea, collected all data, performed analyses and wrote the manuscript. KCB assisted with writing the manuscript. 


\section{Contents}

Summary

Acknowledgements $\quad$ VI

$\begin{array}{lll}\text { Contents } & \text { IX }\end{array}$

List of figures $\quad$ XII

List of tables $\quad \mathrm{XV}$

Chapter 1 General introduction 1

1.1 The island syndrome in animals and the consequences of size 1

1.2 Analogous morphological changes in island plants 4

1.3 Thesis overview $\quad 5$

Chapter 2 Independent evolution of allometric traits: a test of the allometric constraint hypothesis in island vines $\quad 7$

$\begin{array}{ll}2.1 \text { Introduction } & 8\end{array}$

$\begin{array}{ll}2.2 \text { Methods } & 10\end{array}$

$\begin{array}{ll}\text { 2.2.1 Study sites } & 10\end{array}$

2.2.2 Sampling 12

2.2.3 Analyses 12

$\begin{array}{ll}2.3 \text { Results } & 13\end{array}$

$\begin{array}{ll}2.4 \text { Discussion } & 17\end{array}$

$\begin{array}{ll}\text { 2.4.1 Do leaf and stem sizes covary? } & 17\end{array}$

2.4.2 Does leaf-stem allometry differ on islands? 17

$\begin{array}{ll}\text { 2.4.3 Do leaf and stem size differ on islands? } & 18\end{array}$

2.4.4 Are changes in leaf size contingent on changes in stem size? 18

$\begin{array}{ll}2.4 .5 \text { Caveats and conclusions } & 19\end{array}$

Chapter 3 Plants obey (and disobey) the island rule 20

3.1 Introduction $\quad 21$

$\begin{array}{ll}3.2 \text { Methods } & 22\end{array}$

3.2.1 Data collection 22 
$\begin{array}{ll}3.3 \text { Results } & 23\end{array}$

$\begin{array}{ll}3.4 \text { Discussion } & 25\end{array}$

Chapter 4 Evolutionary drift predicts the island rule 26

$\begin{array}{ll}4.1 \text { Introduction } & 27\end{array}$

4.2 Methods $\quad 28$

$\begin{array}{lll}4.3 \text { Results } & 31\end{array}$

$\begin{array}{ll}4.4 \text { Discussion } & 34\end{array}$

Chapter 5 Leaf size evolution on islands $\quad 37$

$\begin{array}{ll}5.1 \text { Introduction } & 38\end{array}$

$\begin{array}{ll}5.2 \text { Methods } & 39\end{array}$

5.2.1 Study site 39

5.2.2 Data collection 39

$\begin{array}{ll}\text { 5.2.3 Statistical analysis } & 40\end{array}$

5.3 Results $\quad 41$

$\begin{array}{ll}\text { 5.4 Discussion } & 47\end{array}$

Chapter 6 General discussion $\quad 50$

6.1 Study context $\quad 50$

6.2 Research summary $\quad 50$

6.2.1 Allometry as a source of evolutionary constraint $\quad 50$

6.2.2 Prior explanations for convergent size changes on islands 51

6.2.3 Drivers of variability in size changes among species 52

6.3 Challenges of studying insular size changes 53

6.3.1 The importance of geological history 53

6.3.2 Problems of phylogenetic uncertainty 55

6.3.3 Diverse statistical approaches and how they might be unified 56

6.4 Future directions $\quad 58$

6.5 Concluding remarks $\quad 59$ 
References

60

Appendix A

70

Appendix B

73

Appendix C

87

Appendix D

96 


\section{List of figures}

Figure 1.1 - Examples of analogous size changes in animals and plants on islands. Top left: Gigantism in lizards (Komodo dragon, Varanus komodoensis, Flores Island). Top right: Gigantism in lobelias (Argyroxiphium sandwicense subsp. macrocephalum, Hawaiian archipelago). Bottom left: Dwarfism in lizards (Pygmy Leaf Chameleon, Brookesia minima, Madagascar). Bottom right: Dwarfism in Cacti (Pachycereus pringlei, San Pedro Mártir Island). 3

Figure 2.1 - Two types of changes in leaf-stem morphology are possible in vine species on islands. First, leaf-stem allometry in island populations (dashed) might increase, decrease, or remain unchanged relative to mainland populations (solid). Second, changes in mean trait sizes (i.e. the position of ellipses in the Cartesian plane) might occur together or independently. According to the allometric constraint hypothesis, a change in leaf area should be associated with a concomitant change in stem diameter because of their allometry (top right outcome). Graphical depiction adopted from Stillwell et al. (2016).

Figure 2.2 - Map illustrating the sampling locations of 21 populations of nine vine species spanning $15^{\circ}$ of latitude in the Southwest Pacific.

Figure 2.3 - The relationship between stem diameter $(\mathrm{mm}, \mathrm{x}$-axis) and leaf area $(\mathrm{cm} 2$, $\mathrm{y}-\mathrm{axis})$ in mainland and island populations of vines. Confidence ellipses (95\%) are plotted solid and dashed for mainland and island populations, respectively. Geographic locales are denoted: Australia (closed circles); New Zealand (closed squares); Lord Howe Island (open triangles); Chatham Islands (open diamonds); and Mayor Island (open reverse triangles).

Figure 2.4 - The slope parameters of leaf-stem scaling relationships in island populations ( $\mathrm{y}-\mathrm{axis})$ are plotted against those of mainland populations ( $\mathrm{x}$-axis). Open circles denote single mainland-island population comparisons.

Figure 2.5 - Insular changes in the size of leaves (leaf area, $\mathrm{cm} 2, \mathrm{y}$-axis) are unrelated to insular changes in the size of stems that support them (stem diameter, $\mathrm{mm}, \mathrm{x}-$ axis). Open circles denote a single island-mainland population comparison.

Figure $3.1-(\mathrm{A})$ The island rule was tested in plants inhabiting islands in the southwest Pacific, whose floras are primarily derived from the New Zealand "mainland." (B and C) Insular size changes ( $\mathrm{Si}$, y axis) vary as a function of mainland values (x axis) in (B) stature $(n=96)$ and $(C)$ leaves $(n=134)$. (D) Changes in seed size are unrelated to mainland values $(n=94)$. A dashed horizontal line intercepting th $\mathrm{y}$ axis at zero denotes morphological isometry. Both axes are logarithm-transformed. Open circles denote single island-mainland pairings...

Figure 4.1 - A simple simulation model illustrating how the island rule can arise from evolutionary drift. The upper horizontal line in (a) represents the range of body sizes for a given group of organisms on the mainland (i.e. 'trait space'). This might represent body mass, carapace length, plant stature or any other trait. The 
point labelled (i) represents the hypothetical body size of a species that colonises an island from the mainland. Assuming that island trait space is equal to that of the mainland, yielding the lower horizontal line in (a), the relative area of each grey triangle represents the relative probabilities of becoming smaller or larger on the island via evolutionary drift. (b) illustrates the probabilities of insular gigantism and insular dwarfism given different initial (mainland) body sizes. (c) illustrates the results of simulated relationships between evolutionary size changes (y-axis) and mainland body sizes (x-axis) for a group of relate species. During each simulation replicate, initial body sizes for 100 species were drawn at random from the mainland trait space. Each species was then allowed to drift to a new location randomly, and the corresponding line of best fit between insular size changes ( $\mathrm{Si}$, island body size $\div$ mainland body size) and mainland body size was then plotted as a grey line. This procedure was iterated 100 times, each resulting in a negative relationship between insular size changes and mainland body sizes (i.e. the 'island rule').

Figure 4.2 - Relationships between insular size changes (island size estimates $\div$ mainland size estimates) and mainland sizes of plants inhabiting islands in the Southwest Pacific. Plant stature is depicted in purple (left), leaf area is depicted in green (middle) and seed size is depicted in orange (right). Woody plants are shown above ('a') and herbaceous species are shown below ('b'). Grey curves represent expected relationships between insular size changes and mainland size estimates generated by the drift model ( $n=100$ replicates). Coloured circles illustrate empirical values. Dashed horizontal lines represent isometric relationships between island and mainland taxa. Vertical histograms are frequency distributions of $\mathrm{Si}$ values. Those with asterisks denote cases illustrating evidence of gigantism. All axes are logarithm10-transformed.

Figure 5.1 - (A) Map illustrating the location of the 98 islands (green hexagons) off the north-eastern coast of the New Zealand 'mainland' from which 9 plant species were sampled. Red hexagons denote mainland sampling locales. (B) The islands included span 3, 6 and 3 orders of magnitude in isolation (x-axis), area (y-axis) and age (z-axis), respectively. All axes are logarithm-transformed.

Figure 5.2 - Mainland and island leaf area $(\mathrm{cm} 2)$ in 9 species inhabiting islands off the coast of the New Zealand mainland. Asterisks denote significance values from Welch unequal variance t-tests $(* * *$ and $* *$ denote $\mathrm{P}<.001$ and $\mathrm{P}<.01$, respectively). Asterisks above the violin plots represent cases of insular leaf gigantism, while asterisks below represent insular dwarfism. Full Latin binomials are provided in Table 2 .

Figure 5.3 - Magnitudes of insular change in leaf area ( $y$-axis, $T$-values from Table 2) are plotted against mainland variability in leaf area $(x$-axis, logarithm10tranformed). Abbreviations denote individual species (e.g. $R s=$ Rhabdothamnus solandri)

Figure 5.4 - The relationships between insular leaf size $\left(\mathrm{cm}^{2}\right)$ and island $(A)$ isolation, $(B)$ age and $(C)$ area in 9 species inhabiting 98 islands off the north-eastern coast of the New Zealand mainland. Island isolation is square-root-transformed, while island area and age are logarithm-transformed. Statistically significant 
relationships are denoted by solid curves with shaded confidence intervals. Statistically insignificant relationships are denoted by dashed curves.

Figure 5.5 - Slope values from the relationships between insular leaf area and $(A)$ island isolation, $(B)$ age and $(C)$ area are plotted against mainland variability. Abbreviations denote individual species (e.g. $R s=$ Rhabdothamnus solandri). Statistically significant results are denoted by solid curves. Curves are not plotted for statistically insignificant relationships

Figure 6.1 - Two common phylogenetic problems when studying insular size changes. Panel $(A)$ illustrates the problem of pseudo-replicating mainland relatives when comparing island clades derived via cladogenesis. Panel $(B)$ illustrates how extinction can lead to erroneous island-mainland comparisons.

Figure 6.2 - Two common statistical approaches to quantifying support for the island rule: $(A)$ Model I and $(B)$ Model II linear regression of logarithm-transformed variables. 


\section{List of tables}

Table 2.1 Summary of results from a series of Pearson's correlations of leaf area (in square centimetres) against stem diameter (in millimetres) for 21 populations of nine cosmopolitan vine species across the Southwest Pacific.

Table 2.2 - Summary of results from a series of t-tests assessing differences in stem diameter (in millimetres) and leaf area (in square centimetres) between mainland and island populations of vines in the Southwest Pacific.

Table 4.1 - Statistical analyses of insular size changes in plants inhabiting islands in the Southwest Pacific. Categories of plant functional traits are shown in the first column along with sample sizes. Tests for evidence of the island rule, linear regression of insular size changes ( $\mathrm{Si}$ ) against mainland values $(\mathrm{M})$, are shown in the second set of columns. Tests for congruency between observed insular size changes ( $\mathrm{Si}$ observed) and predicted insular size changes by a simple drift model ( $\mathrm{Si}$ predicted) are shown in the third set of columns. Tests for unidirectional insular size changes (evidence for gigantism) is shown in the fourth set of columns. The drift model successfully predicted insular size changes when support for the island rule was observed, and it failed to predict insular size changes when it did not occur. Under these circumstances, convergent patterns of insular gigantism were often observed.

Table 5.1 - The results of unequal variance t-tests of mainland and island leaf area $(\mathrm{cm} 2)$, conducted to test for insular leaf gigantism in 9 plant species inhabiting 98 islands off the north-eastern coast of the New Zealand mainland. The number of islands from which island samples were derived is presented in the second column.

Table 5.2 - Summary of species-wise linear models of insular leaf area (in squarecentimetres) as a function of island isolation (in kilometres), area (in squaremetres), and age (in years). 



\section{Chapter 1}

\section{General introduction}

On his voyage across the World on the HMS Beagle, Darwin was struck by the peculiar animals inhabiting the islands he visited. Many of them resembled the continental animals with which he was more accustomed. Yet at the same time, they were somehow different. Some animals like tortoises and iguanas were unusually large. Other animals like elephants and penguins were remarkably small. Even more to his surprise, while exploring the Galapagos, a colleague informed Darwin that he could tell which island a tortoise was from by the shape of its shell. Further still, there appeared to be a type of finch for every island in the archipelago. All of this challenged Darwin's understanding of life on Earth. Until now, he had been taught that all species were divinely created - fixed and unchanging with time. Yet the island animals he observed were clearly modified versions of those from the mainland. This was directly at odds with a static conception of life on Earth. Only decades later would Darwin's observations prove central to developing his theory of evolution via natural selection.

More than 150 years later, we now understand that the unique conditions of isolated islands causes life inhabiting them to evolve in predictable ways (Whittaker \& Fernández-Palacios 2007; Losos \& Ricklefs 2009). These evolutionary changes are collectively known as the 'island syndrome' (Baeckens \& Van Damme 2020). In this chapter, I introduce some of the morphological changes that comprise the island syndrome in animals. I then describe analogous morphological changes in island plants and ask whether they too exhibit an island syndrome. Finally, I argue how studying island plants might help further our understanding of the evolutionary mechanisms at work (in both plants and animals) on islands.

\subsection{The island syndrome in animals and the consequences of size}

The island syndrome is a term used to describe the morphological, ecological, and behavioural traits typically exhibited by animals endemic to isolated islands (Baeckens \& Van Damme 2020). Birds illustrate several aspects of the island syndrome well, often becoming large, losing the ability to fly, and showing no obvious fear of humans or other mainland predators. In fact, nearly every isolated archipelago on Earth housed an assemblage of endemic birds with exactly 
these traits, including: the elephant birds of Madagascar (Aepyornithidae), the moa of New Zealand (Dinornithiformes), and the pigeons of the Mascarene islands (Columbidae). Unfortunately, these attributes were not lost on European sailors. One describes his experience of the Rodriguez solitaire - a cousin of the Dodo of Mauritius - below:

"During the five or six days that we were allowed to go into the woods, so many were killed that our General was constrained to forbid anyone going beyond a hundred paces from the camp for fear the whole quarter would be destroyed, for one needed only to catch one bird alive and make it cry out, to have in a moment whole flocks coming to perch on people, so that often without moving from one spot one could kill hundreds. But, seeing that it would have been impossible to wipe out such a huge quantity, permission was again given to kill, which gave great joy to everyone, because very good fare was had at no expense."

Hume \& Walters (2012)

Except, of course, the birds. The exact mechanisms causing birds to independently converge on these attributes on islands are debated. One possibility is that larger size is favoured on islands, and the ability to fly is lost as a consequence. In support of this notion, changes in body size on islands are found throughout the animal kingdom (Fig. 1.1).

Foster $(1963 ; 1964)$ noticed that many rodents and marsupials increase in size on islands, while carnivores, lagomorphs, and artiodactyls tend to decrease in size. Insectivores, on the other hand, show no consistent trend in body size evolution on islands. A decade later, Van Valen (1973) named the phenomenon the "island rule", and suggested that it comprises a new evolutionary law; one with fewer exceptions than any other ecotypic rule in nature. The island rule describes the repeated evolution of small animal giants and large animal dwarves, and has been demonstrated in various groups, including: rodents (Lomolino 1985, 2005; Lomolino et al. 2013; Nolfo-Clements et al. 2017), marsupials (Lomolino 1985, 2005; Lomolino et al. 2013), primates (Brown et al. 2004; Welch 2009), carnivores (Lomolino 1985, 2005; Rick et al. 2009; Lomolino et al. 2013), artiodactyls (Western 1979; Long et al. 2019), snakes (Vanek \& Burke 2020), birds (Clegg \& Owens 2002), dinosaurs (Benton et al. 2010), and even deep sea gastropods (McClain et al. 2006). However, many authors have also failed to find support for its predictions (Meiri et al. 2006; Meiri 2007; Meiri et al. 2008; Meiri et al. 2009; Itescu et al. 2014; Itescu et al. 2018; Rebouças et al. 2018), which has led to considerable controversy 
surrounding its validity as an evolutionary rule (see Lokatis \& Jeschke 2018 for further discussion). Despite more than 50 years of island rule research, we still lack a mechanistic explanation for why species converge on intermediate body sizes on islands.
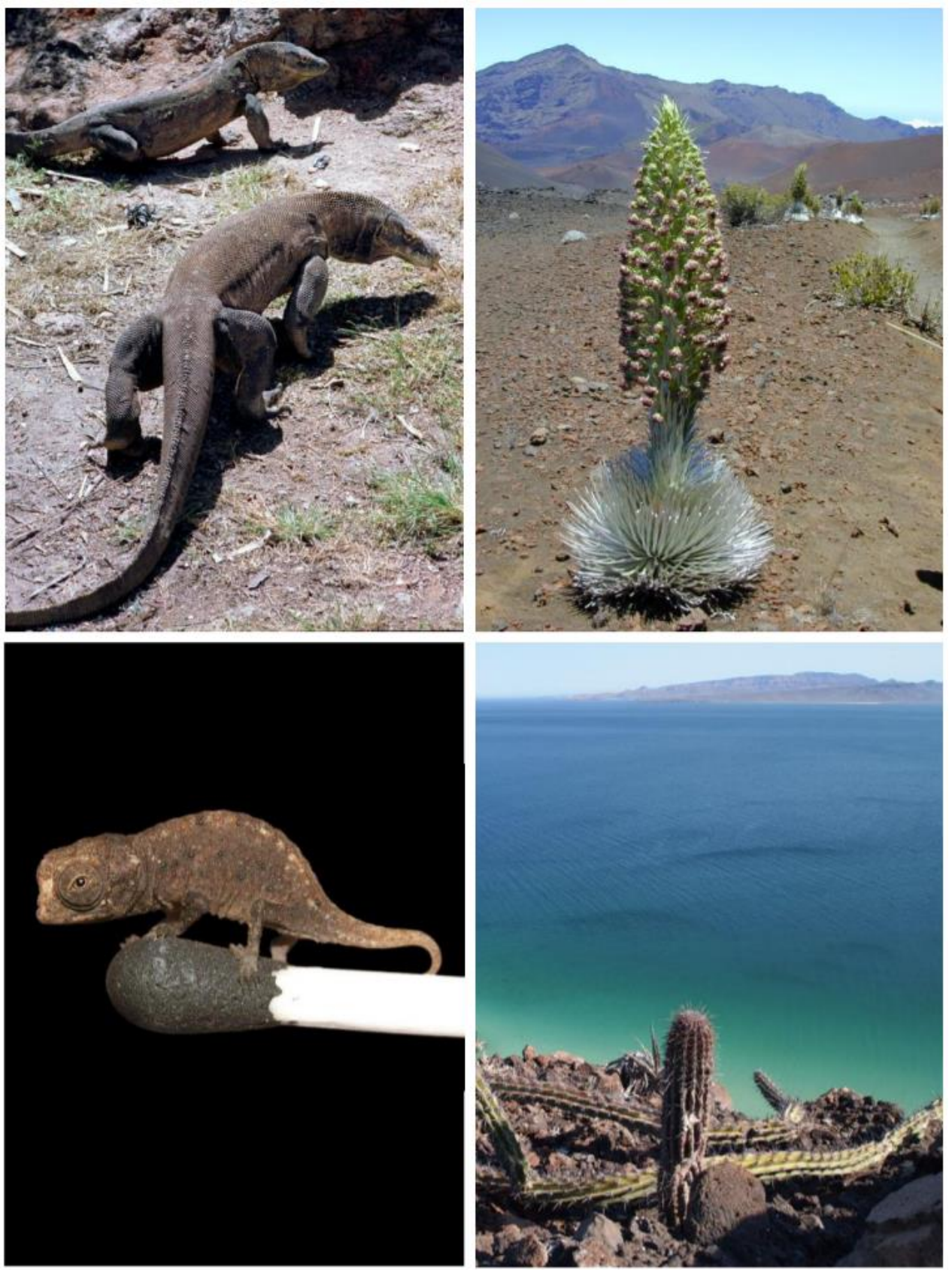

Figure 1.1 - Examples of analogous size changes in animals and plants on islands. Top left: Gigantism in lizards (Komodo dragon, Varanus komodoensis, Flores Island). Top right: Gigantism in lobelias (Argyroxiphium sandwicense subsp. macrocephalum, Hawaiian archipelago). Bottom left: Dwarfism in lizards (Pygmy Leaf Chameleon, Brookesia minima, Madagascar). Bottom right: Dwarfism in Cacti (Pachycereus pringlei, San Pedro Mártir Island). 


\subsection{Analogous morphological changes in island plants}

Studying how plant morphology evolves on islands is useful for two reasons. First, unlike animals, we know very little about how plants evolve on islands. Animals inherently receive more scientific attention than do plants - a phenomenon particularly apparent in the allocation of conservation funding (i.e. 'plant blindness', Balding \& Williams 2016). Second, understanding how plants evolve on islands may help us understand the ecological conditions and evolutionary mechanisms responsible for analogous changes in island animals. In other words, if plants and animals respond to insularity in similar ways, the mechanistic processes underpinning their evolution may be shared.

However, plants differ to animals in two fundamental ways. For one, they are sessile and cannot move to exploit new resources, reduce competition, or avoid predation. Second, their morphology results from the indeterminate growth of 'metamers' - modular physiological units that are reiterated throughout the extent of the plant meristem (Corner 1949). This modularity is interesting from an evolutionary point of view, because it provides the opportunity to understand how multiple traits coevolve. Unfortunately, the co-dependency of plant functional traits is often overlooked in studies of plant evolution (but see Burns et al. 2012).

Many plant traits covary with one another (Corner 1949; Niklas 1994; Westoby \& Wright 2003; Sun et al. 2005). This covariation is known as "allometry" or "the study of size and its consequences" (Gould 1975), and occurs at various scales, including among life stages (ontogenetic allometry), among individuals (static allometry), and among species (evolutionary allometry). Allometry may constrain the capacity of traits to evolve independently of one another (i.e. the 'allometric constraint hypothesis', see Harvey \& Pagel 1991). This is because, as one trait evolves, the other trait with which it covaries must coevolve in order to maintain the allometric relationship between them. Allometry is, therefore, important when interpreting large-scale evolutionary trends, such as those resulting from insularity, because a selection for one trait might influence the evolution of another for reasons that are unrelated to adaptation.

The phenomenon of insular woodiness illustrates this well. Darwin (1859) noticed that many island trees are derived from small, herbaceous lineages on the mainland. The evolution of woodiness in otherwise herbaceous lineages on islands has since been demonstrated in various 
angiosperm groups, using both genetic and comparative approaches (Carlquist 1974; Böhle et al. 1996; Panero et al. 1999; Carlquist et al. 2003; Lens et al. 2009; Lens et al. 2013; Schüßler et al. 2019). Herbaceousness is a derived trait in angiosperms. Therefore, the evolution of woodiness in herbaceous ancestors is termed "secondary woodiness" (i.e. woodiness has evolved twice in their evolutionary history). Why secondary woodiness often evolves in island plants is not known.

Darwin's weeds-to-trees hypothesis posits that, on young oceanic islands, selection favours the evolution of greater stature (and consequently woodiness) in herbs to enable them to better compete for light in the absence of trees. Wallace's lifespan hypothesis differently argues that woodiness evolves to increase flowering times in the presence of depauperate pollinator faunas. Carlquist's insular climate hypothesis assumes that herbaceousness is an adaptation to harsh continental climates, and is no longer advantageous on climatically-stable, oceanic islands (Carlquist 1965; Carlquist 1966, 1974). However, size changes in plants are not always associated with the evolution of woodiness. For example, many herbaceous species have evolved enormous size ('megaherbs') after colonizing the sub-Antarctic islands of Campbell, Auckland, and Antipodes (Wagstaff et al. 2011), none of which resulted in the evolution of woody tissue. Further still, some plants exhibit the reverse trend on islands and become smaller (Tsukaya et al. 2006; Burns 2016), suggesting that size itself may be under selection, and woodiness simply results because of the need for structural support. This begs the question: might plants obey the island rule?

\subsection{Thesis overview}

In this thesis, I investigated morphological changes in species inhabiting islands in the southwest Pacific. To assess macroevolutionary patterns in the evolution of island plants, I utilized a comparative approach, whereby morphological traits of the most closely related sister taxa (or population) was compared to those of the more derived island species (or population). Each chapter of this thesis was written as a stand-alone manuscript for publication. As such, some repetition in the introduction and methods sections of chapters exists. Further, to maintain a consistent and cohesive thesis, a chapter exploring the role of bird-pollination in the evolution of large, colourful flowers on islands was removed (published in Integrative Zoology). 


\section{CHAPTER 1 - GENERAL INTRODUCTION}

In chapter 2, I asked whether island vines (plants that lack independent stature) exhibit the same shift in evolutionary trajectory as many woody plants do. First, I documented how stem and leaf sizes differed between mainland and island populations of cosmopolitan vines occurring on islands across the south-west Pacific. I then investigated whether changes in stem and leaf size are contingent on each other or result from disparate selective pressures.

In chapter 3, I conducted the first large-scale test of the island rule in plants. To do so, I compiled a large dataset of measurements from the field, the literature and several herbariums. The final dataset was comprised of 175 mainland-island taxonomic pairings from 10 isolated archipelagos. I then tested for an island rule pattern in plant stature, leaf area and seed size.

In chapter 4, I demonstrated how the infamous island rule is predicted by evolutionary drift. To do so, I created a simulation model that enabled mainland species to 'walk' to a randomly chosen point along a bounded trait domain. Maintaining 5 fundamental assumptions, I then used the model in a predictive manner to determine whether it could serve as a more parsimonious explanation for evolution of the island rule in plants.

In chapter 5, I conducted a macroevolutionary analysis of insular leaf size. Several studies have found consistent trends toward gigantism in the leaves of island plants. To confirm this empirically, I collected leaf size data from species inhabiting 98 of New Zealand's offshore islands. I then explored how insular leaf size varies as a function of island isolation, age and area.

In chapter 6, I synthesize my findings, assess how they compare and contrast with those of similar studies, and discuss their implications for our understanding of island evolution. Overall this thesis furthers our understanding of how plants evolve on islands. 


\title{
Chapter 2
}

\section{Independent evolution of allometric traits: a test of the allometric constraint hypothesis in island vines}

\begin{abstract}
The capacity of traits to evolve independently of one another is thought to be constrained by their allometry (i.e. the allometric constraint hypothesis). Here, we tested the allometric constraint hypothesis using changes in leaf-stem morphology of nine vine species inhabiting islands in the south-west Pacific. We first quantified leaf-stem allometry and tested whether it differs between islands and the mainland. We then quantified changes in leaf and stem size on islands and tested whether they were correlated. Leaf-stem allometry varied among species but did not differ between islands and the mainland. Leaf gigantism characterized island populations, whereas changes in stem size scaled with latitude. Contrary to predictions of the allometric constraint hypothesis, changes in leaf size were not associated with a concomitant change in stem size. Overall, the results suggest that trait allometry does not prohibit independent trait evolution
\end{abstract}

Publication status: Published

Biddick M, Hutton I, Burns KC (2018). Independent evolution of allometric traits: a test of the allometric constraint hypothesis in island vines. Biological Journal of the Linnean Society 126(1): 203-211. 


\subsection{Introduction}

Darwin was first to consider the evolutionary importance of covariation between characters in populations, writing:

“...the whole organism is so tied together during its growth and development, that when slight variations in one part occur and are accumulated through natural selection, other parts become modified ... this is...most imperfectly understood"

(Darwin 1859).

Covariation of traits is now collectively understood as allometry: the study of size and its consequences (Gould 1975). Though allometry has been a frequent source of scientific inquiry (Gould 1966; Lande 1979; Western 1979; West et al. 1997, 1999; Lin et al. 2018; Packard 2018), its evolutionary consequences are not completely understood.

One potential consequence of allometry is a constraint on the capacity of traits to evolve independently. The influence of trait allometry on trait evolution is known as the 'allometric constraint hypothesis' (see Harvey \& Pagel 1991); the logic of which is as follows. Plants are comprised of organs that operate somewhat autonomously yet covary allometrically (Corner 1949; Niklas 1994; Westoby \& Wright 2003; Sun et al. 2005). For instance, leaf and twig size scale with plant stature, as well as with each other, primarily because of mechanical support and physiological function (Preston \& Ackerly 2003; Westoby \& Wright 2003; Sun et al. 2005). Consequently, selection on one trait might influence the evolution of another for reasons unrelated to adaptation, making it difficult to establish whether evolutionary trends result from distinct selective pressures. Understanding trait allometry is, therefore, crucial to interpreting large-scale evolutionary trends, such as those resulting from insularity.

Plants are known to evolve in predictable and well documented ways on isolated islands. Like animals, island plants are often gigantic (Wagstaff et al. 2011; Lens et al. 2013). 'Weedy' species are thought to first colonize islands first because of their enhanced dispersal abilities and subsequently become larger (i.e. increased arborescence), exploiting niches not yet occupied by trees (i.e. the 'weeds-to-trees hypothesis', Carlquist 1974). Many island plants also produce extraordinarily large leaves (Burns et al. 2012; Cox \& Burns 2017). Leaf gigantism might result from a release from mainland herbivores (i.e. the 'enemy-release-hypothesis', 
Keane \& Crawley 2002) or in response to the distinct environmental conditions of islands (Weigelt et al. 2013). Whether increased arborescence and leaf gigantism represent distinct evolutionary pathways is contingent on the role trait allometry plays in trait evolution.

Here, we test the allometric constraint hypothesis in island populations of 9 vine species from the South-west Pacific. We restrict our analysis to vines because they lack independent stature and thereby allow an empirical test that is not confounded by the additional variable of stature. We then ask 4 questions about possible changes in leaf-stem morphology (Fig. 2.1).

1. Do leaves and stems covary (i.e. trait allometry)?

2. Does leaf-stem allometry differ on islands (i.e. evolution of trait allometry)?

3. Do leaf and stem sizes differ on islands (i.e. trait evolution)?

4. Are changes in leaf size contingent on changes in stem size (i.e. allometry of trait evolution)? 


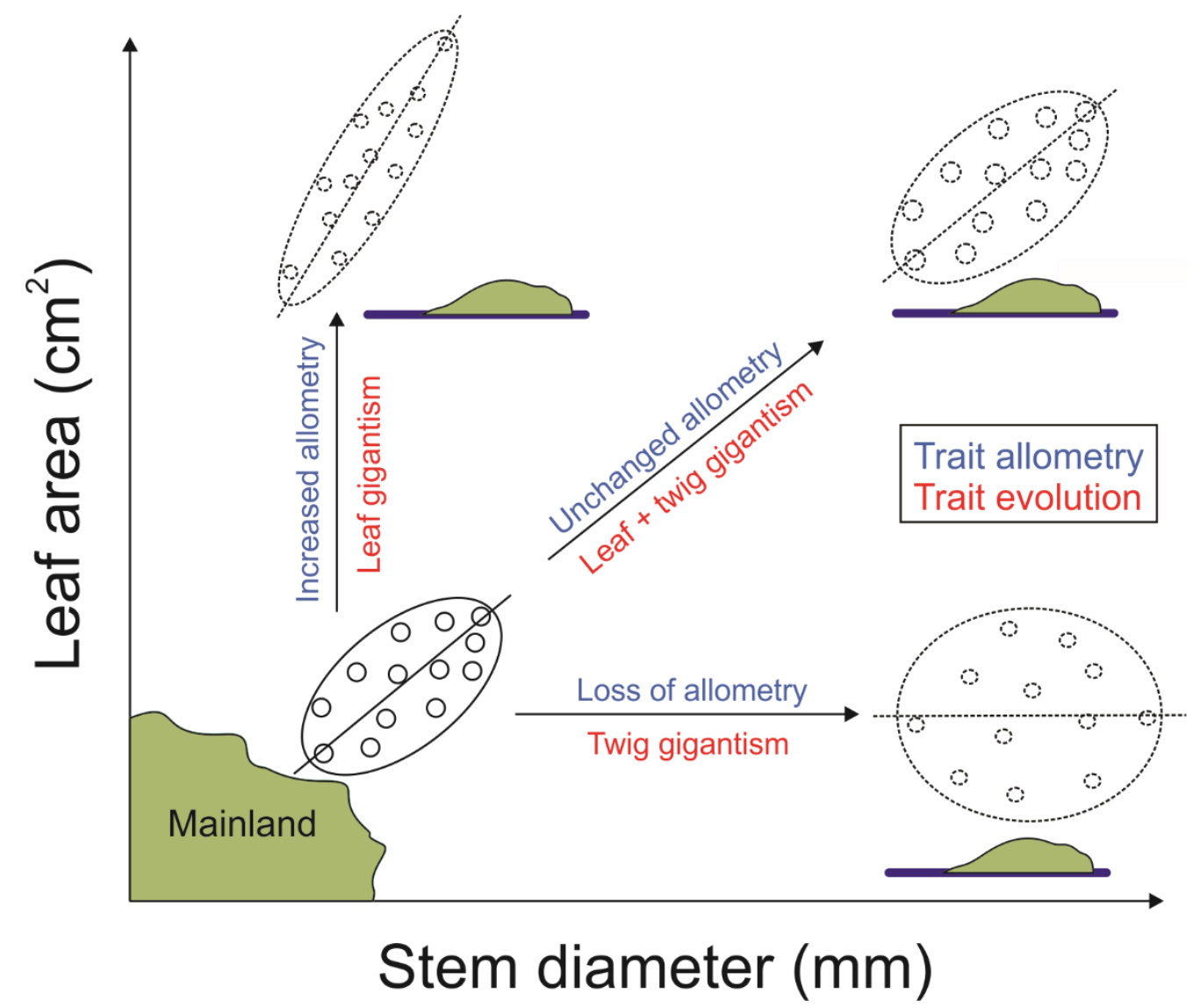

Figure 2.1 - Two types of changes in leaf-stem morphology are possible in vine species on islands. First, leaf-stem allometry in island populations (dashed) might increase, decrease, or remain unchanged relative to mainland populations (solid). Second, changes in mean trait sizes (i.e. the position of ellipses in the Cartesian plane) might occur together or independently. According to the allometric constraint hypothesis, a change in leaf area should be associated with a concomitant change in stem diameter because of their allometry (top right outcome). Graphical depiction adopted from Stillwell et al. (2016).

\subsection{Methods}

\subsubsection{Study sites}

New Zealand is an isolated landmass that represents most of the above-water portion of the Zealandia continent that rafted away from Gondwanan super-continent approximately 80 million years ago (see Gibbs 2006; Fig. 2.2). It is comprised of three main islands (North, South, and Stewart), as well as many offshore satellite islands whose floras are primarily derived from overwater dispersal from New Zealand. New Zealand therefore acts as a mainland source pool for these islands. Sampling on the New Zealand mainland was conducted in the Kaimai-Mamaku Forest Park in Tauranga $\left(37^{\circ} 41^{\prime} \mathrm{S}, 175^{\circ} 45^{\prime} \mathrm{E}\right)$ and Otari-Wilton Bush in Wellington $\left(41^{\circ} 16^{\prime} \mathrm{S}, 174^{\circ} 45^{\prime} \mathrm{E}\right)$. Sampling on the Australian mainland was conducted in Coffs 
Harbour $\left(30^{\circ} 15^{\prime} \mathrm{S}, 153^{\circ} 03^{\prime} \mathrm{E}\right)$. Mainland sites were chosen specifically because of their latitudinal proximity to island sites.

Mayor Island (Tuhua, $37^{\circ} 17^{\prime} \mathrm{S}, 176^{\circ} 15^{\prime} \mathrm{E}$ ) is a $13 \mathrm{~km}^{2}$ remnant of a shield volcano that erupted approximately 7000 years ago located $16 \mathrm{~km}$ off the east coast of New Zealand (Buck et al. 1981). The terrestrial portion of the island is protected by the Department of Conservation as a wildlife refuge. The Chatham Island archipelago (Rēkohu, $43^{\circ} 54^{\prime} \mathrm{S}, 17^{\circ} 631^{\prime} \mathrm{W}$ ) comprises 15 islands that arose $700 \mathrm{~km}$ off the east coast of New Zealand approximately 5 million years ago (Given 1985). Lord Howe Island is a small $\left(<15 \mathrm{~km}^{2}\right)$, isolated subtropical island located 600 $\mathrm{km}$ off the east coast of Australia $\left(31^{\circ} 33^{\prime} \mathrm{S}, 159^{\circ} 05^{\prime} \mathrm{E}\right)$. It is the remnant of a shield volcano that erupted approximately 6.9 million years ago (McDougall et al. 1981). The island is listed as a UNESCO World Heritage Site and thereby retains most of its native flora and fauna.

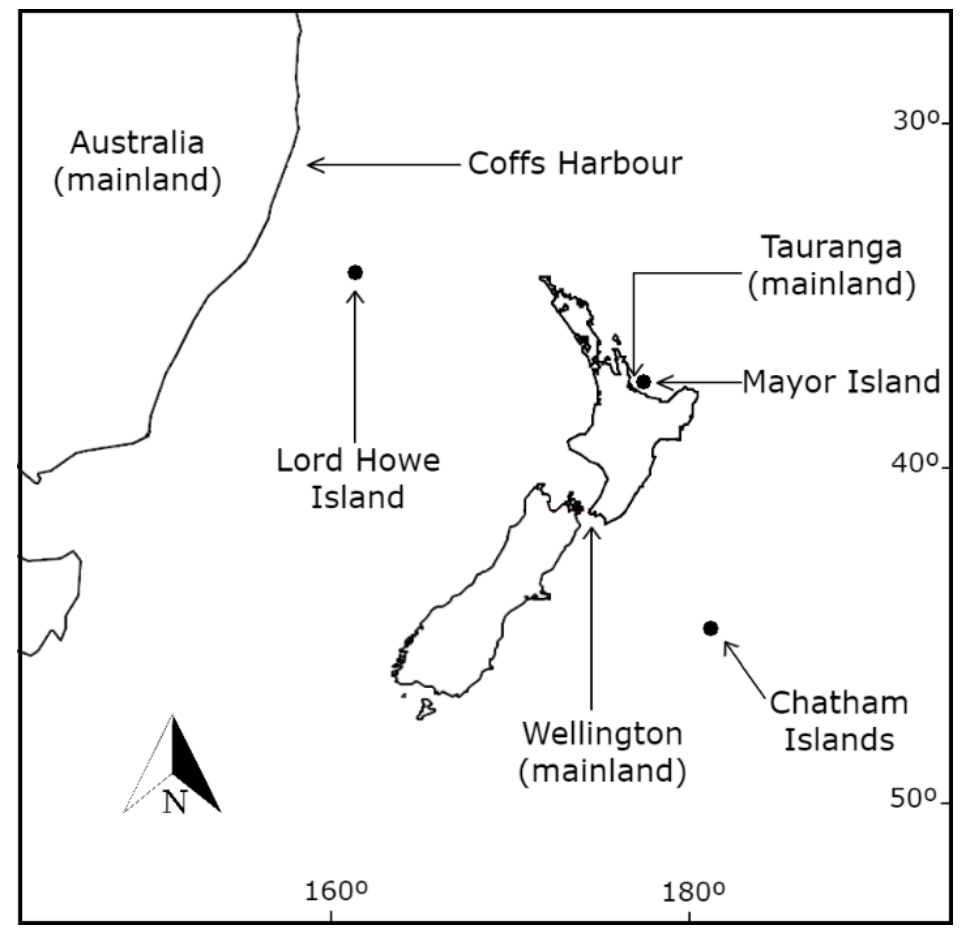

Figure 2.2 - Map illustrating the sampling locations of 21 populations of nine vine species spanning $15^{\circ}$ of latitude in the Southwest Pacific. 


\subsubsection{Sampling}

To quantify the morphology of vine species, we measured the leaves and stems of 21 populations of 9 vine species widespread across the south-west Pacific (Table A.1, Appendix A; Fig. 2.2). Leaf length was measured as the longest distance from the base of the petiole to the most terminal point of the leaf lamina using a digital calliper. Leaf width was measured as the widest distance perpendicular to the plane of the leaf length measurement. Leaf area was calculated as leaf length times leaf width. Stem diameter was measured $10 \mathrm{~mm}$ below the point of petiole attachment to the stem. For each population, 30 mature and undamaged leaves and stems from each of 30 individuals were measured.

Because leaf size is known to vary with local light conditions (Vogel 1968; Fitter \& Hay 2012), measurements were taken consistently from individuals in either full-sun or full-shade for littoral and inland species, respectively. Unlike other morphological studies, we were not interested in intraspecific trait variation across species distributions on the mainland (e.g. how traits vary with latitude). We instead sampled mainland populations that were of similar latitudes to the island populations, thereby providing the most appropriate comparison.

\subsubsection{Analyses}

To explore leaf size--stem size scaling relationships, we ran separate Pearson's correlation tests of leaf area against stem diameter for each population. Data was left untransformed to avoid the statistical artefacts highlighted by Packard $(2012,2018)$. To test whether leaf size-stem size scaling relationships differ between mainland and island populations, we ran a reduced major axis regression of island population slope parameters (i.e. leaf area against stem diameter) against the mainland population slope parameters. To explore whether the strength of leaf-stem scaling relationships were associated with leaf size, we ran a linear model of species slope parameters against mean leaf area.

To explore insular size changes, we ran separate unpaired two-sided Welch t-tests for both leaf area and stem diameter for each population comparison. Unpaired t-tests were utilized because island populations of vines are not recognized as distinct taxonomic entities. The Welch t-test was utilized because it assumes unequal variance between populations. To test whether size 
changes varied with latitude, we ran two linear model regressions (leaf area and stem diameter) of island to mainland ratio against island latitude.

To test whether changes in leaf area were associated with changes in stem size, we ran a linear model regression of the island to mainland ratio of leaf area against the island to mainland ratio of stem diameter. Island to mainland ratios were calculated by dividing the mean island population value by the mean mainland population value. All statistical analyses were conducted in the R environment (Team 2000).

Two concerns of statistical independence are addressed in our dataset. Firstly, some species have colonized more than one island and thereby provide multiple mainland-island comparisons for analysis. We ran all interspecific-level analyses using only one randomly chosen island population value per taxa. This process was then iterated 100 times and the results averaged. In doing so, we can identify whether analysis results are contingent on which island population is used for comparison. Secondly, some species are closely related taxonomically and might therefore introduce issues of morphological conservatism related to phylogeny. We assessed mainland-island differences in 9 taxa from 7 angiosperm families. Overall results at the interspecific level remain unchanged when only a single taxon per family was used for analysis.

\subsection{Results}

Leaf-stem allometry varied among species (Fig. 2.3; Table 2.1). Reduced major axis regression revealed that island slope parameters scaled positively with mainland slope parameters (Fig. 2.4), with a slope (1.185) that was statistically indistinguishable from 1 (95\% confidence interval $=0.678,2.034)$. Likewise, the intercept (2.164) was statistically indistinguishable from zero $(95 \%$ confidence interval $=-4.094,5.897)$, indicating that slope parameters for island populations were generally not greater than those of mainland populations. Instead, leaf-stem allometry was generally stronger in large-leaved species (Fig A.1, Appendix A; $T=3.310, P$ $<0.01)$.

Leaf gigantism characterized island populations across latitudes (Table 2.2; Fig. A.2, Appendix A; $T=-0.857, P=0.411)$. Changes in stem diameter, on the other hand, scaled with latitude 
( $T=2.356, P=0.0411)$, with stem gigantism characterizing low latitude populations and stem dwarfism characterizing those of high latitude islands. Linear model regression revealed that changes in leaf area were not contingent on changes in stem diameter (Fig. 2.5). Island to mainland ratios of leaf area were unrelated to island to mainland ratios of stem diameter $(T=$ $0.454, P=0.659)$.
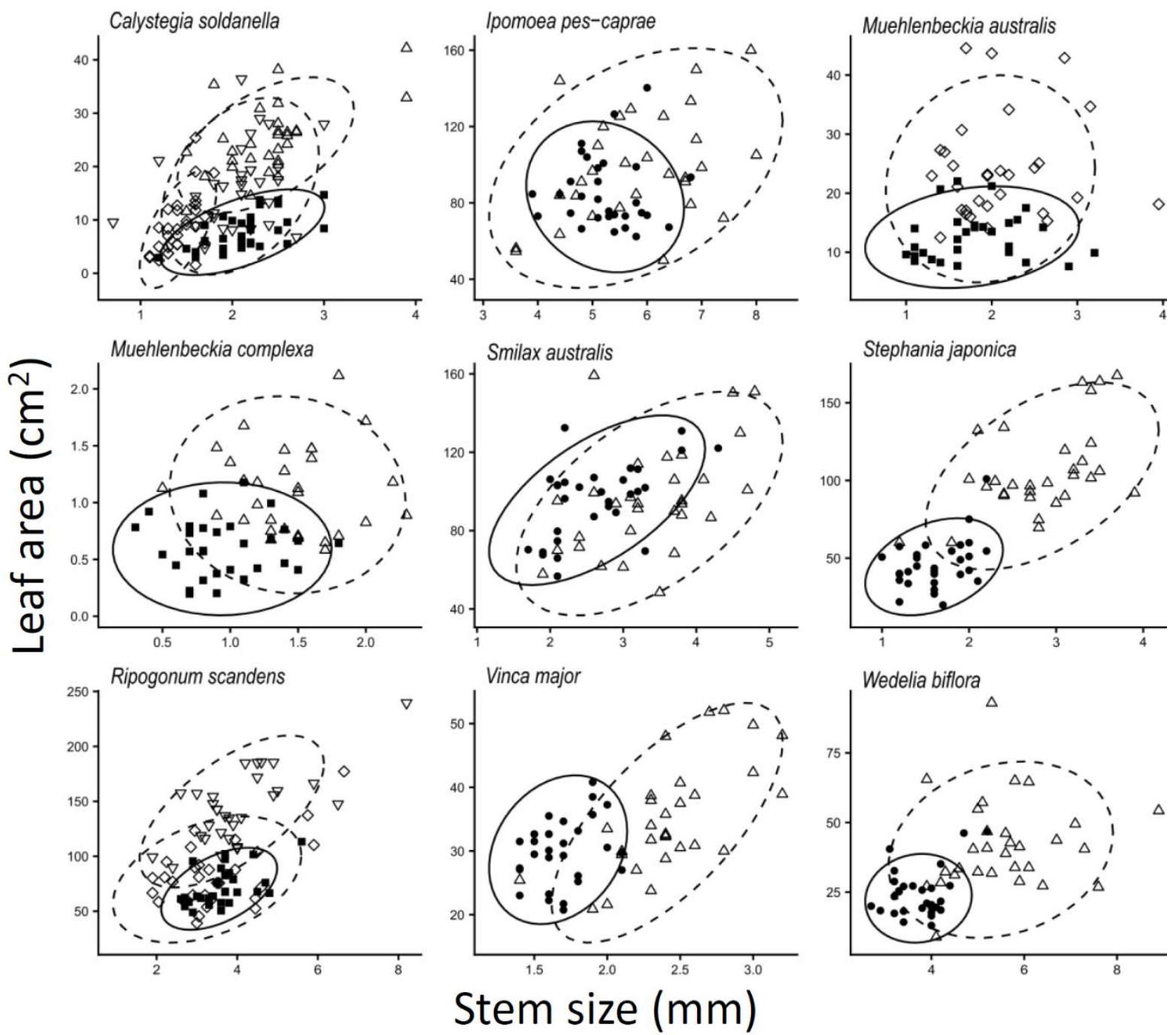

Figure 2.3 - The relationship between stem diameter ( $\mathrm{mm}, \mathrm{x}$-axis) and leaf area ( $\mathrm{cm} 2, \mathrm{y}$-axis) in mainland and island populations of vines. Confidence ellipses (95\%) are plotted solid and dashed for mainland and island populations, respectively. Geographic locales are denoted: Australia (closed circles); New Zealand (closed squares); Lord Howe Island (open triangles); Chatham Islands (open diamonds); and Mayor Island (open reverse triangles). 
Table 2.1 Summary of results from a series of Pearson's correlations of leaf area (in square centimetres) against stem diameter (in millimetres) for 21 populations of nine cosmopolitan vine species across the Southwest Pacific.

\begin{tabular}{llcc}
\hline Species & Location & $r$ & $P$ \\
\hline Calystegia soldanella & Tauranga, New Zealand & 0.599 & $>0.001 * * *$ \\
& Chatham Islands & 0.580 & $>0.001 * * *$ \\
& Mayor Island & 0.577 & $>0.001 * * *$ \\
Ipomoea pes-caprae & Lord Howe Island & 0.316 & 0.089 \\
& Coffs Harbour, Australia & -0.003 & 0.989 \\
Muehlenbeckia australis & Lord Howe Island & 0.394 & $0.031 *$ \\
\multirow{4}{*}{ Muehlenbeckia complexa } & Wellington, New Zealand & 0.063 & 0.740 \\
& Chatham Islands & 0.075 & 0.693 \\
Ripogonum scandens & Wellington, New Zealand & 0.012 & 0.952 \\
& Lord Howe Island & -0.014 & 0.942 \\
\multirow{2}{*}{ Smilax australis } & Tauranga, New Zealand & 0.515 & $0.004 * *$ \\
Stephania japonica & Mayor Island & 0.697 & $>0.001 * * *$ \\
\multirow{2}{*}{ Vinca major } & Chatham Islands & 0.560 & $0.001 * * *$ \\
\multirow{2}{*}{ Wedelia biflora } & Coffs Harbour, Australia & 0.557 & $0.001 * * *$ \\
& Lord Howe Island & 0.481 & $0.007 * *$ \\
& Coffs Harbour, Australia & 0.414 & $0.023 *$ \\
& Lord Howe Island & 0.522 & $0.003 *$ \\
& Tauranga, New Zealand & 0.265 & 0.157 \\
& Mayor Island & 0.679 & $>0.001 * * *$ \\
& Coffs Harbour, Australia & 0.326 & 0.079 \\
& Lord Howe Island & 0.149 & 0.433 \\
\hline
\end{tabular}

Table 2.2 - Summary of results from a series of t-tests assessing differences in stem diameter (in millimetres) and leaf area (in square centimetres) between mainland and island populations of vines in the Southwest Pacific.

\begin{tabular}{llrrrrrr}
\hline \multirow{2}{*}{ Species } & \multirow{2}{*}{ Comparison } & \multicolumn{4}{c}{ Stems } & \multicolumn{3}{c}{ Leaves } \\
\cline { 3 - 8 } & & \multicolumn{1}{c}{$d f$} & \multicolumn{1}{c}{$T$} & \multicolumn{1}{c}{$d f$} & \multicolumn{1}{c}{$T$} & $P$ \\
\hline Calystegia soldanella & $\mathrm{NZ} \leftrightarrow \mathrm{CI}$ & 40.13 & -8.554 & $<0.001 * * *$ & 48.91 & 0.833 & 0.409 \\
& $\mathrm{NZ} \leftrightarrow \mathrm{MI}$ & 54.53 & 2.090 & $0.041 * *$ & 43.47 & 12.843 & $<0.001 * * *$ \\
& $\mathrm{NZ} \leftrightarrow \mathrm{LHI}$ & 57.73 & -0.606 & 0.547 & 40.27 & 5.755 & $<0.001 * * *$ \\
Ipomoea pes-caprae & $\mathrm{AUS} \leftrightarrow$ LHI & 45.38 & 2.260 & $0.029 * *$ & 50.28 & 2.120 & $<0.001 * * *$ \\
Muehlenbeckia australis & $\mathrm{NZ} \leftrightarrow \mathrm{CI}$ & 26.96 & -1.002 & 0.325 & 39.96 & 5.677 & $<0.001 * * *$ \\
Muehlenbeckia complexa & $\mathrm{NZ} \leftrightarrow \mathrm{LHI}$ & 57.12 & 5.045 & $<0.001 * * *$ & 50.44 & 5.955 & $<0.001 * * *$ \\
Smilax australis & $\mathrm{AUS} \leftrightarrow$ LHI & 55.85 & 3.753 & $<0.001 * * *$ & 52.62 & -0.017 & 0.987 \\
Stephania japonica & $\mathrm{AUS} \leftrightarrow$ LHI & 45.31 & 9.408 & $<0.001 * * *$ & 45.39 & 9.974 & $<0.001 * * *$ \\
Ripogonum scandens & $\mathrm{NZ} \leftrightarrow \mathrm{CI}$ & 46.67 & -0.712 & 0.479 & 46.31 & 1.725 & 0.091 \\
& $\mathrm{NZ} \leftrightarrow \mathrm{MI}$ & 45.16 & 1.574 & 0.123 & 43.54 & 10.679 & $<0.001 * * *$ \\
Vinca major & $\mathrm{NZ} \leftrightarrow \mathrm{MI}$ & 44.31 & 9.339 & $<0.001 * * *$ & 47.06 & 2.811 & $0.007 * * *$ \\
Wedelia biflora & $\mathrm{AUS} \leftrightarrow$ LHI & 41.70 & 7.802 & $<0.001 * * *$ & 43.97 & 5.266 & $<0.001 * * *$ \\
\hline
\end{tabular}



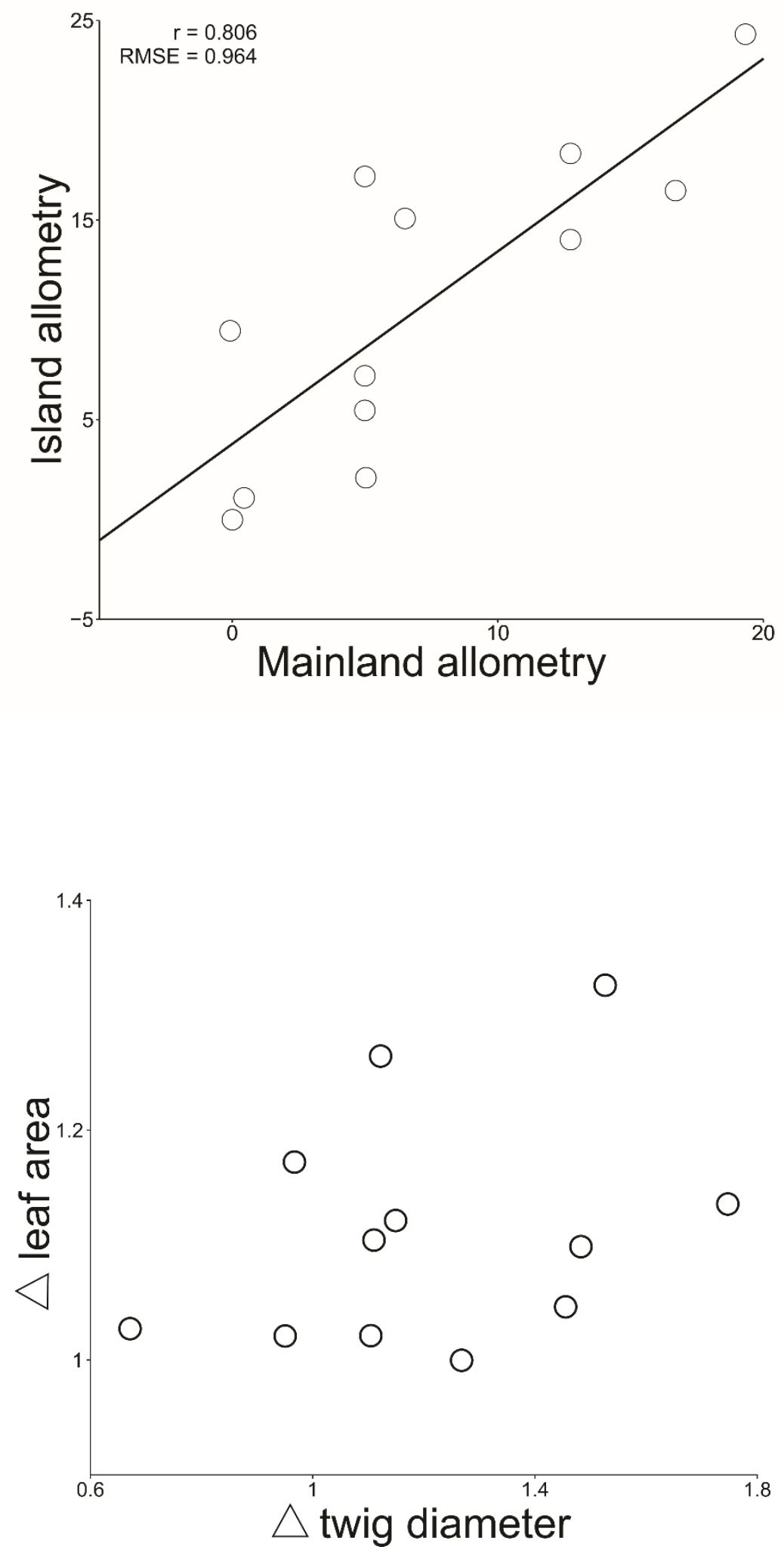

Figure 2.4 - The slope parameters of leaf-stem scaling relationships in island populations (y-axis) are plotted against those of mainland populations ( $\mathrm{x}$-axis). Open circles denote single mainland-island population comparisons.
Figure 2.5 - Insular changes in the size of leaves (leaf area, cm2, yaxis) are unrelated to insular changes in the size of stems that support them (stem diameter, mm, $\mathrm{x}$-axis). Open circles denote a single island-mainland population comparison. 


\subsection{Discussion}

Leaf-stem allometry varied among species yet did not differ between islands and mainlands. While some evidence of dwarfism was observed, most island populations showed evidence of gigantism. Island populations produced larger leaves than those of mainland populations at all latitudes, while changes in stem size scaled with latitude. Contrary to the predictions of the allometric constraint hypothesis, changes in leaf size were not accompanied by a concomitant change in stem size. Overall results illustrate the capacity of allometric traits to evolve independently, suggesting the repeated evolution of large leaves on islands is not contingent on the evolution of increased arborescence.

\subsubsection{Do leaf and stem sizes covary?}

Leaf sizes covaried strongly with the size of stems that supported them in some species and weakly in others. Interspecific differences in leaf-stem allometry might be explained by differences in life history. For instance, divaricate branching (small leaves and large branching angles) in Muehlenbeckia complexa is considered an adaptation to extinct avian herbivores from the New Zealand archipelago (Greenwood \& Atkinson 1977; Bond \& Silander 2007). Leaf heteroblasty - the abrupt production of different leaf forms through ontogeny - in Muehlenbeckia australis is thought to have arisen for similar reasons. Leaf size in divaricate and heteroblastic plants might therefore be determined, not by developmental constraints imposed by stem size, but by selective pressures imposed by predators during their natural history. Indeed, leaf size in both Muehlenbeckia species showed no relationship with stem size. To this end, species not subject to herbivore-induced limitations on leaf size should produce leaves that covary more intrinsically with stem size, which might explain why leaf-stem allometry was greatest in large-leaved species.

\subsubsection{Does leaf-stem allometry differ on islands?}

While plant traits inherently vary with geography (Šímová et al. 2018), scaling relationships between them typically do not (Enquist \& Niklas 2002; Sun et al. 2005). For instance, leafstem scaling exponents of many woody species are functionally equivalent at low, mid, and high altitudes (Sun et al. 2005). Plants instead respond to the environmental stress of high altitudes with a shift in the $y$-intercept of this relationship (i.e. plants produce smaller leaves 
for any given stem size with increasing environmental stress). Invariant allometry is hypothesized to result from developmental constraints, which presumably limit the capacity of plant organs to evolve independently of one another (Primack 1987; Midgley \& Bond 1989; Harvey \& Pagel 1991). Results here support the notion that trait allometry is not modulated by geography.

\subsubsection{Do leaf and stem size differ on islands?}

Assessing size changes is complicated by how plant morphology varies geographically. Many plant traits scale with both altitude (Leuschner 2000; Hulshof et al. 2013) and latitude (Moles et al. 2007; Moles et al. 2009; Gallagher \& Leishman 2012; Šímová et al. 2018). For instance, up to half of global variation in leaf size can be predicted by physiological constraints imposed by leaf-air temperature differences (Wright et al. 2017). Indeed, experimental evidence has confirmed the disproportionate vulnerability of large leaves to low nighttime temperatures (Lusk et al. 2018). Analyses of insular size changes must therefore consider geographic differences between mainland and island sites. Mainland sites in this study were chosen because of their latitudinal proximity to island sites. Latitudinal differences between sites are therefore unlikely to account for the morphological differences observed.

Contrary to trait allometry, trait evolution varied with geography. Island populations consistently produced larger leaves than those of mainland populations. Leaf gigantism across latitudes suggests it results from a selective pressure that is not contingent on local climatic differences. Changes in stem size, on the other hand, were largest (and toward gigantism) at low latitudes and dwarfed at higher latitudes; suggesting they result from a separate evolutionary pathway that is modulated by factors that vary with latitude.

\subsubsection{Are changes in leaf size contingent on changes in stem size?}

Allometric correlations have long been considered causes of evolutionary constraint (Smith et al. 1985; Clark 1987; Primack 1987; Midgley \& Bond 1989; Harvey \& Pagel 1991; Arnold 1992; Niklas 1994; Futuyma 2010). Coevolution of allometric traits can arise in several ways. One possibility is that trait scaling relationships result from physical limitations, which subsequently restrict the ability of traits to respond independently to selective pressures (c.f.fractal and pipe model theories, Shinozaki et al. 1964; West et al. 1997; Enquist 2002). 
Traits also coevolve if they are linked genetically (i.e. linkage disequilibrium, Flint-Garcia $e t$ al. 2003). However, artificial selection experiments in insects have revealed that traits can evolve rapidly and independently of one another despite being developmentally and genetically correlated (e.g. Weber 1990; Wilkinson 1993; Emlen 1996). Evidence of the same capacity in plants is building (Stanton \& Young 1994; Conner et al. 2011). In this study, changes in leaf size were not associated with concomitant changes in stem size, supporting the growing contention that allometric correlations do not always predict evolution.

\subsubsection{Caveats and conclusions}

Prior research has demonstrated the distinct environmental conditions of islands even when compared to equivalent continental habitats (Weigelt et al. 2013). Differences in plant morphology might therefore result, not from evolution, but phenotypic plasticity. Invasive plants often respond plastically to new environments and thereby appear unlike individuals from their native range (Richards et al. 2006; Davidson et al. 2011). Whether phenotypic plasticity might account for the morphological differences documented here remains unknown. Future work might employ methods, such as common garden experiments (c.f. Leger \& Rice 2003; Blumenthal \& Hufbauer 2007), to draw firmer conclusions about the origins of morphological incongruences between populations of contrasting environments.

The capacity for independent evolution of allometric traits might not characterize all plants. For instance, trait allometry might play a more intricate role in the evolution of statured plants like shrubs and trees. Understanding the degree to which traits can evolve in response to new environments without possibly detrimental, yet obligatory, changes in other traits may be a crucial factor influencing invasion success (Davidson et al. 2011). Furthermore, phenotypic malleability likely has important implications for plants under a rapidly changing climate (reviewed in Nicotra et al. 2010).

Overall results do not conform to predictions of the allometric constraint hypothesis. The allometry of plant organs does not prohibit their capacity to evolve independently. Results therefore build upon those of Stillwell et al. (2016), suggesting allometry and evolution are more detached than traditionally considered. 


\title{
Chapter 3
}

\section{Plants obey (and disobey) the island rule}

\begin{abstract}
The island rule predicts that small animals evolve to become larger on islands, while large animals evolve to become smaller. It has been studied for over half a century and its validity is fiercely debated. Here, we provide a new perspective on the debate by conducting the first test of the island rule in plants. Results from an extensive dataset on islands in the Southwest Pacific illustrate that plant stature and leaf area obey the island rule, but seed size does not. Our results indicate that the island rule may be more pervasive than previously thought and that support for its predictions varies among functional traits.
\end{abstract}

Publication status: Published.

Biddick M, Hendriks A, Burns KC (2019). Plants obey (and disobey) the island rule. Proceedings of the National Academy of Sciences 116(36): 17632-17634.

\section{Related publication}

Biddick M, Burns KC (2019). Reply to Brian and Walker-Hale: Support for the island rule does not hide morphological disparity in insular plants. Proceedings of the National Academy of Sciences. 


\subsection{Introduction}

The island rule, a graded trend from gigantism in small species to dwarfism in large species on islands, is a controversial issue in biogeography (Van Valen 1973; Lomolino 1985). While many studies have found support for its predictions (Clegg \& Owens 2002; Lomolino 2005; Welch 2009; Lomolino et al. 2013; Nolfo-Clements et al. 2017), other studies have not (Meiri et al. 2006; Meiri et al. 2008; Meiri et al. 2009; Itescu et al. 2014; Itescu et al. 2018; Rebouças et al. 2018), leading to widespread debate over its validity (Lokatis \& Jeschke 2018). Although studied for over 50 years, previous tests have been limited to animals, and predominantly to particular groups of vertebrates.

Mechanistically, several factors are thought to drive the convergence of body size on islands (Lomolino 2005). For example, competition in species-rich mainland communities is thought to drive phenotypic divergence in order to promote coexistence (Dayan et al. 1990). On islands, which tend to be more species-poor than mainlands, selection for phenotypic divergence is relaxed, leading to reduced size diversity. Given these factors are not exclusive to animals, they might drive convergence in the size of other life groups.

Darwin (1859) noted that many island trees are derived from continental herbs. He reasoned that herbaceous plants evolve woodiness on islands because of selection for increased stature, which improves their capacity to compete for light. Molecular tools have since demonstrated the convergent evolution of woodiness in the Canary (Böhle et al. 1996; Lens et al. 2013), Madeiran (Panero et al. 1999), and Hawaiian (Carlquist et al. 2003) floras. However, a unidirectional evolutionary pathway toward insular woodiness (and consequently increased stature) is not always observed (Tsukaya et al. 2006; Burns 2016) and no previous study has tested for the island rule in plants

We provide the first test of the island rule in plants. We collected data on plant stature, leaf area and seed size in 175 taxonomic pairings inhabiting 10 isolated archipelagos. Data were derived from field measurements, herbarium specimens and flora descriptions from islands spanning 13 degrees of latitude of the Southwest Pacific, to test whether small plants evolve to become larger on islands and large plants evolve to become smaller. 


\subsection{Methods}

\subsubsection{Data collection}

We integrated data from published literature, flora descriptions, herbarium specimens, and field measurements (Table B.1, Appendix B). We extracted data from four studies that share similar methodologies and were carried out by the same working group (Burns et al. 2012; Kavanagh \& Burns 2014; Cox \& Burns 2017; Biddick et al. 2019b). These studies predominantly investigated size changes in taxonomically undifferentiated and partially differentiated islandmainland pairings. To include more taxonomically differentiated taxa, we used published molecular phylogenies to identify island endemics in the South-west Pacific that result from anagenesis following a single colonization event. When no phylogeny was available, geographic proximity was used as a surrogate for genetic relatedness. Stature, leaf area, and seed size values were then extracted from flora descriptions. We systematically extracted the greatest value for stature and the mean value for leaves and seeds. When only a single metric of size was available (e.g. length without width), the same metric was extracted for the respective comparison, such that trait metrics were always kept consistent within pairings. When trait values were unavailable, images of specimens were sourced from online herbaria and measured in ImageJ (Schneider et al. 2012). Field measurements of a further 13 pairings from Tuhua Island were collected following methodology of Biddick et al. (2019b). Mainland measurements were taken from the Kaimai-Mamaku Forest Reserve, which occupies the same ecological district and latitudinal band as Tuhua Island.

\subsubsection{Data analysis}

Following Lomolino et al. (2013), we first performed linear regressions of $\log \left(S_{i}\right.$ [island value divided by mainland value]) against $\log (M$ [mainland value] $)$. Paired t-tests were then used to test whether island values were consistently larger or smaller than mainland values. We utilized linear mixed effects models to control for factors that might obscure island rule trends. Because $S_{i}$ should vary with degree of taxonomic differentiation, we included taxonomic differentiation as a fixed effect with 3 levels (fully differentiated, partially differentiated, and undifferentiated). The partially differentiated level included both subspecies and varieties. Because $M$ values should differ between woody and herbaceous plants, we included growth form as a fixed factor with 2 levels (woody and non-woody). Species occur multiple times in 
the dataset; therefore, species identity was included as a random effect. To control for phylogenetic morphological conservatism, taxonomic family was included as a random effect. To control for variation related to collection method, collection method was included as a random effect.

\subsection{Results}

We compiled 175 taxonomic pairings from 10 archipelagos surrounding the New Zealand 'mainland' (Fig. 3.1A; Table B.1, Appendix B). Linear regression revealed a graded trend from gigantism to dwarfism in both stature (Fig. 3.1B; $T=-5.097, d f=93, P<0.001$ ) and leaf area (Fig. 3.1C; $T=-4.910, d f=131, P<0.001$ ). Mixed effects models confirmed that these trends were robust after controlling for degree of taxonomic differentiation, growth form, collection method, and phylogenetic morphological conservatism $(T=-6.131, P=0.026 ; T=-4.044, P<$ 0.001 , respectively). Paired t-tests revealed that island values of stature and leaf area were not consistently larger or smaller than mainland values $(T=0.271, d f=95, P=0.787 ; T=0.226$, $d f=132, P=0.821$, respectively). Conversely, changes in seed size were ungraded (Fig. 3.1D; $T=0.994, d f=92, P=0.333)$ even after controlling for potentially confounding factors $(T=$ $0.778, P=0.444)$. Island seed sizes were instead predominantly larger than mainland seed sizes $(T=4.051, d f=93, P<0.001)$. 


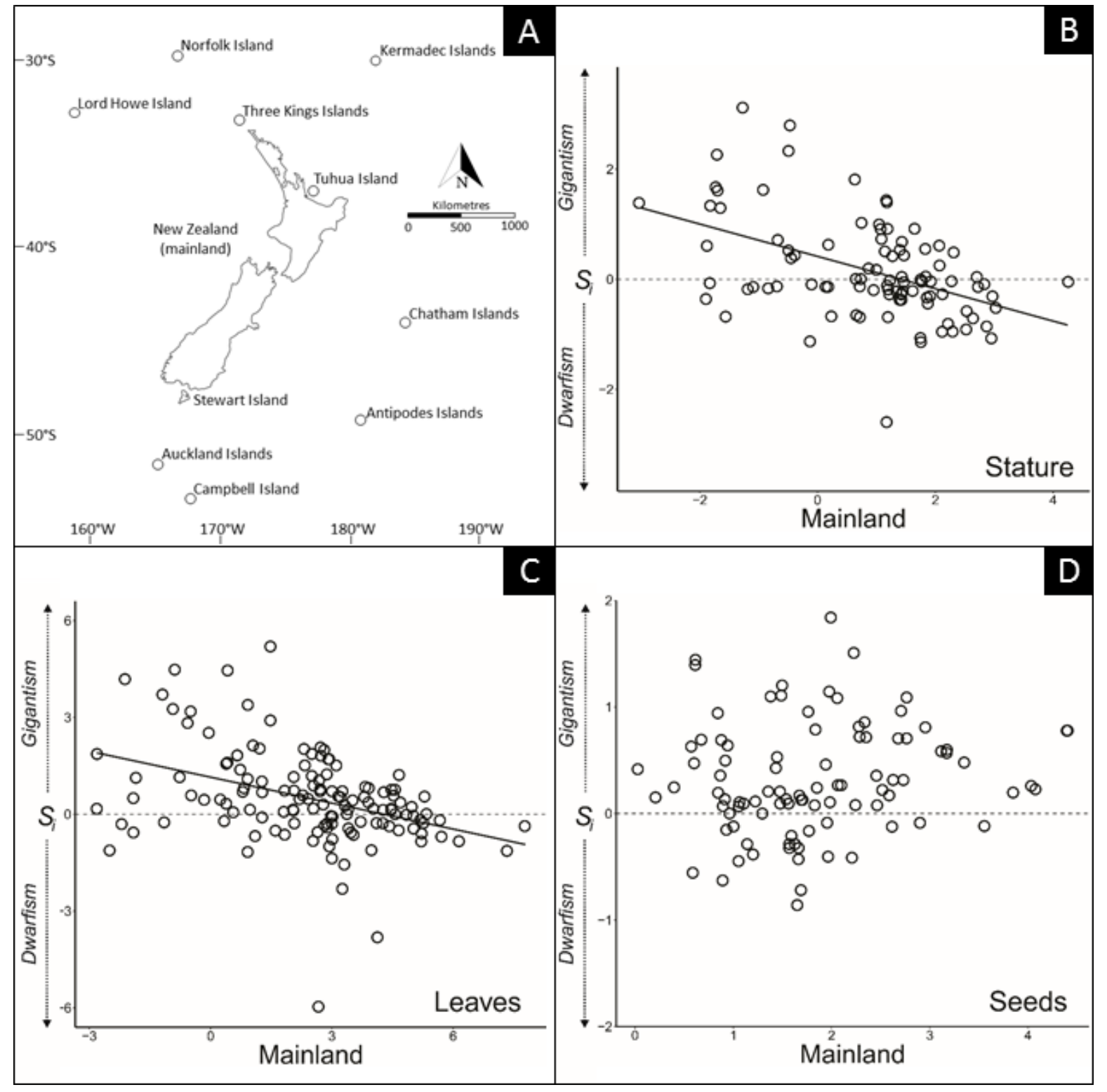

Figure 3.1 - (A) The island rule was tested in plants inhabiting islands in the southwest Pacific, whose floras are primarily derived from the New Zealand "mainland." (B and C) Insular size changes (Si, y axis) vary as a function of mainland values (x axis) in (B) stature $(n=96)$ and $(C)$ leaves $(n=134)$. (D) Changes in seed size are unrelated to mainland values $(\mathrm{n}=94)$. A dashed horizontal line intercepting th $\mathrm{y}$ axis at zero denotes morphological isometry. Both axes are logarithm-transformed. Open circles denote single island-mainland pairings. 


\subsection{Discussion}

Our findings add to a growing body of evidence suggesting that plants, like animals, evolve in consistent ways on islands (Burns 2019). Many previous studies on animals have documented support for the island rule (Clegg \& Owens 2002; Lomolino 2005; McClain et al. 2006; Bromham \& Cardillo 2007; Welch 2009; Lomolino et al. 2013; Nolfo-Clements et al. 2017), while others have failed to find support for its predictions (Meiri et al. 2006; Meiri et al. 2008; Meiri et al. 2009; Itescu et al. 2014; Itescu et al. 2018; Rebouças et al. 2018). Here, we show that plants both obey and disobey the island rule, depending on the plant functional trait in question.

Plant stature and leaf area both obeyed the island rule. Therefore, they may have a single mechanistic explanation, if one trait covaries allometrically with the other. Previous work on animals has linked the island rule to a variety of factors, including insular changes in competitors, predators or environmental conditions (Lomolino 2005; Lomolino et al. 2013). The same ecological mechanisms could drive the evolutionary convergence of size in island plants. On the other hand, given the physiological differences between animals and plants, other processes might be at work.

This would not appear to be the case with seed size, as it disobeyed the island rule. Instead, it exhibited a consistent tendency toward gigantism; a phenomenon that has been documented elsewhere and is thought to arise for reasons related to dispersal ability (i.e. reduced mortality at sea, Darwin 2004; but see Burns 2018). Alternatively, islands house fewer species at greater densities than mainlands (MacArthur et al. 1972). Therefore, a selection for larger (and consequently more competitive) seeds could arise from greater levels of competition among conspecifics.

Future work on island plants may provide a unique window into the processes responsible for the island rule. Plants can be collected, transported and manipulated more easily than animals. They can be grown under different environmental conditions, subjected to different herbivores in cafeteria-style experiments, and planted in competitive arrays. Therefore, future tests of the island rule in plants may help inform the debate over whether animals obey (or disobey) the island rule. 


\title{
Chapter 4
}

\section{Evolutionary drift predicts the island rule}

\begin{abstract}
The island rule is a putative pattern in island evolution, where small species become larger on islands and large species become smaller. Despite decades of intense research interest, a mechanistic explanation for why some taxonomic groups obey the island rule, while others do not, has yet to be identified. Here we demonstrate that the island rule results from evolutionary drift. We derive a simple simulation model that predicts evolutionary size changes based on random evolutionary trajectories along bounded trait domains. The model consistently predicts the island rule and can account for its occurrence in a large dataset on plants inhabiting oceanic islands in the Southwest Pacific. It also fails to predict evolutionary size changes in the absence of evidence for the island rule. When support for the island rule is not detected, convergent patterns in insular gigantism are often observed, suggesting that natural selection can promote consistent insular size changes in the absence of the island rule. Overall results indicate that evolutionary drift provides a parsimonious explanation for the island rule when it occurs, suggesting future work should focus on circumstances where it does not occur and convergent size changes are instead observed.
\end{abstract}

Publication status: Under review

Biddick M, Burns KC (under review). The island rule is predicted by evolutionary drift. Ecology Letters. 


\subsection{Introduction}

Island environments are thought to drive predictable trends in the evolution of island organisms (Carlquist 1974; Burns 2019). The 'island rule' (Foster 1964; Van Valen 1973; Lomolino 1985) is arguably the most repeatedly documented, yet heavily debated, of these trends. It describes a graded trend in island evolution, whereby small species evolve to become larger, and large species evolve to become smaller, and has found support in vertebrates (Heaney 1978; Clegg \& Owens 2002; Boback \& Guyer 2003; Bromham \& Cardillo 2007; Benton et al. 2010; Lomolino et al. 2013; Nolfo-Clements et al. 2017), invertebrates (Palmer 2002; McClain et al. 2006) and plants (Biddick et al. 2019a; Burns 2019). However, many other studies have failed to find support for the island rule (Meiri et al. 2006; Meiri et al. 2008; Meiri et al. 2009; Lokatis \& Jeschke 2018). Despite decades of research interest, why species obey or disobey the island rule remains an evolutionary mystery.

Many mechanistic hypotheses have been erected to explain why selection favours intermediate body size in land organisms (Case 1978; Palkovacs 2003; Lomolino 2005). Most invoke natural selection arising from differences in the ecological or environmental conditions on islands relative to continents (e.g. competition, predation or resource availability). For instance, because many predators are absent on isolated islands, release from predation could drive species to converge on their more 'optimal' body size (Lomolino 1985). However, no single hypothesis has yet to be derived to explain the diverse range of size changes observed in island life.

Here, we test whether the island rule might arise from evolutionary drift along finite trait domains. We derive a simple simulation model to predict evolutionary size changes in island organisms based on drift. We then apply the model to an updated dataset on plants inhabiting small islands in the Southwest Pacific. Results are used to answer three questions:

1. Does evolutionary drift generate the island rule?

2. Does drift provide a parsimonious explanation for previously reported evidence for the island rule in plants, and does it fail to account for insular size changes when it does not occur?

3. When the drift model fails, and evidence for the island rule is not observed, is there evidence for convergent, directional size changes? 


\subsection{Methods}

We derived a simple simulation model to predict how insular size changes might arise from evolutionary drift (Fig. 4.1). The model begins by establishing an arbitrary range of body sizes for a group of related species on the mainland (i.e. mainland 'trait space'). The body size of a hypothetical island colonist is then chosen at random from within this trait space, between minimum (min) and maximum (max) potential body sizes. The island colonist is then allowed to drift to a new, random location in trait space. Under these conditions, the probability of gigantism $\left[P(G)=(\max -i) \max ^{-1}\right]$ and the probability of dwarfism $\left[P(D)=(i) \max ^{-1}\right]$ sum to unity and vary linearly with a species' original position in trait space (i.e. before it colonised the island from the mainland). When this process is iterated for a suite of related species, the island rule always arises by chance, with the probability of dwarfism increasing with initial (mainland) body size, and the probability of gigantism declining with initial size.

The model makes five assumptions. First, all species immigrate to the island from the mainland at the same time. Second, species drift at the same rate to a new point in trait space following island colonisation. Third, there is no gene flow between island and mainland populations following island colonisation. Fourth, island and mainland trait spaces are the same. Lastly, insular size changes are not under natural selection.

To test whether the simple drift model could predict the island rule in plants, we analysed an updated version of our previously published dataset on plants (Biddick et al. 2019a). These data (Table C.1, Appendix C) come from isolated islands in the Southwest Pacific, whose floras were derived by long-distance dispersal from New Zealand or Australia. To promote conformity to the assumption of no island-mainland gene flow, we removed measurements from Tuhua (Mayor Island) in the updated dataset, which was the least isolated island in the dataset (30 km from the North Island of New Zealand).

Data were split into two lifeform categories (woody \& herbaceous [i.e. 'forbs', excluding graminoids]), and three trait categories (stature, leaf area \& seed size), which were each analysed separately ( $\mathrm{n}=6$ life form $x$ trait groupings). We then tested for evidence of island rule by regressing insular size changes ( $\mathrm{Si}$, island size estimate $\div$ mainland size estimate) against mainland values $(M)$, following Lomolino et al. (2013). Alternative statistical tests for evidence of the island rule are available and may be more appropriate under certain 
circumstances (see Welch 2009), but we chose this method because we later use our drift model to predict insular size changes, regardless of whether $S_{i}$ values decline with $M$ values. Both variables were logarithm transformed prior to analysis.

To determine whether the simple drift model could predict observed size changes on islands, we generated expected island size changes under evolutionary drift as described in Fig. 4.1. However, rather than selecting mainland values from a uniform random distribution, simulations began with empirical estimates of mainland body sizes, which were assumed to reflect ancestral states (see Welch 2009). To conform to the assumption of equivalent trait domains between islands and the mainland, we subsequently selected island trait values from a probability density function fit to observed frequency distributions of mainland trait values. Probability density functions were derived using the kernel density function in the msm package in $R$ (R Core Team, 2013). Observed $S_{i}$ values were then regressed against expected $S_{i}$ values using simple linear models. This process was then iterated 1000 times to obtain average $p$ and $r^{2}$ values for the six trait $x$ life form groupings, as well as for each trait across all life forms. All variables were logarithm-transformed prior to analyses.

Lastly, we tested for convergent patterns in gigantism or dwarfism in all nine trait $x$ life form categories described above. Island and mainland trait values were compared using unequal variance paired t-tests (i.e. Welch's t-tests). All analyses were conducted in the R environment ( $\mathrm{R}$ Core Team, 2013). The dplyr package (Wickham et al. 2015) was used for data manipulation, ggplot2 (Wickham 2016) for data visualization, purr (Henry \& Wickham 2019) for modelling across nested datasets, and broom (Robinson 2014) for tidy model outputs. 


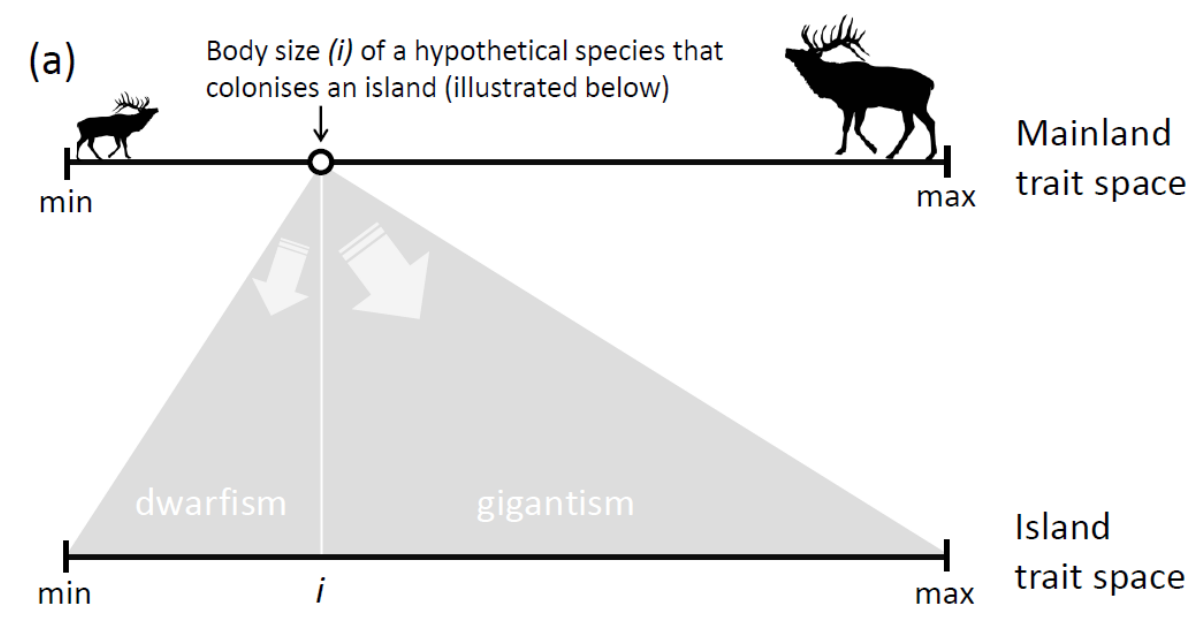

(b)

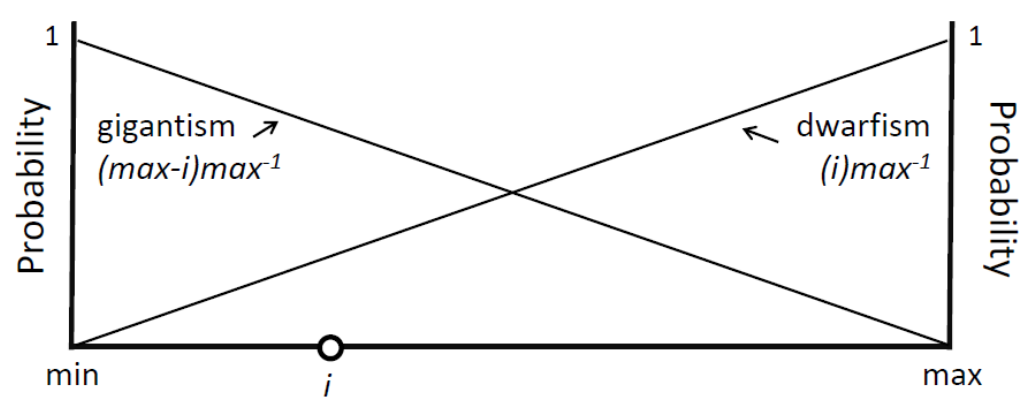

Body size of a hypothetical species that colonises an island

(c)

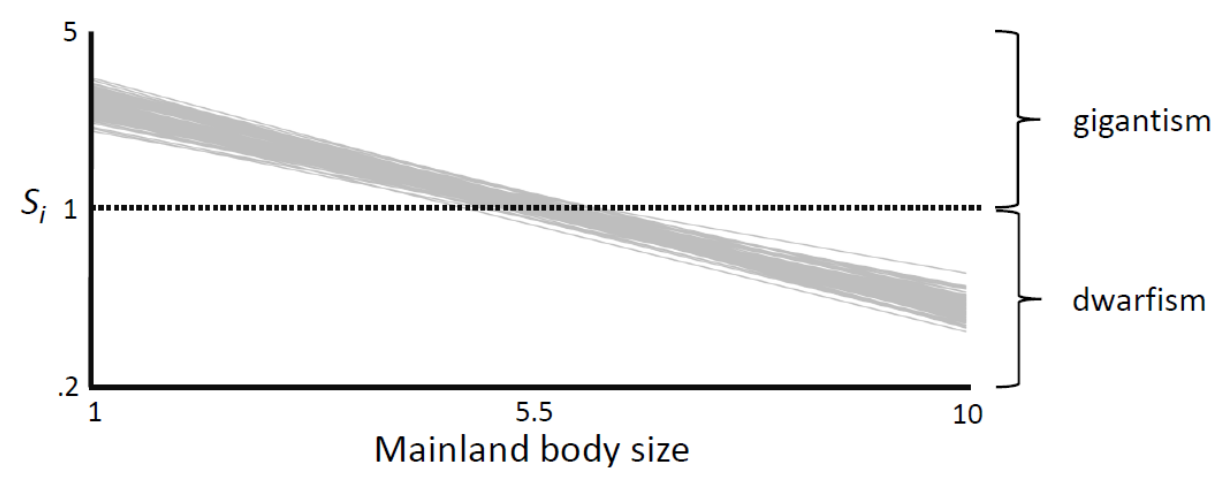

Figure 4.1 - A simple simulation model illustrating how the island rule can arise from evolutionary drift. The upper horizontal line in (a) represents the range of body sizes for a given group of organisms on the mainland (i.e. 'trait space'). This might represent body mass, carapace length, plant stature or any other trait. The point labelled (i) represents the hypothetical body size of a species that colonises an island from the mainland. Assuming that island trait space is equal to that of the mainland, yielding the lower horizontal line in (a), the relative area of each grey triangle represents the relative probabilities of becoming smaller or larger on the island via evolutionary drift. (b) illustrates the probabilities of insular gigantism and insular dwarfism given different initial (mainland) body sizes. (c) illustrates the results of simulated relationships between evolutionary size changes (y-axis) and mainland body sizes (x-axis) for a group of relate species. During each simulation replicate, initial body sizes for 100 species were drawn at random from the mainland trait space. Each species was then allowed to drift to a new location randomly, and the corresponding line of best fit between insular size changes ( $\mathrm{Si}$, island body size $\div$ mainland body size) and mainland body size was then plotted as a grey line. This procedure was iterated 1000 times, each resulting in a negative relationship between insular size changes and mainland body sizes (i.e. the 'island rule'). 


\subsection{Results}

Our simple drift model consistently predicted the island rule. In all nine trait $x$ lifeform categories, it predicted that insular sizes should decline compared to increasing mainland sizes. Negative relationships were consistently observed between insular size changes and mainland trait values (depicted as grey lines in Fig. 4.2).

Most trait $x$ life form categories (all three stature comparisons and two leaf area categories) showed empirical support for the island rule (Table 4.1, Fig. 4.2). In all of these cases, insular size changes were predicted statistically by the drift model (Table 4.1). In the four remaining categories that showed no support for the island rule (all seed size categories and leaf area in forbs), the drift model failed to predict insular size changes. Therefore, the drift model predicted insular size changes in every case when the island rule was observed and had no predictive value when it was not observed.

Three of the four trait $x$ life form categories that did not show support for the island rule (all but seed size in forbs) instead showed a different evolutionary trend (Table 4.1). All three showed evidence for convergence towards insular gigantism. One final category, seed sizes in forbs, showed little predictable differentiation in insular size changes. It showed no evidence for the island rule, the drift model failed to predict size changes on islands, and no support for convergent patterns in either gigantism or dwarfism was observed. 
Table 4.1 - Statistical analyses of insular size changes in plants inhabiting islands in the Southwest Pacific. Categories of plant functional traits are shown in the first column along with sample sizes. Tests for evidence of the island rule, linear regression of insular size changes $(\mathrm{Si}$ ) against mainland values $(\mathrm{M})$, are shown in the second set of columns. Tests for congruency between observed insular size changes ( $\mathrm{Si}$ observed) and predicted insular size changes by a simple drift model (Si predicted) are shown in the third set of columns. Tests for unidirectional insular size changes (evidence for gigantism) is shown in the fourth set of columns. The drift model successfully predicted insular size changes when support for the island rule was observed, and it failed to predict insular size changes when it did not occur. Under these circumstances, convergent patterns of insular gigantism were often observed.

\begin{tabular}{|c|c|c|c|c|c|c|}
\hline \multirow[b]{2}{*}{ Plant functional trait $(n)$} & \multicolumn{2}{|c|}{$\begin{array}{c}\text { Support for island rule? } \\
\text { Linear regression: } \\
\log _{10}\left(S_{i}\right) \sim \log _{10}(M)\end{array}$} & \multicolumn{2}{|c|}{$\begin{array}{c}\text { Support for drift? } \\
\text { Linear regression: } \\
\log _{10}\left(S_{\text {iobserved }}\right) \sim \log _{10}\left(S_{i}\right. \\
\text { predicted })\end{array}$} & \multicolumn{2}{|c|}{$\begin{array}{c}\text { Support for convergence? } \\
\text { Paired t-test: } \\
\mathrm{H}_{0}: \overline{\mathrm{x}}_{\mathrm{I}}=\overline{\mathrm{x}}_{\mathrm{M}}\end{array}$} \\
\hline & $b_{1}$ & $p$ & $\mathrm{r}^{2}$ & $p$ & $t$ & $p$ \\
\hline Stature - All (84) & -0.319 & $<0.001 *$ & .17 & $0.040 *$ & 0.036 & 0.971 \\
\hline Stature - Woody (66) & -0.530 & $<0.001 *$ & .24 & $<0.001^{*}$ & 1.442 & 0.154 \\
\hline Stature - Forbs (19) & -0.637 & $<0.001 *$ & .37 & $0.007^{*}$ & 2.033 & 0.058 \\
\hline Leaf area - All (118) & -0.236 & $<0.001 *$ & .15 & $<0.001 *$ & 4.314 & $<0.001 *$ \\
\hline Leaf area - Woody (95) & -0.247 & $<0.001 *$ & .18 & $<0.001 *$ & 3.33 & $0.001^{*}$ \\
\hline Leaf area - Forbs (23) & -0.001 & 0.994 & .03 & 0.459 & 2.986 & $0.007^{*}$ \\
\hline Seed size - All (85) & 0.052 & 0.333 & .01 & 0.359 & 5.251 & $<0.001 *$ \\
\hline Seed size - Woody (61) & 0.057 & 0.260 & .02 & 0.257 & 5.625 & $<0.001 *$ \\
\hline Seed size - Forbs (24) & -0.139 & 0.431 & .03 & 0.469 & 1.490 & 0.150 \\
\hline
\end{tabular}



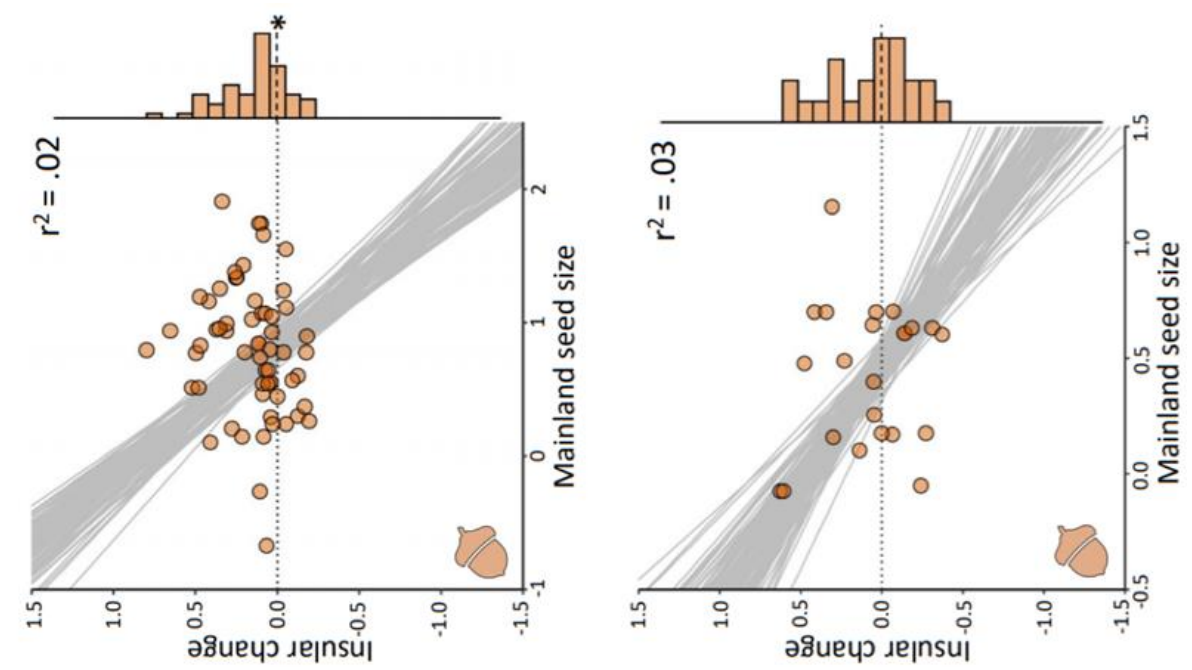

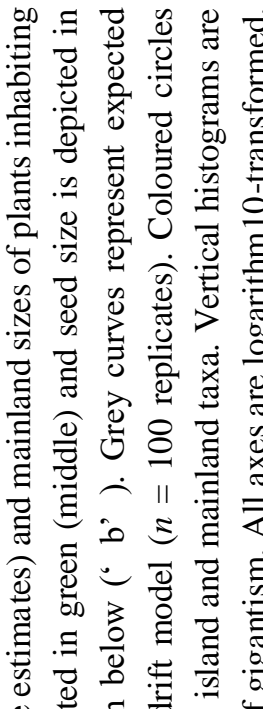
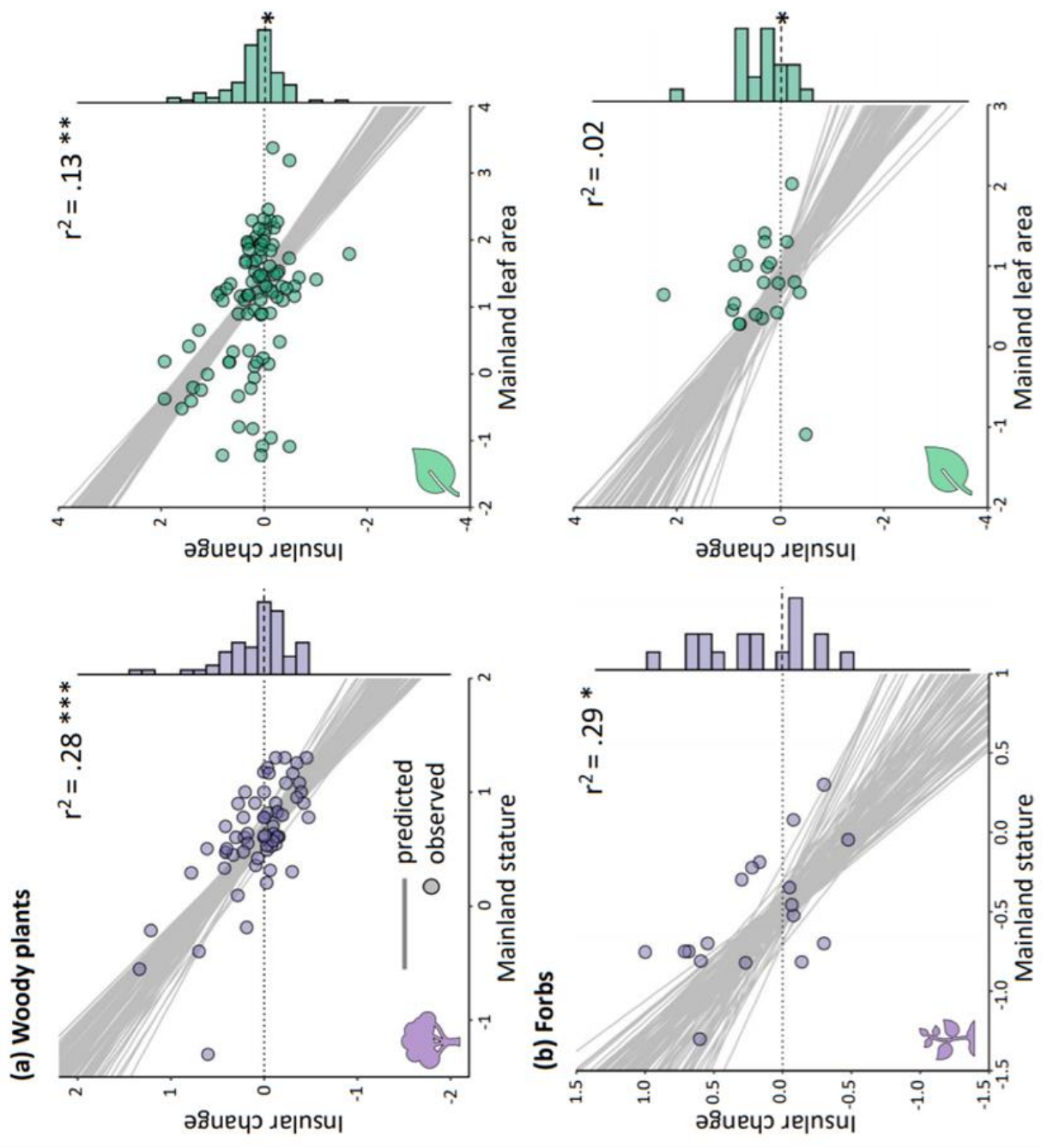

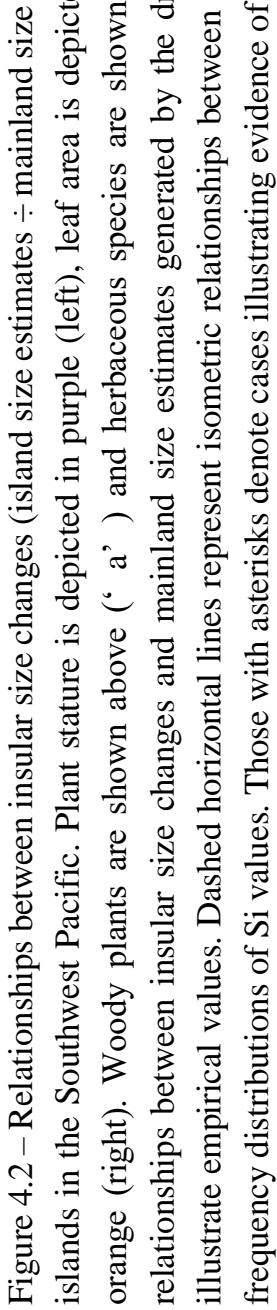




\subsection{Discussion}

Previous work has typically evoked natural selection to account for the island rule (Sondaar 1977; Heaney 1978; Lomolino 1985). Because islands house fewer species than mainland sites of equivalent size (MacArthur \& Wilson 1967), interspecific competition may be reduced on islands. Consequently, larger size in small-bodied organisms may enhance resource acquisition, if larger size enables the capture of both small and large food items. On the other hand, because resources tend to be more limited on islands, smaller size in large-bodied organisms may evolve to reduce their energetic requirements (McClain et al. 2006). Islands also lack many types of predators that are common on the mainland, and reduced predation pressure may enable smaller bodied prey to evolve larger size. On the other hand, larger bodied prey may no longer benefit from their large size to fend off predators (Sondaar 1977; although see discussion in Lomolino 1985).

The island rule has only recently been explored in plants (Biddick et al. 2019a). However, trends in plant evolution on islands have intrigued biologists for centuries. Darwin (1859) noticed that many trees endemic to oceanic islands evolved from herbaceous ancestors on continents. He reasoned that 'weedy' species are the first to colonize young oceanic islands and subsequently evolved into trees (the 'weeds-to-trees' phenomenon) due to competition for light (Darwin 1859), or selection for increased longevity (Wallace 1902), or shifts in preferred habitats (Carlquist 1974). Darwin's hypothesis has since found support in several archipelagos (Böhle et al. 1996; Baldwin 2007; Wagstaff et al. 2011; Lens et al. 2013). However, the 'weeds-to-trees' phenomenon cannot not explain why plants sometimes dwarf on islands. It also fails to explain why some plant traits conform to the island rule, but others do not (Burns 2016; Biddick et al. 2019a).

Results from this study suggest a parsimonious explanation for the island rule in plants. Approximately half of our empirical analyses showed evidence for the island rule, which typifies previous work on the subject in animals. In all of these cases, evolutionary drift predicted a significant amount of variation in observed evolutionary size changes. On the other hand, our simple drift model failed to predict insular size changes in the absence of empirical evidence for the island rule. Simple evolutionary drift thereby provides a parsimonious explanation for the island rule in plants. 
We intentionally made our drift model as simple as possible, as a starting point to better understand how drift might promote patterns in the evolution of island organisms. Consequently it makes a number of simplifying assumptions, which when violated are likely to compromise its predictions. First, it assumes that species colonise islands at the same time. Because recent colonists have comparatively little time to evolve on islands relative to earlier colonists, differences in the time since colonisation is likely to generate heterogeneity in insular size changes in suites of similar species, even when they are evolving along the same trajectories. Cox \& Burns (2017) show that time since divergence explains a small but significant amount of variation in insular size changes in the Chatham Island flora, providing direct evidence that this assumption can be unrealistic. Nevertheless, the model still predicted a significant amount of variation in insular size changes in cases where evidence for the island rule was observed. Violations of this assumption may explain why it predicted less variable, steeper relationships between $S_{i}$ and $M$ than was observed. Future work using dated phylogenies is needed to better understand how differences in the time since divergence among island species might affect patterns in insular size changes.

Second, our simple drift model assumes that species evolve at similar rates. Adaptive radiations, which refer to the rapid evolution of closely related species, are common on isolated islands (Marques et al. 2019). Paradoxically, oceanic islands are also storehouses for relictual species (Roubik \& de Camargo 2012), some of which have remained unchanged for millennia. This suggests that the assumption of similar rates of evolution may also be frequently violated, thereby diminishing the drift model's capacity to predict insular size changes.

Our simple drift model also assumes no gene flow between islands and the mainland. Gene flow is likely to slow the divergence of insular species, and could also influence the evolution of mainland taxa (Welch 2009). Unlike the previous two assumptions, this assumption is unlikely to be seriously violated in our study. Our dataset was intentionally restricted to islands that are oceanic in origin and distantly located from the mainland, providing a severe impediment to pollen and seed dispersal. The assumption of equivalent trait domains between islands also seems realistic, although we lack evidence to demonstrate it directly.

Lastly, the model assumes that island traits are not under selection. Our tests for directional size changes indicate that this assumption was frequently violated. While plant stature consistently obeyed the island rule and showed no evidence for gigantism, results for leaf area 
and seed size were different. Forbs consistently produced larger leaves on islands, regardless of their mainland (ancestral) size. Leaf area was also higher in woody plant species. However, in this growth form, increases in leaf size were higher in small-leaved species than they were for large-leaved species. These results suggest that selection sometimes overrides the importance of drift in determining leaf size evolution on islands. Selection may favour increased leaf size for a variety of reasons, including differences in the climatic conditions on islands or changes in herbivore communities (Burns 2019). However, insular leaf gigantism remains an unsolved evolutionary riddle that awaits future study.

Seed sizes were also generally larger on islands. However, seed gigantism was more pronounced in woody species than herbaceous species. Although they were unable to determine why large seeds are advantageous on islands, Kavanagh \& Burns (2014) show that differences in seed gigantism between growth forms are linked to dispersal mode. Forbs tend to be wind dispersed, which is likely to limit the evolution of larger, heavier seeds that constrain their dispersal potential. On the other hand, fleshy-fruited species that are dispersed by frugivorous animals are freed from this constraint, allow the evolution of larger leaves. Fleshy-fruitedness is more common in woody plant species, providing an explanation for why seed gigantism is more pronounced in this growth form.

Overall results from this study showed that a very simple model mimicking evolutionary drift across bounded trait domains consistently predicts the island rule in island plants. Evolutionary drift therefore provides a parsimonious explanation for the island rule. However, analyses also revealed the signature of selection in many plant traits that did not show evidence of the island rule. Under these circumstances, convergent patterns of trait gigantism often occurred for reasons that await additional study. 


\title{
Chapter 5
}

\section{Leaf size evolution on islands}

\begin{abstract}
Organisms that are endemic to isolated islands often differ markedly in size to their mainland relatives. Most previous work on insular size changes test whether island species converge on intermediate body size (i.e. the island rule) and their results are highly variable. Here, we investigate species-specific variation in insular size changes at two scales of resolution in the Southwest Pacific. We characterised leaf size variation among 98 islands and comparable mainland populations in 9 widespread species using both field surveys and measurements of herbarium specimens. We then tested for insular size changes at two scales of resolution. First, we tested for broad-scale changes in leaf size between island and mainland populations. Next, we tested for fine-scale variation in leaf size among islands according to their isolation, age, and area. Broad-scale analyses showed that island populations tended to produce larger leaves than mainland populations. However, levels of leaf gigantism differed among species and increased with leaf size variation on the mainland. Fine-scale analyses showed that leaf gigantism covaried with island age, isolation and area. However, fine-scale patterns in leaf size were again highly variable, and species that showed progressively stronger evidence of leaf gigantism with island isolation and age were also more variable on the mainland. Although commonplace, insular leaf gigantism varied markedly among species. Interspecific variability in leaf gigantism was linked to size variability on the mainland, suggesting trait variability in larger, more contiguous populations could be a fundamental precursor to insular size changes.
\end{abstract}

Publication status: Submitted

Biddick M, Burns KC (submitted). Leaf size evolution on islands. Journal of Biogeography. 


\subsection{Introduction}

Plants and animals inhabiting oceanic islands often differ markedly in size from their closest relatives on continents. Many island species have evolved into giants. For example, the world's biggest seed, which can be over $50 \mathrm{~cm}$ long, is produced by a palm species that is endemic to the Sechele Islands (Lodoicea maldivica, Bellot et al. 2020). Paradoxically, other island species have evolved into dwarfs. For example, the world's smallest reptile, which can be as small as $16 \mathrm{~mm}$ long at maturity, occurs only on small islands in the Caribbean (Whitfield 2001). Why some animals evolve into giants on islands, while other become dwarfed, is one of the biggest unresolved riddles in biogeography.

The island rule attempts to account for paradoxical size changes in island populations by relating size changes to body size itself. It predicts that big species evolve into dwarfs after colonising islands and that small species evolve into giants. Couched in other terms, the island rule predicts that plants and animals converge on intermediate body sizes after colonising isolated islands.

Some studies have documented support for the island rule, while others have not. Variable support for the island rule has been attributed to a variety factors. Evolutionary size changes can differ taxonomically. For example, primates seem to obey the island rule (Lomolino 2005, Welch 2009), while reptiles disobey the island rule and instead show a trend towards dwarfism (Meiri 2007). Support for the island can also vary among traits. For example, the stature of plant species inhabiting islands in the Southwest Pacific conforms to the island rule, while seed sizes show an overarching trend towards gigantism (Kavanagh \& Burns 2014; Burns 2019; Biddick \& Burns 2019). Results also vary among investigators, with some lab groups consistently reporting evidence for the island rule, while other lab groups do not (Lokatis \& Jeschke 2018).

Here, we investigated species-specific variation in leaf size changes on islands off the coast of New Zealand at two scales of resolution. First, we conducted broad-scale comparisons of leaf area between islands and the mainland. Next, we assessed fine-scale patterns in leaf size among islands that differed in area, isolation and age. Lastly, we established whether interspecific variation at both scales of resolution were associated with trait variability. 


\subsection{Methods}

\subsubsection{Study site}

New Zealand is an isolated land mass that represents the above-water portion of the ancient continent 'Zealandia', which rifted away from the Gondwanan super-continent approximately 80 million years ago (Gibbs 2006). It is comprised of three main islands (North, South \& Stewart) and hundreds of satellite islands, whose floras are almost exclusively derived via overwater dispersal from the New Zealand mainland. The upper North Island of New Zealand has a temperate to sub-tropical climate, with warm humid summers and mild winters. Most areas average 2000-2200 sunshine hours. Maximum air temperatures in summer are typically around $25^{\circ} \mathrm{C}$, but can exceed $30^{\circ} \mathrm{C}$. In winter, maximum air temperatures of $14^{\circ} \mathrm{C}$ are typical and minimum air temperatures seldom drop below $0^{\circ} \mathrm{C}$. Most rainfall occurs in winter, but summer and autumn storms originating in the tropics of are also frequent. The islands bordering the north-eastern coast of the North Island experience a similar climate to the mainland. However, because they are more exposed, they often experience greater wind speeds, wind-chill and rainfall. Some of the larger islands, such as Ahauhu, Aotea, or Tūhua provide enough elevation and relief to generate microclimates. Te Hauturu o toi, for instance, is particularly wet and may experience greater levels of precipitation than many mainland sites of equivalent latitude and elevation.

\subsubsection{Data collection}

Data collection was conducted between June 2018 and April 2019. To gather data in the field, a single leaf from each of 30 individuals per species was measured at each site. Individuals were chosen haphazardly while walking through easily accessible forest sections. Only fully expanded, mature leaves were measured. Leaf length was measured as the longest linear distance from the most proximal to the most distal point of the leaf lamina using a digital calliper. Leaf width was measured as the widest distance across the leaf laminal perpendicular to the leaf length measurement. Leaf area was calculated as the product of leaf length and leaf width. Field sampling was conducted on 13 of the 98 islands (see Table S1). Field sampling on the mainland was conducted in the Kaimai-Mamaku Forest Park in Tauranga $\left(37^{\circ} 41^{\prime} \mathrm{S}\right.$, $\left.175^{\circ} 45^{\prime} \mathrm{E}\right)$. This site was chosen because the Kaimai Ranges span a large latitudinal extent of the north-eastern corner of New Zealand, and therefore represent the most probable source pool 
for many island populations.

To expand our dataset from the field, we measured pressed herbarium specimens from the Auckland War Memorial Museum Herbarium. The Herbarium houses an extensive collection of high quality, preserved specimens of both indigenous and exotic plants spanning the full geographic extent of the New Zealand landmass - including its offshore islands. To standardize our sampling across specimens, we measured 3 leaves per specimen using the same methodology explained above. Leaves were chosen haphazardly and care was taken to not damage specimens (i.e. gloves and minimal calliper-specimen contact).

To measure island parameters, we used the ArcGIS extension of the ArcMAP software (ESRI, Johnston et al. 2001). Island area was calculated by drawing polygons around each island and using the 'measure' tool. Island isolation was measured as the shortest linear distance from the mainland coastline to that of the island. The vast majority of islands bordering the north-eastern coastline of New Zealand are of the same geological origin as the Zealandia 'continent'. Thus, we estimated island age as the number of years since the island and mainland were connected above sea level. To do so, we measured the deepest bathymetric depth between the island and the mainland and divided this by the rate of sea level rise since the last glacial maximum (i.e. depth $\div$ rate of sea level rise = estimated island age). The last glacial maximum occurred approximately 21,500 years ago and sea level is estimated to have been $125 \mathrm{~m}$ below contemporary measures at this time (Milne et al. 2005). This provides a mean estimate sea level rise of $0.006 \mathrm{my}^{-1}$.

In cases of known volcanic origin, island ages were extracted manually from the geological literature. For example, Tuhua ('Mayor island', $37^{\circ} 17^{\prime} \mathrm{S}, 176^{\circ} 15^{\prime} \mathrm{E}$ ) is a $13 \mathrm{~km}^{2}$ remnant of a shield volcano that erupted $16 \mathrm{~km}$ off the east coast of Tauranga $\sim 7000$ years ago (Buck et al. 1981). Likewise, Rangitoto is a volcanic island that erupted in the Hauraki Gulf $>600$ years ago (retrieved from the Global Volcanism Program of the Smithsonian Institution at https://volcano.si.edu/volcano.cfm?vn=241020).

\subsubsection{Statistical analysis}

To test for insular changes in leaf size, we conducted unequal variance t-tests between mainland and island leaf sizes (i.e. Welch's t-test). All species were analysed separately and all data were 
logarithm-transformed to conform to the assumption of normality. We chose to use Welch's ttest as it is robust to unequal variances and therefore avoids problems associated with mean estimation (i.e. the 'Behrens-Fisher problem'). To test whether changes in leaf size on islands were associated with trait variability on the mainland, we performed Pearson's product moment correlation between the $T$-values from each t-test against the coefficients of variations on the mainland (logarithm 10 -transformed).

To quantity whether leaf size varies as a function of island isolation, age or area, we performed simple linear regressions of each independent variable against logarithm-transformed insular leaf area. Finally, to test whether insular trends in leaf size are strongest in species that exhibit high trait variability, we performed Pearson's product moment correlation between slope parameters of these trends against mainland trait variability.

All statistical analyses were conducted in the R 4.0.0 environment (R Core Team, 2013) using the RStudio 1.2.5042 client. The dplyr package (Wickham et al. 2015) was used for data manipulation, ggplot2 (Wickham 2016) for data visualization, purr (Henry \& Wickham 2019) for modelling across nested datasets, and broom (Robinson 2014) for tidy model outputs. All code is available upon request.

\subsection{Results}

We sampled from populations spanning more than 6 degrees of latitude on the mainland (Fig. 1A). A total of 98 offshore islands were sampled (Table D.1, Appendix D), similarly spanning 6 degrees of latitude and ranging $0.021-74.74 \mathrm{~km}$ in isolation, from 73-28,500 years in age, and $0.067-44,477 \mathrm{~m}^{2}$ in area (Fig. $1 B$ ). Island sampling was conducted on an average of 30 islands per species.

The leaves of island populations were significantly larger than those of mainland populations in 7 of the 9 species examined (Table 2, Fig. 2). Only one species (Coprosma repens) showed evidence of insular leaf dwarfism, while one other (Elaeocarpus dentatus) did not show evidence of insular dwarfism or gigantism. Further, changes in leaf size on islands were positively correlated with intraspecific trait variability on the mainland (Fig. 3). 


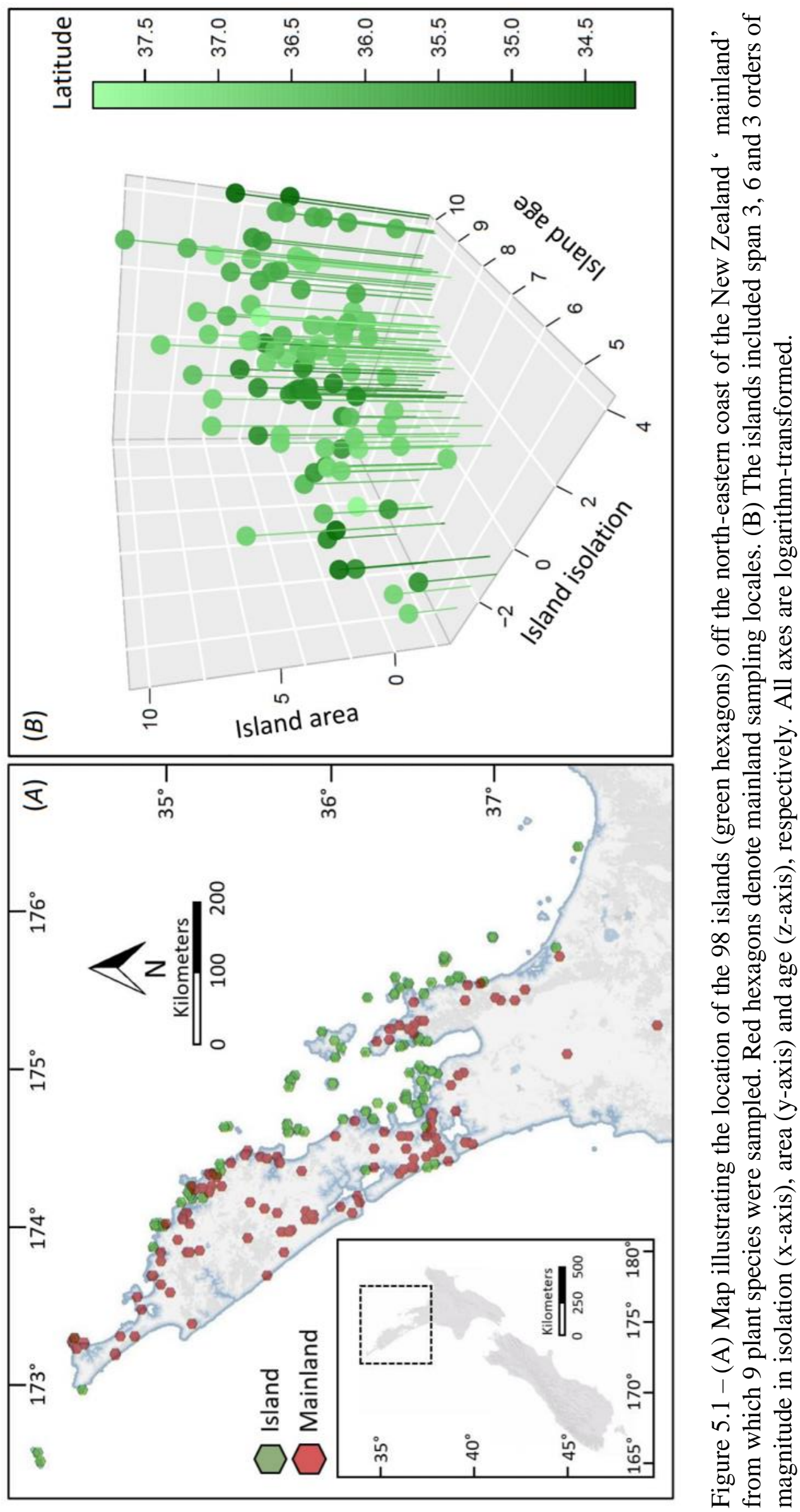


Table 5.1 - The results of unequal variance t-tests of mainland and island leaf area $(\mathrm{cm} 2)$, conducted to test for insular leaf gigantism in 9 plant species inhabiting 98 islands off the north-eastern coast of the New Zealand mainland. The number of islands from which island samples were derived is presented in the second column.

\begin{tabular}{lcccc}
\hline Species & \# islands & $d f$ & $T$ & $P$ \\
\hline Coprosma rhamnoides & 26 & 229 & 9.399 & $<.0001$ \\
Coprosma robusta & 20 & 119 & 3.443 & $<.001$ \\
Pepperomia urvilleana & 39 & 253 & 8.917 & $<.0001$ \\
Coprosma repens & 47 & 410 & -3.510 & 0.001 \\
Piper excelsum subsp. excelsum & 47 & 457 & 14.313 & $<.0001$ \\
Coprosma lucida & 12 & 341 & 7.554 & $<.0001$ \\
Elaeocarpus dentatus & 8 & 45 & 0.746 & 0.458 \\
Rhabdothamnus solandri & 30 & 308 & 18.144 & $<.0001$ \\
Geniostoma lingustrifolium & 40 & 474 & 7.654 & $<.0001$ \\
\hline
\end{tabular}

Insular leaf size was positively correlated with island isolation in 5 species and with island age in 3 species (Table 3, Fig. 4A,B). Relationships between insular leaf size and island area were inconsistent, with 3 species exhibiting positive relationships and 2 species exhibiting negative relationships (Fig. 4C). Finally, the strength of leaf area-island age relationships were greatest in species with high trait variability on the mainland. (Fig. $5 B$ ). Leaf area-island isolation and leaf area-island area were unrelated to mainland variability (Fig. $5 A, \mathrm{C})$.

Table 5.2 - Summary of species-wise linear models of insular leaf area (in square-centimetres) as a function of island isolation (in kilometres), area (in square-metres), and age (in years).

\begin{tabular}{lccccccc}
\hline \multirow{2}{*}{ Species } & \multirow{2}{*}{$d f$} & \multicolumn{2}{c}{ Isolation } & \multicolumn{2}{c}{ Area } & \multicolumn{2}{c}{ Age } \\
\cline { 3 - 8 } & & $b_{1}$ & $P$ & $b_{1}$ & $P$ & $b_{1}$ & $P$ \\
\hline Coprosma rhamnoides & 288 & 0.08 & $<0.001$ & 0.04 & 0.003 & 0.08 & 0.028 \\
Coprosma robusta & 118 & 0.03 & 0.231 & 0.01 & 0.638 & -0.03 & 0.376 \\
Geniostoma lingustrifolium & 378 & 0.00 & 0.946 & -0.01 & 0.576 & 0.01 & 0.738 \\
Pepperomia urvilleana & 252 & 0.00 & 0.959 & 0.03 & 0.002 & -0.01 & 0.731 \\
Coprosma repens & 409 & 0.05 & 0.026 & 0.04 & 0.003 & 0.00 & 0.975 \\
Piper excelsum & 256 & 0.04 & 0.024 & 0.01 & 0.479 & 0.04 & 0.086 \\
Coprosma lucida & 299 & 0.126 & $<0.001$ & -0.08 & $<0.001$ & 0.19 & $<0.001$ \\
Elaeocarpus dentatus & 44 & -0.09 & 0.134 & -0.12 & $<0.001$ & -0.07 & 0.408 \\
Rhabdothamnus solandri & 307 & 0.22 & $<0.001$ & -0.02 & 0.331 & 0.17 & $<0.001$ \\
\hline
\end{tabular}




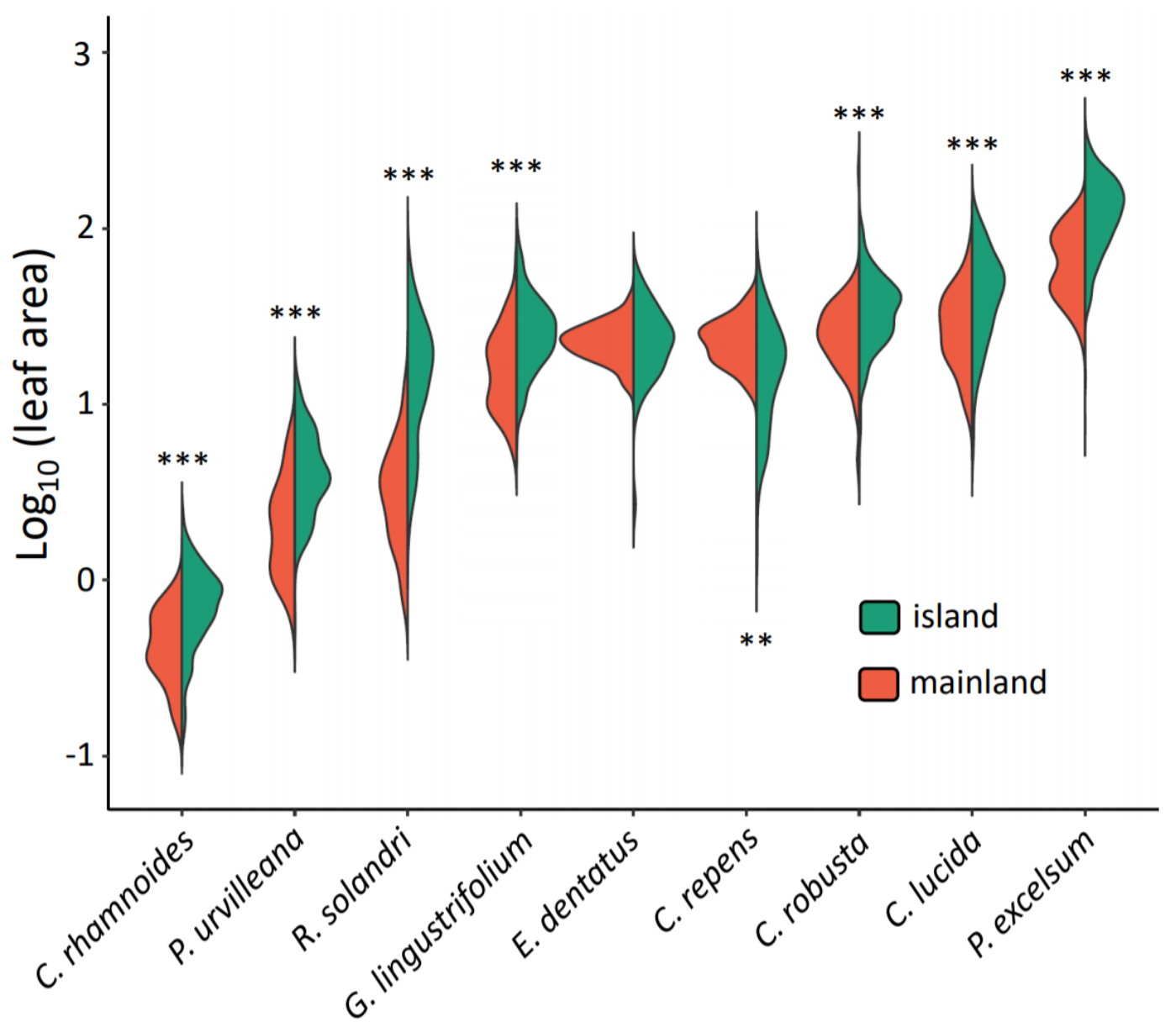

Figure 5.2 - Mainland and island leaf area $(\mathrm{cm} 2)$ in 9 species inhabiting islands off the coast of the New Zealand mainland. Asterisks denote significance values from Welch unequal variance t-tests $(* * *$ and $* *$ denote $\mathrm{P}<$ .001 and $\mathrm{P}<.01$, respectively). Asterisks above the violin plots represent cases of insular leaf gigantism, while asterisks below represent insular dwarfism. Full Latin binomials are provided in Table 2.

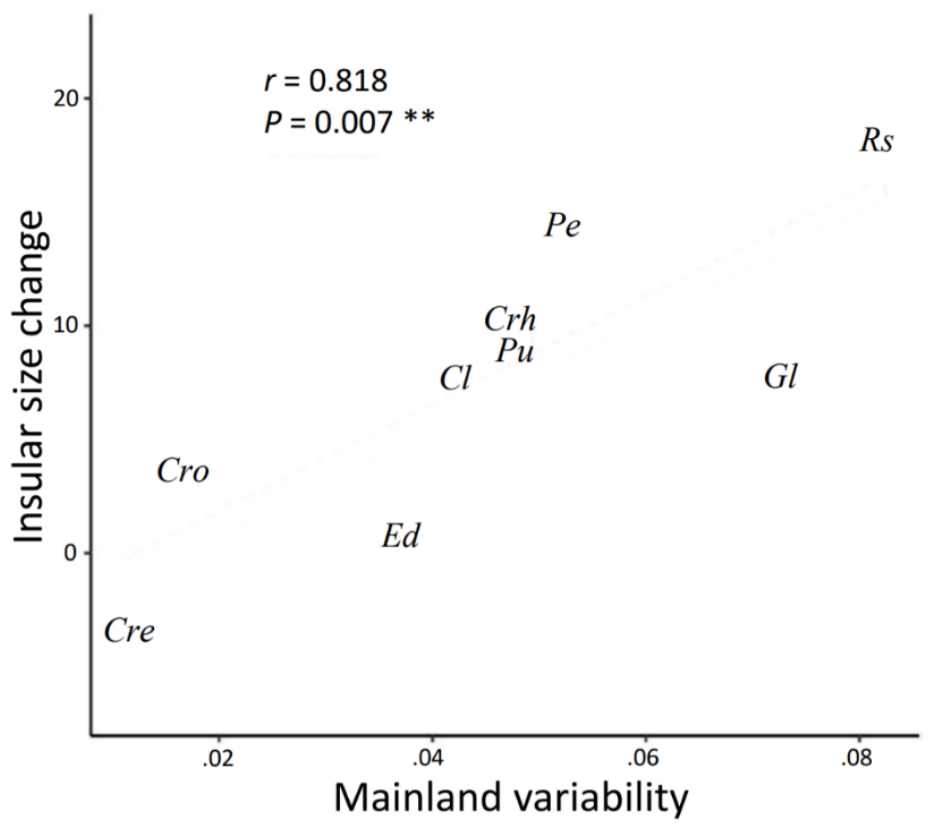

Figure 5.3 - Magnitudes of insular change in leaf area ( $y$-axis, $T$-values from Table 2) are plotted against mainland variability in leaf area $(x$-axis, logarithm10-tranformed).

Abbreviations denote individual species (e.g. $R s=$ Rhabdothamnus solandri). 
(A)

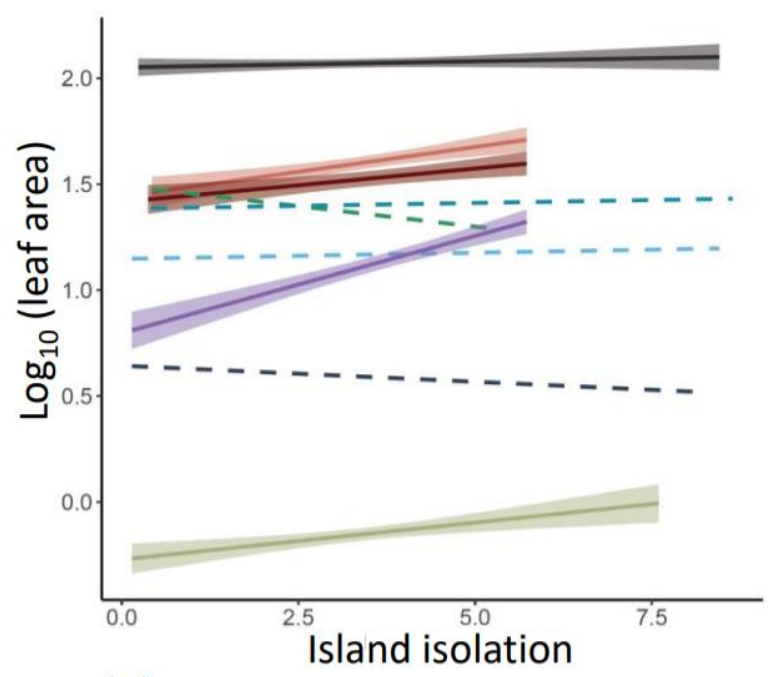

(C)

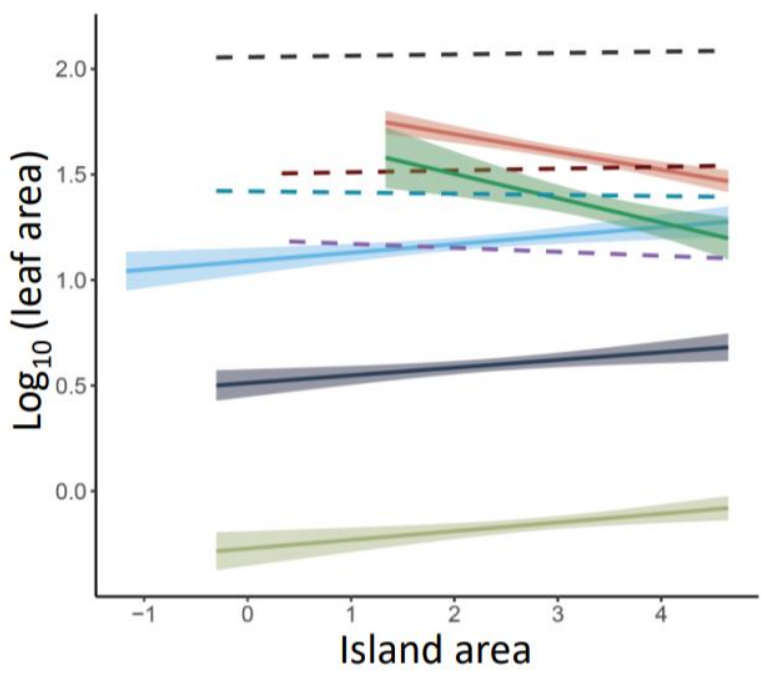

(B)

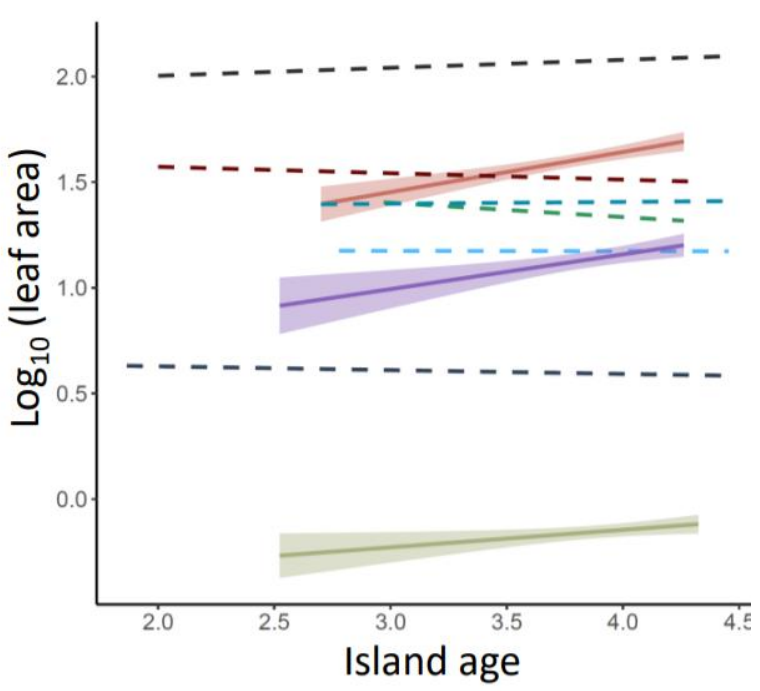

Piper excelsum subsp. excelsum

Coprosma lucida

Coprosma robusta

Geniostoma lingustrifolium

Elaeocarpus dentatus

Coprosma repens

Rhabdothamnus solandri

Pepperomia urvilleana

Coprosma rhamnoides

Figure 5.4 - The relationships between insular leaf size $\left(\mathrm{cm}^{2}\right)$ and island $(A)$ isolation, $(B)$ age and $(C)$ area in 9 species inhabiting 98 islands off the north-eastern coast of the New Zealand mainland. Island isolation is square-root-transformed, while island area and age are logarithm-transformed. Statistically significant relationships are denoted by solid curves with shaded confidence intervals. Statistically insignificant relationships are denoted by dashed curves. 


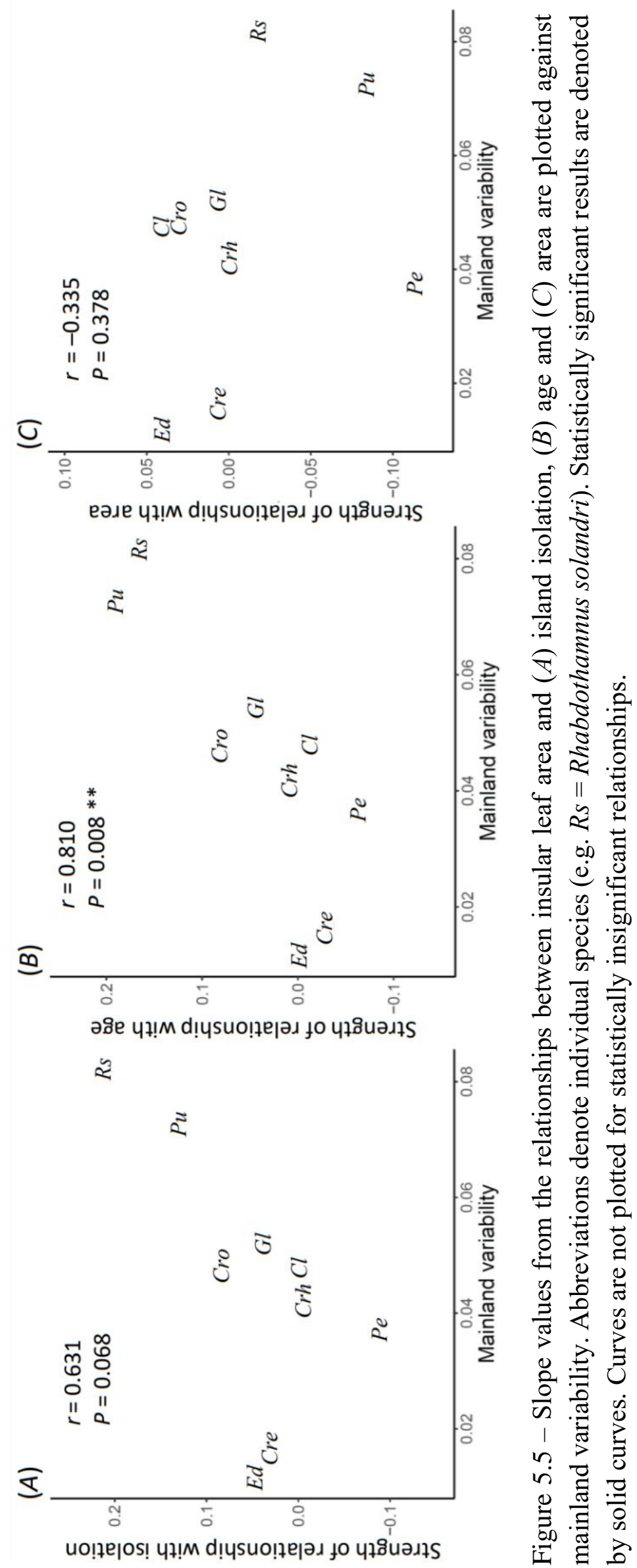




\subsection{Discussion}

All but one species exhibited marked changes in leaf size on islands. Most taxa produced larger leaves on islands than on the mainland. However, a single species (Coprosma repens) showed the opposite trend, producing smaller leaves on islands relative to the mainland. Overall results from broad-scale analyses are therefore consistent with previous work illustrating that island plant populations tend to produce larger leaves than mainland populations (Burns 2019, Biddick et al. 2019a, 2019b).

Why might island environments favour large leaves? Environmental conditions on islands differ from continental conditions in several ways. First, islands tend to have cooler but more stable climates than continents (Weigelt et al. 2013). Leaf size may therefore increase because large leaves do not suffer the same thermodynamic costs that govern leaf size distribution on continents (Wright et al. 2017; Lusk et al. 2018). Second, islands often lack mainland herbivore assemblages, as they do not possess the dispersal ability to reach them. Consequently, larger leaves could reflect a release from herbivory (Gibbs 2006; Fadzly \& Burns 2010; Kavanagh 2015). Third, the depauperate nature of island biotas (MacArthur \& Wilson 1967) is thought to increase intraspecific competition (Case 1978; Lomolino 2005), and larger leaves may provide a competitive advantage. Individuals with larger leaves may be selected for during the colonization process for this same reason, or because individuals with large leaves are coincidentally better dispersers (i.e. immigrant selection). Lastly, leaf size is coordinated with many other aspects of plant morphology that change in size on islands (Corner 1949; Niklas 1994; Niklas \& Enquist 2001), such that larger leaves might result from a selection for larger plants in general, rather than a selection for larger leaves per se.

Interspecific variability in leaf size changes between islands and the mainland are also consistent with previous work relating changes in leaf size to leaf size itself. Interspecific variation in leaf size evolution was weakly correlated with average leaf sizes on the mainland. Therefore, species with smaller leaf sizes on the mainland tended to produce much larger leaves on islands, while leaf size increases were less pronounced or reversed in species producing larger leaves on the mainland. This result echoes that reported by Biddick et al. (2019a), who found a similar pattern based on a much larger number of species inhabiting islands in the Southwest Pacific. 
Changes in leaf size were greatest in taxa with high mainland variability. Trait variation represents a substantial source of information that is otherwise discarded when mean trait values are used (Bolnick et al. 2011; Violle et al. 2012). However, recent work has demonstrated its importance in various ecological and evolutionary processes (Messier et al. 2010; González-Suárez \& Revilla 2013; Hulshof et al. 2013; Des Roches et al. 2018; Snell et al. 2019). In this case, those species with greater leaf size variation on the mainland may be more evolutionary mailable, as these species have greater trait variation for selection to act upon. Greater trait variation might also be displayed by species with greater capacity to respond plastically to environmental conditions. How exactly the variability of leaf size modulates its evolution is not known and may result from a combination of selection and plastic responses to environmental conditions. However, previous work on evolutionary size changes of species endemic to more isolated islands that provide similar results suggests that selection may be at work. Results from analyses of fine-scale variation in leaf size among islands of different age also consistent with selection as an explanation for leaf size increases across the archipelago. Regardless, future work might benefit from investigating the role of trait variability in the evolution of other traits, such as seeds, which exhibit similar evolutionary changes on islands (Kavanagh \& Burns 2014).

Populations inhabiting old, distant islands often produced larger leaves than populations inhabiting young, nearby islands. An obvious explanation for this pattern is that the putative selective process has had longer to operate on island taxa on older islands. Time since divergence has been shown to vary positively with the degree of morphological differentiation between island and mainland taxa (Cox \& Burns 2017). In situ selection for large leaves after island colonisation may therefore result in relationships between leaf size, island isolation and age. In contrast, relationships between leaf size and island area were inconsistent among taxa, suggesting the mechanisms underpinning leaf size evolution on islands may be unrelated to island area. Larger islands were generally more isolated than smaller islands. Leaf size-island area relationships might therefore result from the selective pressures associated with island isolation or age. Alternatively, plants may exhibit strong plastic responses to the varying environmental conditions of differently sized islands.

Leaf gigantism may not characterize all island plants. For instance, two species in our dataset - Elaeocarpus dentatus and Corposma repens - did not show evidence of gigantism, with the latter exhibiting the opposite trend. Coprosma repens is a cosmopolitan shrub that inhabits 
rugged coastal habitats. Given that islands are often exposed to severe wind gusts and extreme whether events, smaller leaves may have evolved in island populations of $C$. repens to avoid damage. Leaf gigantism may also be less prominent in plants inhabiting islands at higher latitudes or elevation, as large leaves are particularly susceptible to low night-time temperatures (Lusk et al. 2018).

Finally, investigating insular patterns in trait evolution is complicated by how plant functional traits scale geographically, particularly with elevation (Leuschner 2000; Hulshof et al. 2013) and latitude (Moles et al. 2007; Moles et al. 2009; Gallagher \& Leishman 2012; Símová et al. 2018). Our sampling was conducted at similar elevations at island and mainland sites, and spanned 6 degrees of latitude in both instances. Therefore, mainland samples should encompass at least the same amount of latitudinal variation in leaf size as island samples.

Overall results confirm that leaf gigantism is commonplace in island populations. That being said, both insular size changes and geographic patterns in insular leaf size varied markedly among species. Interspecific variation in leaf size evolution was associated with trait variability on the mainland. Therefore, trait variability in larger, more contiguous populations may be an important antecedent to evolutionary size changes on islands. Future work should seek to better understand how exactly trait variability modulates trait evolution. 


\section{Chapter 6}

\section{General discussion}

\subsection{Study context}

The study of insular evolution has long been centred on animals. This is probably because naturalists are inherently more likely to notice the distinct morphology and habit of island animals than plants. But also because, following the discovery of the island rule, most studies have focused (almost exclusively) on testing whether or not particular groups of animals obey the rule or not. This fixation on animals, and more specifically on testing the island rule, has resulted in three major gaps in the discipline. Firstly, we know far less about how plants evolve on islands than we do about animals. Consequently, the study of how plants and animals evolve on islands are essentially two separate sub-disciplines. Secondly, despite more than half a century of island rule research, we still lack a mechanistic explanation for its existence. Finally, very few studies attempt to explore insular size changes outside the context of the island rule.

\subsection{Research summary}

The overarching aims of this thesis were to bridge the gap between the sub-disciplines of plant and animal evolution on islands, to empirically test whether plants exhibit the same evolutionary changes on islands as do animals, and to explore whether studying how plants evolve on islands can further our understanding of the same in animals. My specific objectives were to: 1) establish whether allometry constrains the ability of morphological traits to independently evolve on islands; 2) provide the first large-scale, empirical test of the island rule in plants; 3) ask whether the island rule might be driven by stochastic evolutionary drift; and 4) explore correlates of insular size changes that are not explained by the island rule.

\subsubsection{Allometry as a source of evolutionary constraint}

Allometry is a pervasive phenomenon apparent at almost all levels of analysis both within and among species (Gould 1966, 1975; Brouat et al. 1998; West et al. 1999; Enquist 2002). As such, it has long been considered a source of evolutionary constraint (Harvey \& Pagel 1991). Chapter 2 illustrates that trait allometry does not prohibit independent trait evolution. This 
finding builds upon those of Stillwell et al. (2016), suggesting that allometry and evolution are more detached than traditionally considered.

\subsubsection{Prior explanations for convergent size changes on islands}

The island rule has remained the predominant explanation for insular size changes. Five primary hypotheses have been put forth to explain the island rule in animals. The first of these hypotheses, and the only one of which considers processes operating during colonization, is immigrant selection (Lomolino 1984, 1985). For organisms whose dispersal abilities increase with body size, it is suggested that the filtering effect of colonizing isolated islands naturally selects for the largest individuals, and that the signal of this process should remain, at least in the early stages of colonization. However, this only explains why islands would harbour gigantic forms of mainland organisms. Further, it is not applicable to organisms whose dispersal abilities are unrelated to body size, such as plants.

After colonization, a suite of selective pressures are thought to jointly drive convergence on medium body sizes (Sondaar 1977; Heaney 1978; Lomolino 1985). Because islands are more species depauperate than mainland areas of equivalent size (MacArthur \& Wilson 1967), interspecific competition for niche space should be reduced. Consequently, larger size in smallbodied organisms may confer a fitness advantage by enabling them to exploit more resources, particularly if larger size enables them to handle both small and large food items. On the other hand, because resources are more limited on islands than on mainlands, smaller size in largebodied organisms may evolve to reduce their net energetic requirement (McClain et al. 2006). Islands also lack many mammalian predators, as they do not possess the dispersal powers required to reach them. This reduction in predation pressure is thought to enable small-bodied prey to evolve larger size, while larger bodied organisms like ungulates may dwarf as they no longer require the physical advantages of large size to fend off predators (Sondaar 1977; although see discussion in Lomolino 1985). Finally, the combined effects of reduced resource availability and predation pressure are thought to modify life history traits, such as age at maturity (Palkovacs 2003).

Despite decades of island rule research, none of the above hypotheses have been confirmed empirically, nor can they account for convergent size changes in all types of organisms. Chapter 3 illustrates that plants obey they island rule. This rules out all prior hypothetical 
explanations for the island rule in animals. Chapter 4 demonstrates that the island rule pattern arises from stochastic evolutionary drift within bounded trait domains. This has two major implications. Firstly, the island rule can no longer be used as evidence for the hypotheses outlined above. Second, because the island rule occurs in plants and animals, and because all prior explanations invoke various selective processes operating simultaneously at multiple scales, evolutionary drift is the most parsimonious explanation for the island rule pattern in both plants and animals.

\subsubsection{Drivers of variability in size changes among species}

The island rule accounts for a significant proportion of size changes in both plants and animals. However, a great deal of variation about the island rule trend exists. Moreover, some traits, life groups, and species exhibit remarkable size changes on islands that do not conform to the rule, nor do they appear to result from evolutionary drift. Finally, size changes vary considerably among islands; something that often ignored in island rule research. Thus, while the island rule itself is best explained by stochastic drift, natural selection appears to be driving both variation about and conformity to the rule.

Chapter 3 revealed that leaf size obeys the island rule. However, upon closer inspection, most of the negative relationship between $S i$ and $M$ is comprised of instances of gigantism. In chapter 4, to better understand more nuanced patterns, I split woody and herbaceous growth forms. This revealed that the leaves of herbaceous plants show no support for the island rule, and instead convergently become gigantic on islands. In chapter 5, I explored geographic and among-species variability in leaf gigantism on islands. Results demonstrate that there is considerable variation in leaf size evolution both among species and islands. Unlike changes in plant stature, this variation was unrelated trait or plant size. Instead, leaf gigantism was greatest in species with highly variable leaf morphologies on the mainland and in populations inhabiting old, strongly isolated islands. Thus, trait variation appears to be a fundamental precursor to evolutionary size changes on islands. 


\subsection{Challenges of studying insular size changes}

Interpreting insular size changes, in both animals and plants, is contingent on an intricate understanding of the geological history of the study site, the phylogenetic relationships of the taxa under examination, and the appropriate statistical treatment. In the sections below, I discuss the common difficulties that these three facets of biogeography cause, and propose several recommendations for future research that might resolve them.

\subsubsection{The importance of geological history}

The Mascarene islands illustrate the importance of considering geological history well. The islands of Mauritius, Reunion and Rodriguez are remotely situated in the middle of the Indian Ocean, some $1700 \mathrm{~km}$ from Africa's east coast and more than $4000 \mathrm{~km}$ from the Indian subcontinent. At first glance, the Mascarene islands could not be more isolated. However, a chain of underwater islands - namely, the Nazareth and Salya de Malha banks - stretches along the northern edge of the Mascarene Basin, covering much of the lateral distance separating the Mascarene islands from Madagascar. Considering that water levels were at least 127 meters lower during the last glacial maximum (Milne et al. 2005), many species endemic to the Mascarene islands may be derived from extinct ancestors that island hopped from Africa to Madagascar, and then across these now submerged islands. In fact, drilling projects have demonstrated that many of these islands were above water in the Oligocene, subsiding thereafter (McDougall \& Chamalaun 1969). This changes how we interpret classic examples of size changes in the Mascarene flora and fauna. For example, the Dodo was a large, flightless, naïve pigeon endemic to the Mauritius island, whose most closely related living relative is a small, flighted, nervous pigeon from the Nicobar islands, more than $5400 \mathrm{~km}$ away (Shapiro et al. 2002). Ignoring the geological history of these sites, the Dodo represents a spectacular example of the island syndrome in birds. However, if we consider the possibility that the most recent common ancestor of the Dodo inhabited a now-submerged island on the Mascarene plateau, it becomes difficult to interpret. Thus, considering the geological history of the islands which we study can radically alter our evolutionary interpretation of the species inhabiting them.

More locally, it is widely speculated that much (if not all) of New Zealand was submerged during the Oligocene 25-30 million years ago (the 'Oligocene drowning', Cooper \& Cooper 
1995; Stöckler et al. 2002; Biffin et al. 2010; Buckley et al. 2020). New Zealand is the above water landmass of a much larger continent called 'Zealandia'. The above water area of Zealandia has changed considerably throughout time after separating from the Gondwanan supercontinent approximately 80 million years ago and drifting into the Southwest Pacific, where it is now situated (Gibbs 2006). Much of New Zealand's endemic flora and fauna are considered deeply insular, having been isolated for up to 80 million years. However, if we consider that the habitats these species were adapted to may have submerged during the Oligocene, or that the entire Zealandia continent submerged enitrely, then the we must consider that the remarkable morphologies of New Zealand's biota may have evolved in far fewer than 80 million years. Equally, many of New Zealand's endemic flora, such as Beech (Fuscospora sp.), may have colonized from Australia or elsewhere no later than 25 million years ago. This reiterates the importance of geological history in making proper inferences about the natural history of insular taxa.

In more extreme cases, a failure to consider geological history can entirely reverse the direction of putative change. For instance, the World's largest extant lizard, the Komodo dragon (Varanus komodoensis), is found on the island of Flores. Growing to 3 meters long, the Komodo dragon appears a remarkable case of insular gigantism. However, we now have good evidence that an even larger relative inhabited Australia, but has since gone extinct (Gould \& MacFadden 2004). Thus, somewhat paradoxically, the largest living lizard may in fact represent the best example of insular dwarfism in reptiles to date. Analogous examples are found in plants. Piper excelsum subsp. excelsum and Pepperomia urvilleana were considered in several datasets of this thesis. Both represent great examples of leaf gigantism in plants. However, most of the Piperaceae family inhabits the tropics, suggesting that this species may be derived from several island hopping events from the sub-tropics to New Zealand's offshore islands, and subsequently to the mainland (Lim et al. 2019). In this case, Piper excelsum subsp. excelsum and Pepperomia urvilleana may instead represent cases of insular leaf dwarfism, much like the Komodo dragon. 


\subsubsection{Problems of phylogenetic uncertainty}

"Nothing in evolution makes sense without a phylogeny"

Society of Systematic Biologists (2001)

Two problems regarding phylogenetic uncertainty complicate the study of insular size changes. The first is mode of speciation. Anagenesis is a mode of speciation whereby a species gradually evolves while existing as an interbreeding population (i.e. within lineage evolution). In the context of islands, anagenesis occurs when a species colonizes an island and subsequently evolves to the point of being distinct from its mainland relative. Cladogenesis, on the other hand, is a mode of speciation whereby multiple species originate from a single common ancestor (i.e. to form a clade). On islands, cladogenesis occurs when a single colonizing species radiates into many (e.g. Coprosma or Brachyglottis in New Zealand). Interpreting size changes in species that are derived via cladogenesis on islands is difficult, as one mainland relative can be compared to several island species (Fig. 6.1A). An example from this thesis that illustrates this well is Veronica elliptica, which colonized the Chatham islands and subsequently radiated into 3 species of markedly different sizes (see discussion between Biddick \& Burns 2019; and Brian \& Walker-Hale 2019). To avoid potentially pseudo-replicating mainland species in this way, in chapters $3 \& 4$, I only included island species that were derived via anagenesis from a single colonization event.

$(A)$

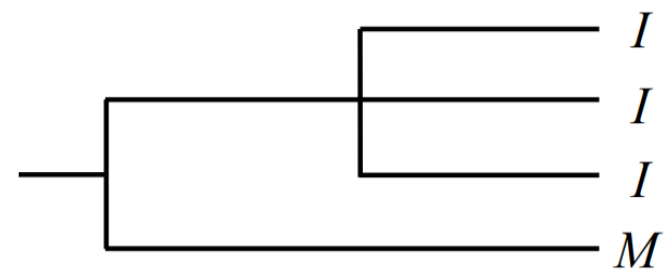

$(B)$

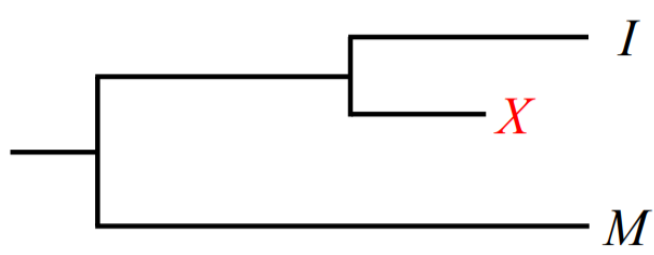

Figure 6.1 - Two common phylogenetic problems when studying insular size changes. Panel $(A)$ illustrates the problem of pseudo-replicating mainland relatives when comparing island clades derived via cladogenesis. Panel $(B)$ illustrates how extinction can lead to erroneous island-mainland comparisons. 
However, this does not mean that cladogenetic products do not exist in these datasets. This illustrates the second problem of phylogenetic uncertainty: extinctions (Fig. 6.1B). Plant extinctions are particularly difficult because, unlike bones, plant materials rarely form fossils. Thus, if an island species derived via cladogenesis goes extinct, we may compare the extant mainland and island taxa, falsely assuming they are anagenetically related. Alternatively, extinction may occur on the mainland, leading us to incorrectly identify a more distantly related mainland taxon as the closest relative of the island taxon.

\subsubsection{Diverse statistical approaches and how they might be unified}

Much of the controversy surrounding the island rule, and indeed insular size changes more generally, concerns appropriate statistical treatment (Meiri et al. 2006; Welch 2009). Traditionally, the island rule has been explored using model I linear regression, whereby the relative size of the insular taxa or populations (i.e. $S_{i}$ values) are regressed against those of the mainland taxa or populations. $S_{i}$ values above one represent insular gigantism, while those below one represent insular dwarfism. Support for the island rule is found when a negative correlation is observed (Fig. 6.2A). While this approach is probably most intuitive, and has been the predominant statistical test in island rule research for the past three decades, several authors have taken issue with such a model (Welch personal communication).

$(A)$

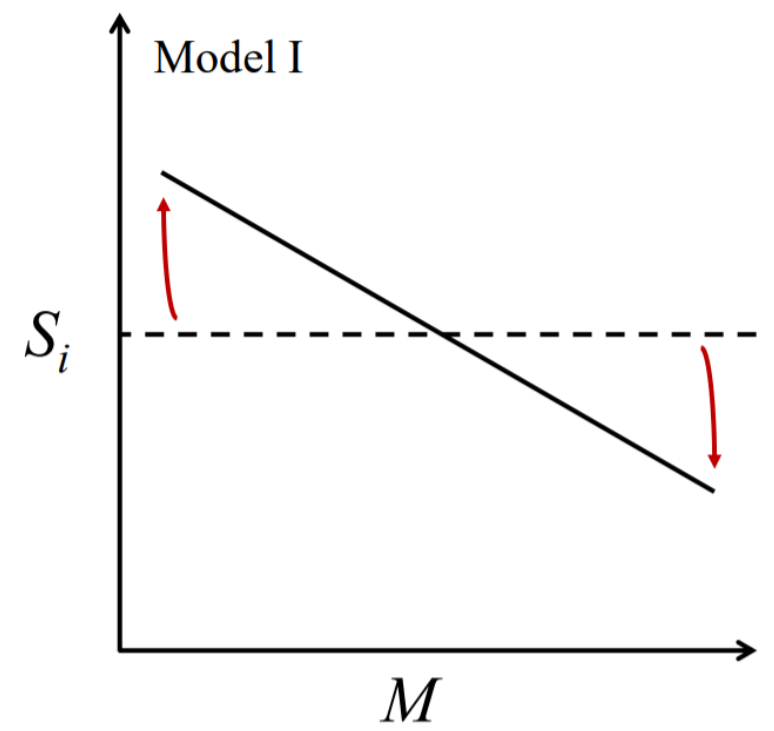

$(B)$

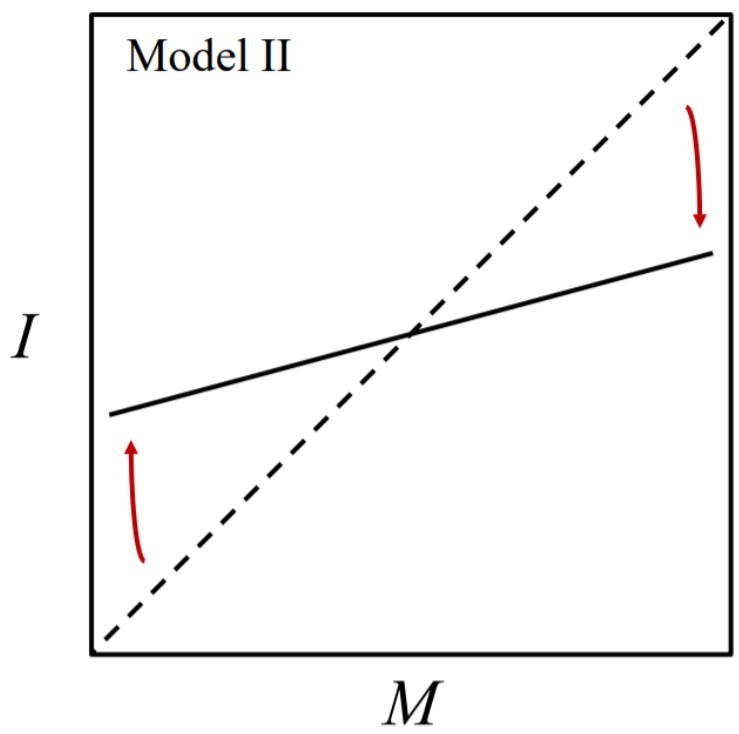

Figure 6.2 - Two common statistical approaches to quantifying support for the island rule: (A) Model I and $(B)$ Model II linear regression of logarithm-transformed variables. 
Model I regression makes several assumptions that may not always be satisfied. Firstly, it assumes that the mainland member of each island-mainland comparison represents the ancestral form. That is, the body size (or trait value) of the mainland taxon has not changed since the most recent common ancestor of the two taxa being compared. This is of course extremely unlikely. However, it is also not possible to obtain a measure of body mass (or any other trait for that matter) of the shared common ancestor, given that it no longer exists. It may further be argued that the mainland taxon has likely undergone less morphological evolution since the divergence of the island colonist than has the island taxon. In any case, while the assumption of no mainland evolution is probably violated in most cases, it remains fundamental to the use of the model I approach.

The second problem with the model I approach pertains to the use of the ratio $S_{i}$. The use of ratios in regression has been criticized more generally in biology (Albrecht 1978), primarily because of the 'regression to the mean' artefacts that are associated with regressing a ratio against its denominator. Regression to the mean is a statistical phenomenon that occurs when repeat measures are taken. Put simply, when values from the extremes of a population are measured a second time, they are inherently more likely to be less extreme on the second measure. In fact, medical studies often regress second measures against first measures in order to quantify how much regression to the mean is apparent in their findings. In the context of island rule research, $M$ (mainland body size) can be considered analogous to the first measure, and because values of $S_{i}$ depend on $M$, a negative slope might be expected in the absence of any underlying selective regime operating on islands. Ratios also generate problems with magnitude. For instance, in the case of $S_{i}$, values of insular gigantism could conceivably range anywhere above one to infinity. Values of insular dwarfism, on the other hand, are restricted within the bounds of zero and one.

To avoid the assumptions associated with model I regression, and the potential artefacts generated by the use of the ratio $S_{i}$, Meiri et al. $(2006 ; 2008)$ have suggested the use of model II regression, whereby island values are regressed directly against mainland values (Fig. 6.2B). In this case, the investigator attempts to falsify the null hypothesis that island and mainland trait evolution are indistinguishable, with a slope less than one (morphological isometry) providing empirical support for the island rule. This approach does not assume that $M$ reflects the ancestral state. However, it is a parametric test and therefore vulnerable to violations of normality and equal variance assumptions. 
To avoid assumptions of normality and equal variance, and the potentially inflated type I error rates of assuming no mainland evolution, Welch (2009) proposed the use of non-parametric Monte Carlo permutation, wherein the member of each species pair designated as 'insular' is randomized. Standard-major-axis regression of island and mainland body size is then performed and compared to the distribution of correlation coefficients generated under null permutation. In this case, the investigator attempts to falsify the null hypothesis that island evolution is characterized by directional change. This method is undoubtedly useful in cases where back-colonization of the mainland is feasible, such as islands that are only weakly isolated from the mainland, or those that have been connected to the mainland in recent geological history (e.g. islands in Indonesia). However, for true oceanic islands like the Chatham group (isolated $600 \mathrm{~km}$ from the New Zealand mainland for more than 4 million years), where mainland-island geneflow is trivial, this approach may be "ultra-conservative" and carry inflated type II error rates (i.e. failure to detect a true island rule pattern).

Evidently, the 'appropriate' statistical means of testing the island rule (and insular size changes in general) is contingent on the evolutionary assumptions that can be made about the study system. Thus, an unambiguous statistical framework is needed to resolve contention and release the discipline from stasis. Future research should develop a unifying framework that employs a procedure of assumption checking to select the appropriate statistical model for a given study system (e.g. a dichotomous key or decision tree).

\subsection{Future directions}

Virtually all aspects of plant evolution on islands are understudied and would benefit from additional scientific attention. However, considering the factors discussed above, five clear objectives stand out. First, we need a better integration of geological knowledge. In particular, geologists and natural historians should work together to reconstruct the natural history of both the species and island archipelago under investigation. Second, more phylogenetic work is required. Many island clades remain taxonomically unresolved. This leads to contention among investigators and leaves many unable to make strong inferences about the species in question. Third, we need a rigorous and unambiguous statistical framework. The island rule illustrates how disagreement about statistical approaches and the inferences that can be made from them 
can stagnate a discipline. Fourth, a paradigm shift is in order - namely, a shift away from island-rule-centric studies. We now understand that the island rule is a passive artefact of evolutionary drift (Chapter 4). Future work should therefore strive to understand the drivers of the remaining variation in insular size changes on islands. Finally, we need a standardized experimental procedure that disentangles the role of phenotypic plasticity from genuine morphological changes that have a genetic basis. Plants offer the simplest and most effective answer to this problem, as island and mainland relatives can be planted in common gardens to determine whether they still exhibit the same morphological differences.

\subsection{Concluding remarks}

While there are many challenges to studying how species evolve on islands, this thesis has demonstrated that there are great insights to be found from including plants in this endeavour. Plants are sessile and can be easily manipulated to test mechanistic hypotheses (e.g. common garden experiments). Further, they exhibit many of the same morphological changes on islands that animals do, suggesting they experience similar selective regimes and drift processes. Ultimately, the study of insular evolution should consider all organisms. Only then can we gain a more holistic understanding of how life evolves on islands. 


\section{References}

Albrecht, G.H. (1978). Some comments on the use of ratios. Systematic Zoology, 27, 67-71.

Arnold, S.J. (1992). Constraints on phenotypic evolution. The American Naturalist, 140, S85S107.

Baeckens, S. \& Van Damme, R. (2020). The island syndrome. Current Biology: CB, 30, R338.

Balding, M. \& Williams, K.J. (2016). Plant blindness and the implications for plant conservation. Conservation Biology, 30, 1192-1199.

Baldwin, B.G. (2007). Adaptive radiation of shrubby tarweeds (Deinandra) in the California Islands parallels diversification of the Hawaiian silversword alliance (CompositaeMadiinae). American Journal of Botany, 94, 237-248.

Bellot, S., Bayton, R.P., Couvreur, T.L., Dodsworth, S., Eiserhardt, W.L., Guignard, M.S. et al. (2020). On the origin of giant seeds: the macroevolution of the double coconut (Lodoicea maldivica) and its relatives (Borasseae, Arecaceae). New Phytologist, 228 1134-1148.

Benton, M.J., Csiki, Z., Grigorescu, D., Redelstorff, R., Sander, P.M., Stein, K. et al. (2010). Dinosaurs and the island rule: The dwarfed dinosaurs from Haţeg Island. Palaeogeography, Palaeoclimatology, Palaeoecology, 293, 438-454.

Biddick, M. \& Burns, K. (2019). Support for the island rule does not hide morphological disparity in insular plants. Proceedings of the National Academy of Sciences, 412-424.

Biddick, M., Hendriks, A. \& Burns, K. (2019a). Plants obey (and disobey) the island rule. Proceedings of the National Academy of Sciences, 116, 17632-17634.

Biddick, M., Hutton, I. \& Burns, K. (2019b). Independent evolution of allometric traits: A test of the allometric constraint hypothesis in island vines. Biological Journal of the Linnean Society, 126, 203-211.

Biffin, E., Hill, R.S. \& Lowe, A.J. (2010). Did kauri (Agathis: Araucariaceae) really survive the Oligocene drowning of New Zealand? Systematic Biology, 59, 594-602.

Blumenthal, D.M. \& Hufbauer, R.A. (2007). Increased plant size in exotic populations: a common-garden test with 14 invasive species. Ecology, 88, 2758-2765.

Boback, S.M. \& Guyer, C. (2003). Empirical evidence for an optimal body size in snakes. Evolution, 57, 345-451.

Böhle, U.-R., Hilger, H.H. \& Martin, W.F. (1996). Island colonization and evolution of the insular woody habit in Echium L.(Boraginaceae). Proceedings of the National Academy of Sciences, 93, 11740-11745. 
Bolnick, D.I., Amarasekare, P., Araújo, M.S., Bürger, R., Levine, J.M., Novak, M. et al. (2011). Why intraspecific trait variation matters in community ecology. Trends in Ecology \& Evolution, 26, 183-192.

Bond, W.J. \& Silander, J.A. (2007). Springs and wire plants: anachronistic defences against Madagascar's extinct elephant birds. Proceedings of the Royal Society of London B: Biological Sciences, 274, 1985-1992.

Brian, J.I. \& Walker-Hale, N. (2019). Focus on an island rule may hide morphological disparity in insular plants. Proceedings of the National Academy of Sciences, 116, 24929-24930.

Bromham, L. \& Cardillo, M. (2007). Primates follow the 'island rule': implications for interpreting Homo floresiensis. Biology Letters, 3, 398-400.

Brouat, C., Gibernau, M., Amsellem, L. \& McKey, D. (1998). Corner's rules revisited: ontogenetic and interspecific patterns in leaf-stem allometry. The New Phytologist, $139,459-470$.

Brown, P., Sutikna, T., Morwood, M.J., Soejono, R.P., Saptomo, E.W. \& Due, R.A. (2004). A new small-bodied hominin from the Late Pleistocene of Flores, Indonesia. Nature, 431, 1055-1061.

Buck, M., Briggs, R.M. \& Nelson, C.S. (1981). Pyroclastic deposits and volcanic history of Mayor Island. New Zealand Journal of Geology and Geophysics, 24, 449-467.

Buckley, T.R., Lord, N.P., Ramón-Laca, A., Allwood, J.S. \& Leschen, R.A. (2020). Multiple lineages of hyper-diverse Zopheridae beetles survived the New Zealand Oligocene Drowning. Journal of Biogeography, 47, 927-940.

Burns, K. (2016). Size changes in island plants: independent trait evolution in Alyxia ruscifolia (Apocynaceae) on Lord Howe Island. Biological Journal of the Linnean Society, 119, 847-855.

Burns, K. (2018). Time to abandon the loss of dispersal ability hypothesis in island plants: A comment on García-Verdugo, Mairal, Monroy, Sajeva and Caujapé-Castells (2017). Journal of Biogeography, 45, 1219-1222.

Burns, K.C. (2019). Evolution in isolation: the search for an island syndrome in plants. Cambridge University Press.

Burns, K.C., Herold, N. \& Wallace, B. (2012). Evolutionary size changes in plants of the south-west Pacific. Global Ecology and Biogeography, 21, 819-828.

Carlquist, S. (1966). The biota of long-distance dispersal. I. Principles of dispersal and evolution. The Quarterly Review of Biology, 41, 247-270.

Carlquist, S. (1974). Island biology. Columbia University Press: New York \& London. 660pp, $581,5279$. 
Carlquist, S.J. (1965). Island life. Garden City, NY. Natural History Museum Press.

Carlquist, S.J., Baldwin, B.G. \& Carr, G.D. (2003). Tarweeds \& silverswords: evolution of the Madiinae (Asteraceae). Missouri Botanical Garden Press.

Case, T.J. (1978). A general explanation for insular body size trends in terrestrial vertebrates. Ecology, 59, 1-18.

Clark, A. (1987). Genetic correlations: the quantitative genetics of evolutionary constraints. In: Genetic constraints on adaptive evolution. Springer, pp. 25-45.

Clegg, S.M. \& Owens, P. (2002). The 'island rule'in birds: medium body size and its ecological explanation. Proceedings of the Royal Society of London. Series B: Biological Sciences, 269, 1359-1365.

Conner, J.K., Karoly, K., Stewart, C., Koelling, V.A., Sahli, H.F. \& Shaw, F.H. (2011). Rapid independent trait evolution despite a strong pleiotropic genetic correlation. The American Naturalist, 178, 429-441.

Cooper, A. \& Cooper, R.A. (1995). The Oligocene bottleneck and New Zealand biota: genetic record of a past environmental crisis. Proceedings of the Royal Society of London. Series B: Biological Sciences, 261, 293-302.

Corner, E.J.H. (1949). The durian theory or the origin of the modern tree. Annals of Botany, $13,367-414$.

Cox, B.T.M. \& Burns, K.C. (2017). Convergent evolution of gigantism in the flora of an isolated archipelago. Evolutionary Ecology, 31, 741-752.

Darwin, C. (2004). On the origin of species, 1859. Routledge.

Davidson, A.M., Jennions, M. \& Nicotra, A.B. (2011). Do invasive species show higher phenotypic plasticity than native species and, if so, is it adaptive? A meta-analysis. Ecology Letters, 14, 419-431.

Dayan, T., Simberloff, D., Tchernov, E. \& Yom-Tov, Y. (1990). Feline canines: communitywide character displacement among the small cats of Israel. The American Naturalist, 136, 39-60.

Des Roches, S., Post, D.M., Turley, N.E., Bailey, J.K., Hendry, A.P., Kinnison, M.T. et al. (2018). The ecological importance of intraspecific variation. Nature Ecology \& Evolution, 2, 57-64.

Emlen, D.J. (1996). Artificial selection on horn length-body size allometry in the horned beetle Onthophagus acuminatus (Coleoptera: Scarabaeidae). Evolution, 50, 12191230.

Enquist, B.J. (2002). Universal scaling in tree and vascular plant allometry: toward a general quantitative theory linking plant form and function from cells to ecosystems. Tree Physiology, 22, 1045-1064. 
Enquist, B.J. \& Niklas, K.J. (2002). Global allocation rules for patterns of biomass partitioning in seed plants. Science, 295, 1517-1520.

Fadzly, N. \& Burns, K. (2010). Hiding from the ghost of herbivory past: evidence for crypsis in an insular tree species. International Journal of Plant Sciences, 171, 828-833.

Fitter, A.H. \& Hay, R.K. (2012). Environmental Physiology of Plants. Academic press.

Flint-Garcia, S.A., Thornsberry, J.M. \& Buckler IV, E.S. (2003). Structure of linkage disequilibrium in plants. Annual Review of Plant Biology, 54, 357-374.

Foster, J. (1963). The evolution of the native land mammals of the Queen Charlotte Islands and the problem of insularity. University of British Columbia.

Foster, J.B. (1964). Evolution of mammals on islands. Nature, 202, 234-235.

Futuyma, D.J. (2010). Evolutionary constraint and ecological consequences. Evolution, 64, $1865-1884$.

Gallagher, R.V. \& Leishman, M.R. (2012). A global analysis of trait variation and evolution in climbing plants. Journal of Biogeography, 39, 1757-1771.

Gibbs, G.W. (2006). Ghosts of Gondwana: the history of life in New Zealand. Craig Potton Publishing.

Given, D.R. (1985). Conservation of Chatham Island flora and vegetation. Botany Division, Department of Scientific and Industrial Research.

González-Suárez, M. \& Revilla, E. (2013). Variability in life-history and ecological traits is a buffer against extinction in mammals. Ecology Letters, 16, 242-251.

Gould, G.C. \& MacFadden, B.J. (2004). Gigantism, dwarfism, and Cope's rule:"nothing in evolution makes sense without a phylogeny". Bulletin of the American Museum of Natural History, 2004, 219-237.

Gould, S.J. (1966). Allometry and size in ontogeny and phylogeny. Biological Reviews, 41, 587-638.

Gould, S.J. (1975). Allometry in primates, with emphasis on scaling and the evolution of the brain. Contributions to Primatology, 5, 244-292.

Greenwood, R. \& Atkinson, I. (1977). Evolution of divaricating plants in New Zealand in relation to moa browsing. In: Proceedings (New Zealand Ecological Society). JSTOR, pp. 21-33.

Harvey, P.H. \& Pagel, M.D. (1991). The comparative method in evolutionary biology. Oxford university press, Oxford. 
Heaney, L.R. (1978). Island area and body size of insular mammals: evidence from the tricolored squirrel (Callosciurus prevosti) of Southeast Asia. Evolution, 32, 29-44.

Henry, L. \& Wickham, H. (2019). purrr: Functional Programming Tools, 2017. R package version $0.2,3$.

Hulshof, C.M., Violle, C., Spasojevic, M.J., McGill, B., Damschen, E., Harrison, S. et al. (2013). Intra-specific and inter-specific variation in specific leaf area reveal the importance of abiotic and biotic drivers of species diversity across elevation and latitude. Journal of Vegetation Science, 24, 921-931.

Itescu, Y., Karraker, N.E., Raia, P., Pritchard, P.C. \& Meiri, S. (2014). Is the island rule general? Turtles disagree. Global Ecology and Biogeography, 23, 689-700.

Itescu, Y., Schwarz, R., Donihue, C.M., Slavenko, A., Roussos, S.A., Sagonas, K. et al. (2018). Inconsistent patterns of body size evolution in co-occurring island reptiles. Global Ecology and Biogeography, 27, 538-550.

Johnston, K., Ver Hoef, J.M., Krivoruchko, K. \& Lucas, N. (2001). Using ArcGIS geostatistical analyst. Esri Redlands.

Kavanagh, P.H. (2015). Herbivory and the evolution of divaricate plants: structural defences lost on an offshore island. Austral Ecology, 40, 206-211.

Kavanagh, P.H. \& Burns, K.C. (2014). The repeated evolution of large seeds on islands. Proceedings of the Royal Society of London B: Biological Sciences, 281, 20140675.

Keane, R.M. \& Crawley, M.J. (2002). Exotic plant invasions and the enemy release hypothesis. Trends in Ecology \& Evolution, 17, 164-170.

Lande, R. (1979). Quantitative genetic analysis of multivariate evolution, applied to brain: body size allometry. Evolution, 33, 402-416.

Leger, E.A. \& Rice, K.J. (2003). Invasive California poppies (Eschscholzia californica Cham.) grow larger than native individuals under reduced competition. Ecology Letters, 6, 257-264.

Lens, F., Davin, N., Smets, E. \& del Arco, M. (2013). Insular woodiness on the Canary Islands: a remarkable case of convergent evolution. International Journal of Plant Sciences, 174, 992-1013.

Lens, F., Groeninckx, I., Smets, E. \& Dessein, S. (2009). Woodiness within the Spermacoceae-Knoxieae alliance (Rubiaceae): retention of the basal woody condition in Rubiaceae or recent innovation? Annals of Botany, 103, 1049-1064.

Leuschner, C. (2000). Are high elevations in tropical mountains arid environments for plants? Ecology, 81, 1425-1436.

Lim, J.Y., Marshall, C.R., Zimmer, E.A. \& Wagner, W.L. (2019). Multiple colonizations of the Pacific by Peperomia (Piperaceae): Complex patterns of long-distance dispersal 
and parallel radiations on the Hawaiian Islands. Journal of Biogeography, 46, 26512662.

Lin, S., Shao, L., Hui, C., Song, Y., Reddy, G.V., Gielis, J. et al. (2018). Why does not the leaf weight-area allometry of bamboos follow the 3/2-power law? Frontiers in Plant Science, 9, 583.

Lokatis, S. \& Jeschke, J.M. (2018). The island rule: An assessment of biases and research trends. Journal of Biogeography, 45, 289-303.

Lomolino, M.V. (1984). Immigrant selection, predation, and the distributions of Microtus pennsylvanicus and Blarina brevicauda on islands. The American Naturalist, 123, 468-483.

Lomolino, M.V. (1985). Body size of mammals on islands: the island rule reexamined. The American Naturalist, 125, 310-316.

Lomolino, M.V. (2005). Body size evolution in insular vertebrates: generality of the island rule. Journal of Biogeography, 32, 1683-1699.

Lomolino, M.V., Geer, A.A., Lyras, G.A., Palombo, M.R., Sax, D.F. \& Rozzi, R. (2013). Of mice and mammoths: generality and antiquity of the island rule. Journal of Biogeography, 40, 1427-1439.

Long, E.S., Courtney, K.L., Lippert, J.C. \& Wall-Scheffler, C.M. (2019). Reduced body size of insular black-tailed deer is caused by slowed development. Oecologia, 189, 675685.

Lusk, C.H., Clearwater, M.J., Laughlin, D.C., Harrison, S.P., Prentice, I.C., Nordenstahl, M. et al. (2018). Frost and leaf-size gradients in forests: global patterns and experimental evidence. New Phytologist, 219, 565-573.

MacArthur, R.H., Diamond, J.M. \& Karr, J.R. (1972). Density compensation in island faunas. Ecology, 53, 330-342.

MacArthur, R.H. \& Wilson, E.O. (1967). The theory of island biogeography. Princeton university press.

Marques, D.A., Meier, J.I. \& Seehausen, O. (2019). A combinatorial view on speciation and adaptive radiation. Trends in Ecology \& Evolution, 34, 531-544.

McClain, C.R., Boyer, A.G. \& Rosenberg, G. (2006). The island rule and the evolution of body size in the deep sea. Journal of Biogeography, 33, 1578-1584.

McDougall, I. \& Chamalaun, F. (1969). Isotopic dating and geomagnetic polarity studies on volcanic rocks from Mauritius, Indian Ocean. Geological Society of America Bulletin, $80,1419-1442$.

McDougall, I., Embleton, B. \& Stone, D. (1981). Origin and evolution of Lord Howe Island, southwest Pacific Ocean. Journal of the Geological Society of Australia, 28, 155-176. 
Meiri, S. (2007). Size evolution in island lizards. Global Ecology and Biogeography, 16, 702708.

Meiri, S., Cooper, N. \& Purvis, A. (2008). The island rule: made to be broken? Proceedings of the Royal Society of London B: Biological Sciences, 275, 141-148.

Meiri, S., Dayan, T. \& Simberloff, D. (2006). The generality of the island rule reexamined. Journal of Biogeography, 33, 1571-1577.

Meiri, S., Dayan, T., Simberloff, D. \& Grenyer, R. (2009). Life on the edge: carnivore body size variation is all over the place. Proceedings of the Royal Society of London B: Biological Sciences, 276, 1469-1476.

Messier, J., McGill, B.J. \& Lechowicz, M.J. (2010). How do traits vary across ecological scales? A case for trait-based ecology. Ecology Letters, 13, 838-848.

Midgley, J. \& Bond, W. (1989). Leaf size and inflorescence size may be allometrically related traits. Oecologia, 78, 427-429.

Milne, G.A., Long, A.J. \& Bassett, S.E. (2005). Modelling Holocene relative sea-level observations from the Caribbean and South America. Quaternary Science Reviews, $24,1183-1202$.

Moles, A.T., Ackerly, D.D., Tweddle, J.C., Dickie, J.B., Smith, R., Leishman, M.R. et al. (2007). Global patterns in seed size. Global Ecology and Biogeography, 16, 109-116.

Moles, A.T., Warton, D.I., Warman, L., Swenson, N.G., Laffan, S.W., Zanne, A.E. et al. (2009). Global patterns in plant height. Journal of Ecology, 97, 923-932.

Nicotra, A.B., Atkin, O.K., Bonser, S.P., Davidson, A.M., Finnegan, E., Mathesius, U. et al. (2010). Plant phenotypic plasticity in a changing climate. Trends in Plant Science, 15, 684-692.

Niklas, K.J. (1994). Plant allometry: the scaling of form and process. University of Chicago Press.

Niklas, K.J. \& Enquist, B.J. (2001). Invariant scaling relationships for interspecific plant biomass production rates and body size. Proceedings of the National Academy of Sciences, 98, 2922-2927.

Nolfo-Clements, L., Butcher, R., Leite, M. \& Clements, M. (2017). Evidence of the island rule and microevolution in white-footed mice (Peromyscus leucopus) in an urban harbor archipelago. Mammal Research, 62, 423-430.

Packard, G.C. (2012). Is non-loglinear allometry a statistical artifact? Biological Journal of the Linnean Society, 107, 764-773.

Packard, G.C. (2018). Evolutionary allometry of horn length in the mammalian family Bovidae reconciled by non-linear regression. Biological Journal of the Linnean Society, 125, 657-663. 
Palkovacs, E.P. (2003). Explaining adaptive shifts in body size on islands: a life history approach. Oikos, 103, 37-44.

Palmer, M. (2002). Testing the 'island rule'for a tenebrionid beetle (Coleoptera, Tenebrionidae). Acta Oecologica, 23, 103-107.

Panero, J.L., Francisco-Ortega, J., Jansen, R.K. \& Santos-Guerra, A. (1999). Molecular evidence for multiple origins of woodiness and a New World biogeographic connection of the Macaronesian Island endemic Pericallis (Asteraceae: Senecioneae). Proceedings of the National Academy of Sciences, 96, 13886-13891.

Preston, K.A. \& Ackerly, D.D. (2003). Hydraulic architecture and the evolution of shoot allometry in contrasting climates. American Journal of Botany, 90, 1502-1512.

Primack, R.B. (1987). Relationships among flowers, fruits, and seeds. Annual Review of Ecology and Systematics, 18, 409-430.

Rebouças, R., da Silva, H.R. \& Solé, M. (2018). Frog size on continental islands of the coast of Rio de Janeiro and the generality of the Island Rule. PloS One, 13, e0190153.

Richards, C.L., Bossdorf, O., Muth, N.Z., Gurevitch, J. \& Pigliucci, M. (2006). Jack of all trades, master of some? On the role of phenotypic plasticity in plant invasions. Ecology Letters, 9, 981-993.

Rick, T.C., Erlandson, J.M., Vellanoweth, R.L., Braje, T.J., Collins, P.W., Guthrie, D.A. et al. (2009). Origins and antiquity of the island fox (Urocyon littoralis) on California's Channel Islands. Quaternary Research, 71, 93-98.

Robinson, D. (2014). broom: An R package for converting statistical analysis objects into tidy data frames. arXiv preprint arXiv:1412.3565.

Roubik, D.W. \& de Camargo, J.M.F. (2012). The Panama microplate, island studies and relictual species of Melipona (Melikerria)(Hymenoptera: Apidae: Meliponini). Systematic Entomology, 37, 189-199.

Schneider, C.A., Rasband, W.S. \& Eliceiri, K.W. (2012). NIH Image to ImageJ: 25 years of image analysis. Nature Methods, 9, 671.

Schüßler, C., Bräuchler, C., Reyes-Betancort, J.A., Koch, M.A. \& Thiv, M. (2019). Island biogeography of the Macaronesian Gesnouinia and Mediterranean Soleirolia (Parietarieae, Urticaceae) with implications for the evolution of insular woodiness. Taxon, 68, 537-556.

Shapiro, B., Sibthorpe, D., Rambaut, A., Austin, J., Wragg, G.M., Bininda-Emonds, O.R. et al. (2002). Flight of the dodo. Science, 295, 1683-1683.

Shinozaki, K., Yoda, K., Hozumi, K. \& Kira, T. (1964). A quantitative analysis of plant form-the pipe model theory: II. Further evidence of the theory and its application in forest ecology. Japanese Journal of Ecology, 14, 133-139. 
Š́mová, I., Violle, C., Svenning, J.C., Kattge, J., Engemann, K., Sandel, B. et al. (2018). Spatial patterns and climate relationships of major plant traits in the New World differ between woody and herbaceous species. Journal of Biogeography 45, 895-916.

Smith, J.M., Burian, R., Kauffman, S., Alberch, P., Campbell, J., Goodwin, B. et al. (1985). Developmental constraints and evolution: a perspective from the Mountain Lake conference on development and evolution. The Quarterly Review of Biology, 60, 265287.

Snell, R.S., Beckman, N.G., Fricke, E., Loiselle, B.A., Carvalho, C.S., Jones, L.R. et al. (2019). Consequences of intraspecific variation in seed dispersal for plant demography, communities, evolution and global change. AoB Plants, 11, plz016.

Sondaar, P.Y. (1977). Insularity and its effect on mammal evolution. In: Major patterns in vertebrate evolution. Springer, pp. 671-707.

Stanton, M. \& Young, H.J. (1994). Selecting for floral character associations in wild radish, Raphanus sativus L. Journal of Evolutionary Biology, 7, 271-285.

Stillwell, R.C., Shingleton, A.W., Dworkin, I. \& Frankino, W.A. (2016). Tipping the scales: evolution of the allometric slope independent of average trait size. Evolution, 70, 433444.

Stöckler, K., Daniel, I.L. \& Lockhart, P.J. (2002). New Zealand kauri (Agathis australis (D. Don) Lindl., Araucariaceae) survives Oligocene drowning. Systematic Biology, 51, 827-832.

Sun, S., Jin, D. \& Shi, P. (2005). The leaf size-twig size spectrum of temperate woody species along an altitudinal gradient: an invariant allometric scaling relationship. Annals of Botany, 97, 97-107.

Team, R.C. (2000). R language definition. Vienna, Austria: $R$ foundation for statistical computing.

Team, R.C. (2013). R: A language and environment for statistical computing.

Tsukaya, H., Imaichi, R. \& Yokoyama, J. (2006). Leaf-shape variation of Paederia foetida in Japan: reexamination of the small, narrow leaf form from Miyajima Island. Journal of Plant Research, 119, 303-308.

Van Valen, L. (1973). A new evolutionary law. Evolutionary Theory, 1, 1-30.

Vanek, J.P. \& Burke, R.L. (2020). Insular dwarfism in female Eastern Hog-nosed Snakes (Heterodon platirhinos; Dipsadidae) on a barrier island. Canadian Journal of Zoology, 98, 157-164.

Violle, C., Enquist, B.J., McGill, B.J., Jiang, L., Albert, C.H., Hulshof, C. et al. (2012). The return of the variance: intraspecific variability in community ecology. Trends in Ecology \& Evolution, 27, 244-252. 
Vogel, S. (1968). " Sun leaves" and "shade leaves": differences in convective heat dissipation. Ecology, 49, 1203-1204.

Wagstaff, S.J., Breitwieser, I. \& Ito, M. (2011). Evolution and biogeography of Pleurophyllum (Astereae, Asteraceae), a small genus of megaherbs endemic to the subantarctic islands. American Journal of Botany, 98, 62-75.

Wallace, A.R. (1902). Island life, or, the phenomena and causes of insular faunas and floras: including a revision and attempted solution of the problem of geological climates. Macmillan.

Weber, K.E. (1990). Selection on wing allometry in Drosophila melanogaster. Genetics, 126, 975-989.

Weigelt, P., Jetz, W. \& Kreft, H. (2013). Bioclimatic and physical characterization of the world's islands. Proceedings of the National Academy of Sciences, 110, 15307-15312.

Welch, J.J. (2009). Testing the island rule: primates as a case study. Proceedings of the Royal Society B: Biological Sciences, 276, 675-682.

West, G.B., Brown, J.H. \& Enquist, B.J. (1997). A general model for the origin of allometric scaling laws in biology. Science, 276, 122-126.

West, G.B., Brown, J.H. \& Enquist, B.J. (1999). A general model for the structure and allometry of plant vascular systems. Nature, 400, 664.

Western, D. (1979). Size, life history and ecology in mammals. African Journal of Ecology, $17,185-204$.

Westoby, M. \& Wright, I.J. (2003). The leaf size-twig size spectrum and its relationship to other important spectra of variation among species. Oecologia, 135, 621-628.

Whitfield, J. (2001). The littlest lizard. Nature News, doi:10.1038/news011206-3.

Whittaker, R.J. \& Fernández-Palacios, J.M. (2007). Island biogeography: ecology, evolution, and conservation. Oxford University Press.

Wickham, H. (2016). ggplot2: elegant graphics for data analysis. Springer.

Wickham, H., Francois, R., Henry, L. \& Müller, K. (2015). dplyr: A grammar of data manipulation. $R$ package version $0.4,3$.

Wilkinson, G.S. (1993). Artificial sexual selection alters allometry in the stalk-eyed fly Cyrtodiopsis dalmanni (Diptera: Diopsidae). Genetics Research, 62, 213-222.

Wright, I.J., Dong, N., Maire, V., Prentice, I.C., Westoby, M., Díaz, S. et al. (2017). Global climatic drivers of leaf size. Science, 357, 917-921. 


\section{APPENDIX A}

Table A.1 - Family, habitat, and source locations for 9 species of cosmopolitan vines and trailing plants inhabiting mainland Australia and New Zealand, as well as several other island groups in the south-west Pacific.

\begin{tabular}{|c|c|c|c|}
\hline Species & Family & Habitat & Source \\
\hline Calystegia soldanella & Convolvulaceae & Littoral & $\begin{array}{l}\text { Tauranga, New Zealand } \\
\text { Mayor Island } \\
\text { Chatham Islands } \\
\text { Lord Howe Island }\end{array}$ \\
\hline $\begin{array}{l}\text { Ipomoea pes-caprae } \\
\qquad(\text { subsp. brasiliensis) }\end{array}$ & Convolvulaceae & Littoral & $\begin{array}{l}\text { Coffs Harbour, Australia } \\
\text { Lord Howe Island }\end{array}$ \\
\hline Muehlenbekia australis & Polygonaceae & Inland & $\begin{array}{l}\text { Wellington, New Zealand } \\
\text { Chatham Islands }\end{array}$ \\
\hline Muehlenbekia complexa & Polygonaceae & Littoral & $\begin{array}{l}\text { Wellington, New Zealand } \\
\text { Lord Howe Island }\end{array}$ \\
\hline Ripogonum scandens & Ripogonaceae & Inland & $\begin{array}{l}\text { Tauranga, New Zealand } \\
\text { Mayor Island } \\
\text { Chatham Islands }\end{array}$ \\
\hline Smilax australis & Smilacaceae & Inland & $\begin{array}{l}\text { Coffs Harbour, Australia } \\
\text { Lord Howe Island }\end{array}$ \\
\hline Stephania japonica & Menispermaceae & Littoral & $\begin{array}{l}\text { Coffs Harbour, Australia } \\
\text { Lord Howe Island }\end{array}$ \\
\hline Vinca major & Apocynaceae & Inland & $\begin{array}{l}\text { Tauranga, New Zealand } \\
\text { Mayor Island }\end{array}$ \\
\hline Wedelia biflora & Asteraceae & Littoral & $\begin{array}{l}\text { Coffs Harbour, Australia } \\
\text { Lord Howe Island }\end{array}$ \\
\hline
\end{tabular}




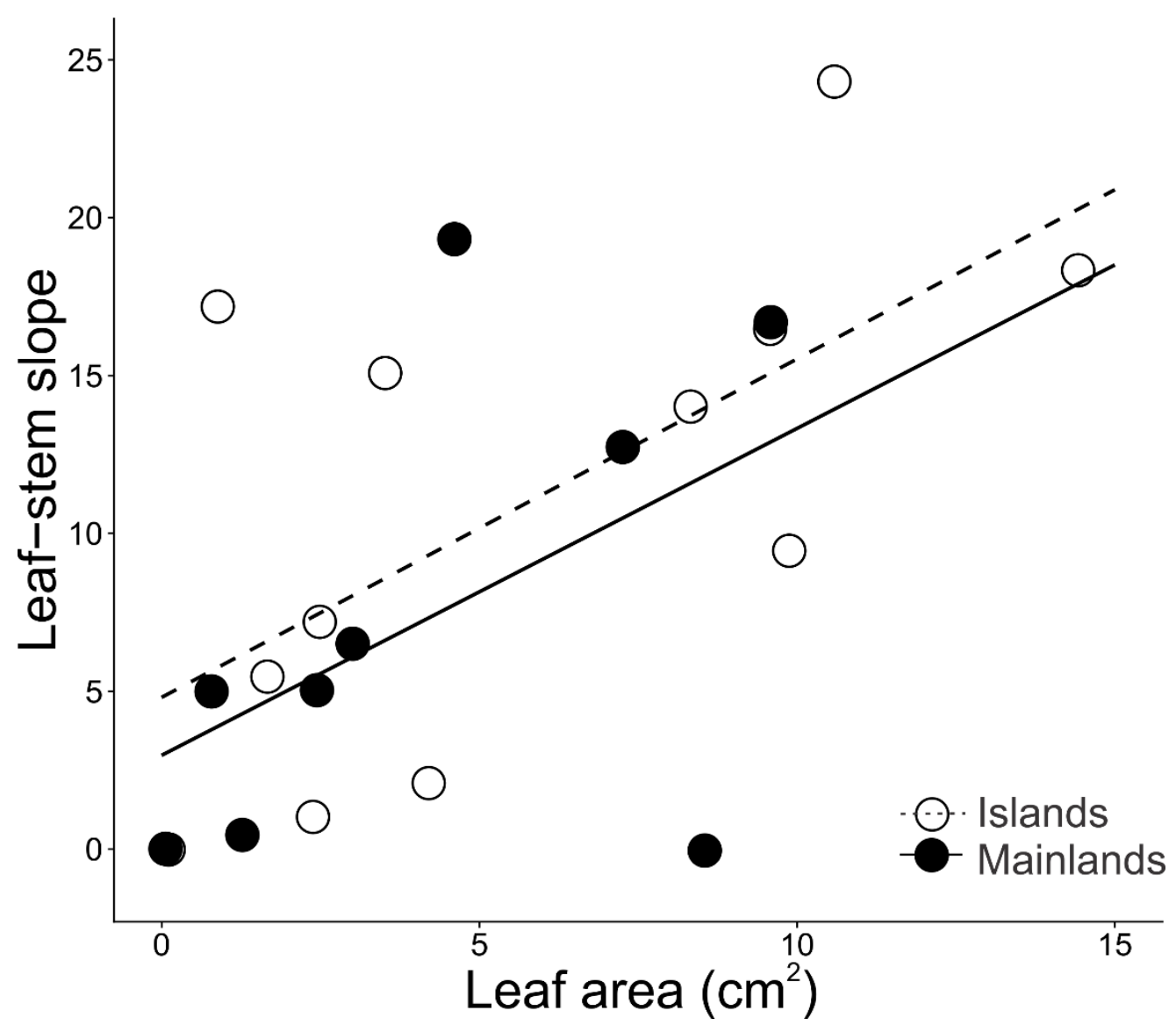

Figure A.1 - Slope parameters of leaf-stem scaling relationships are plotted against mean leaf area. Points denote single populations. 

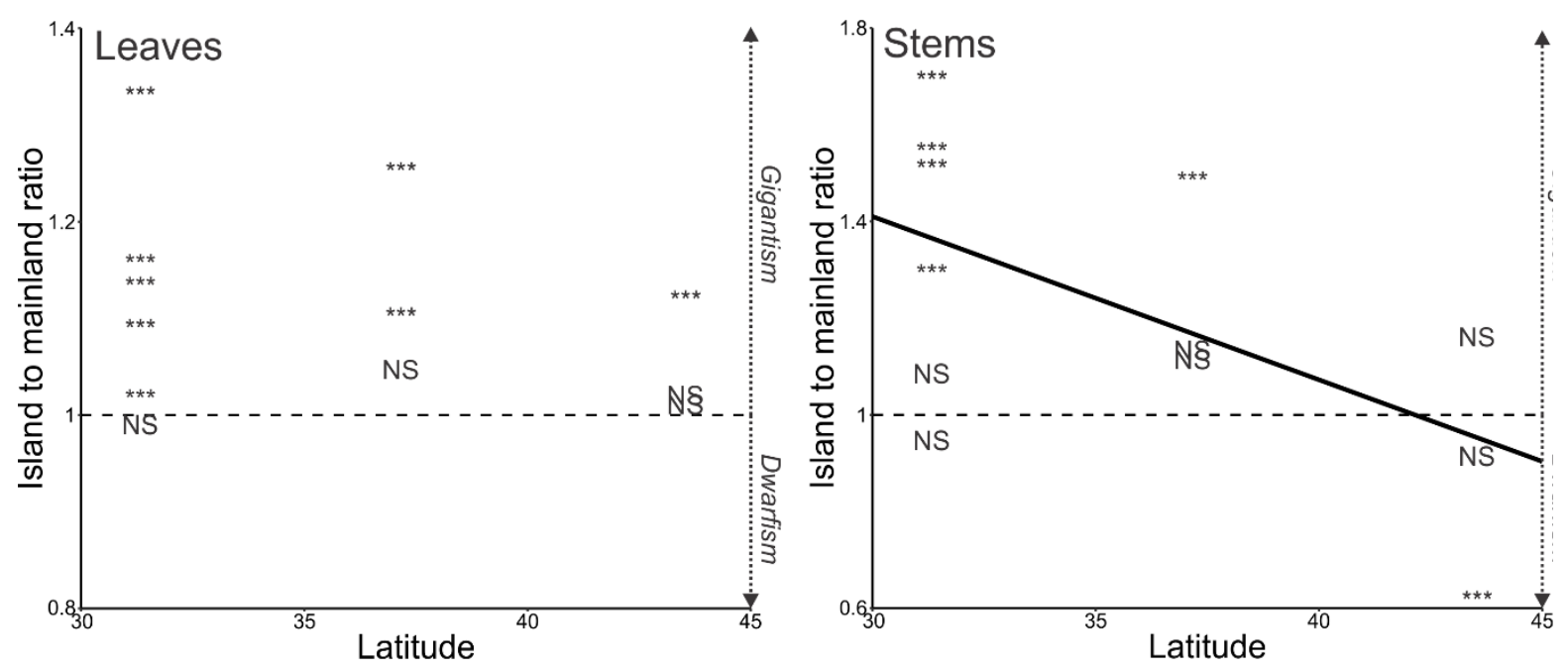

Figure A.2 - Graphical depiction of association between insular size changes (island to mainland ratio) and latitude. Values are plotted according to their level of significance (see Table 2.2). A dashed line intercepting the $y$-axis at zero denotes morphological isometry (i.e. island values = mainland values). Points above this line represent insular gigantism, points below represent insular dwarfism. 


\section{APPENDIX B}

Table B.1. - Supplementary dataset from Biddick et al. (2019). 


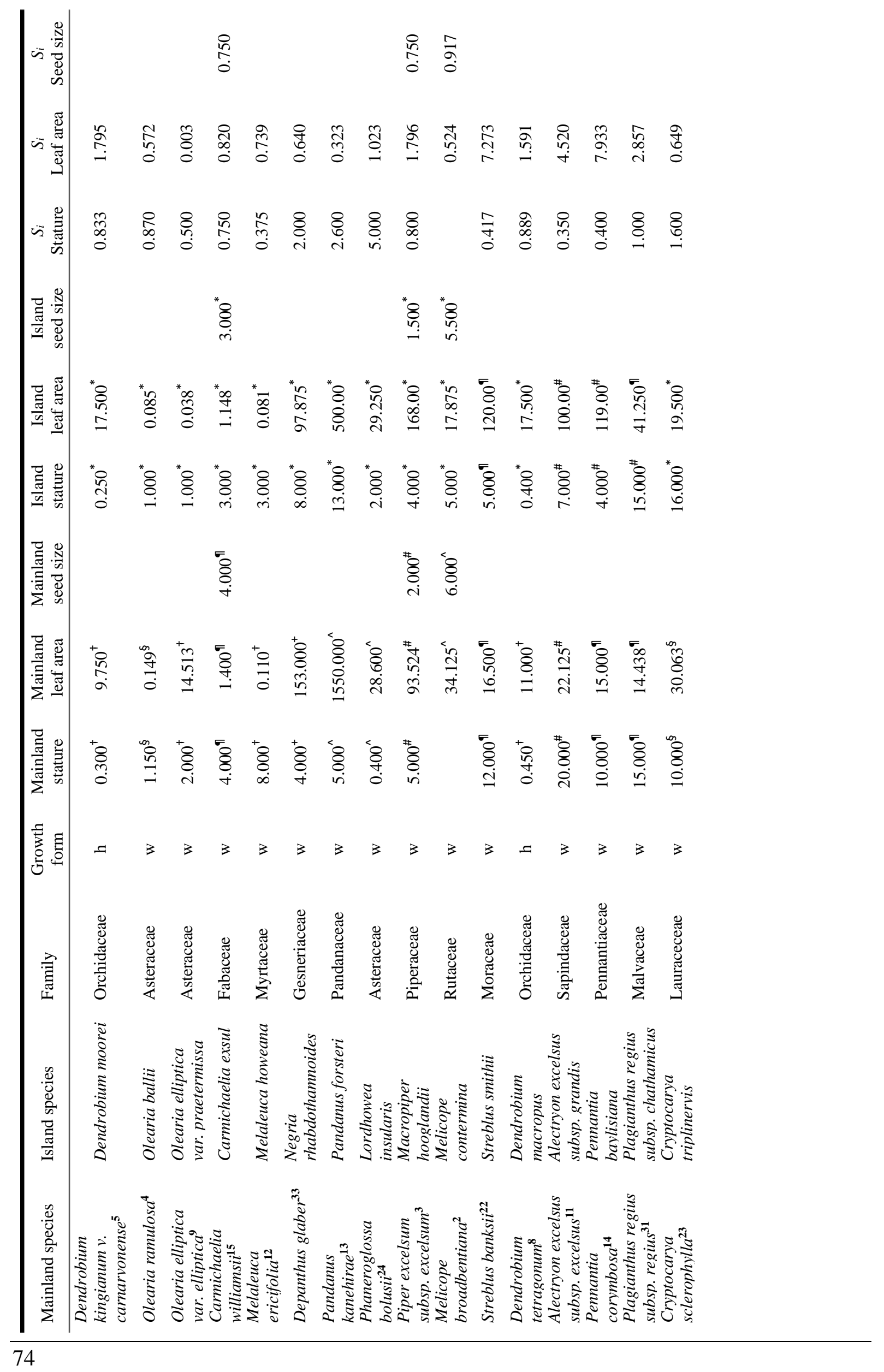




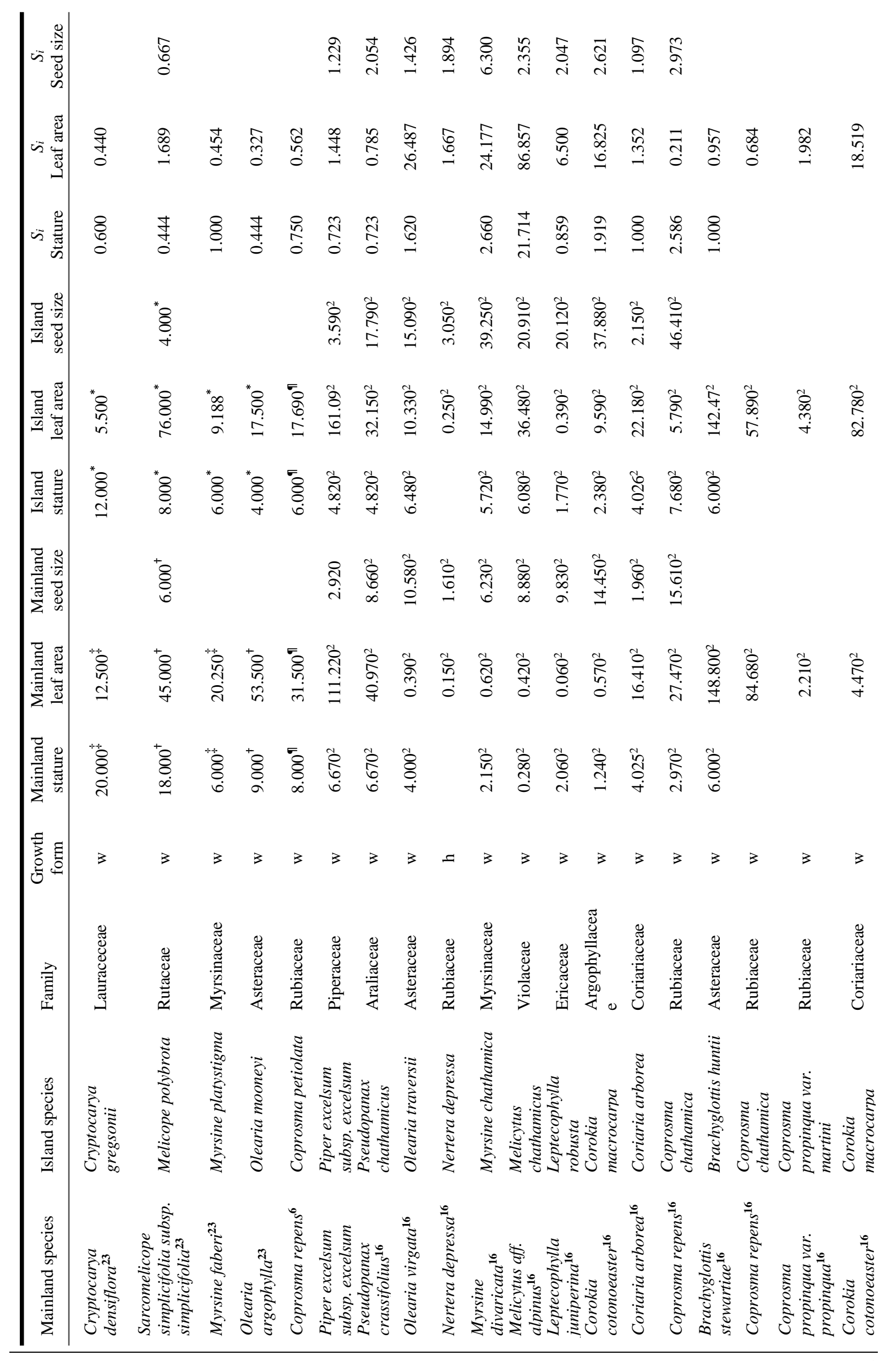




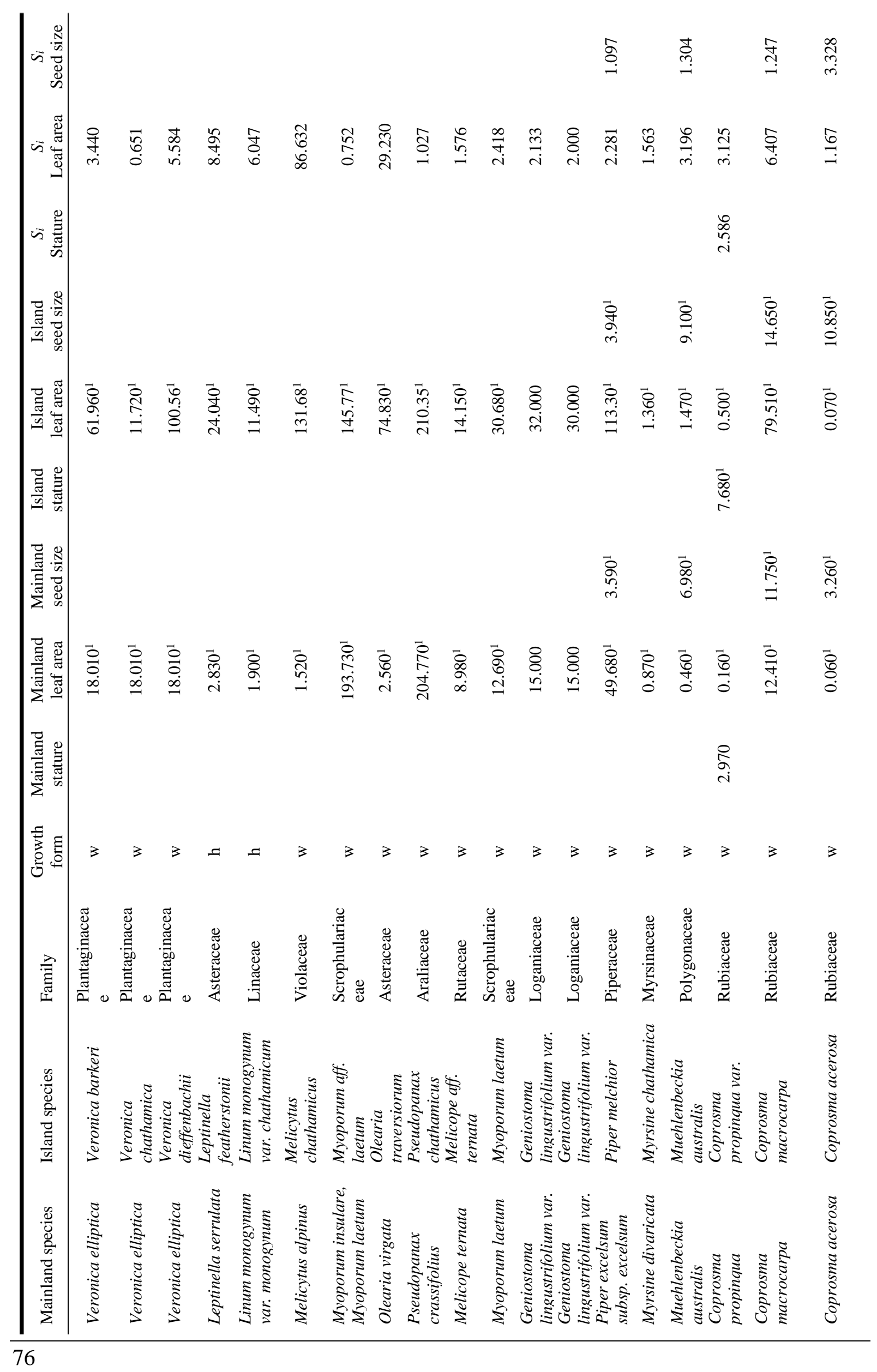




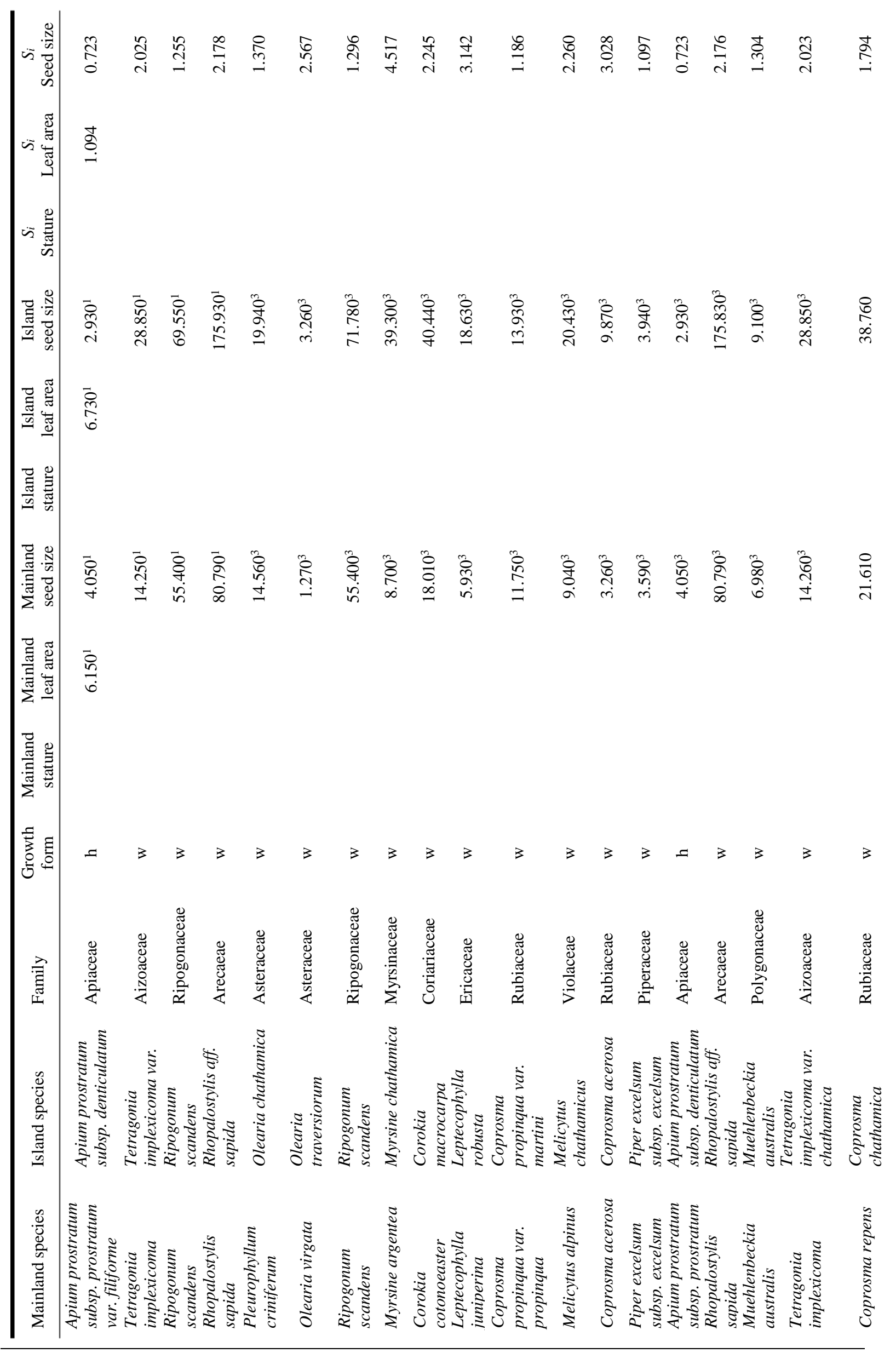




\section{APPENDIX B}

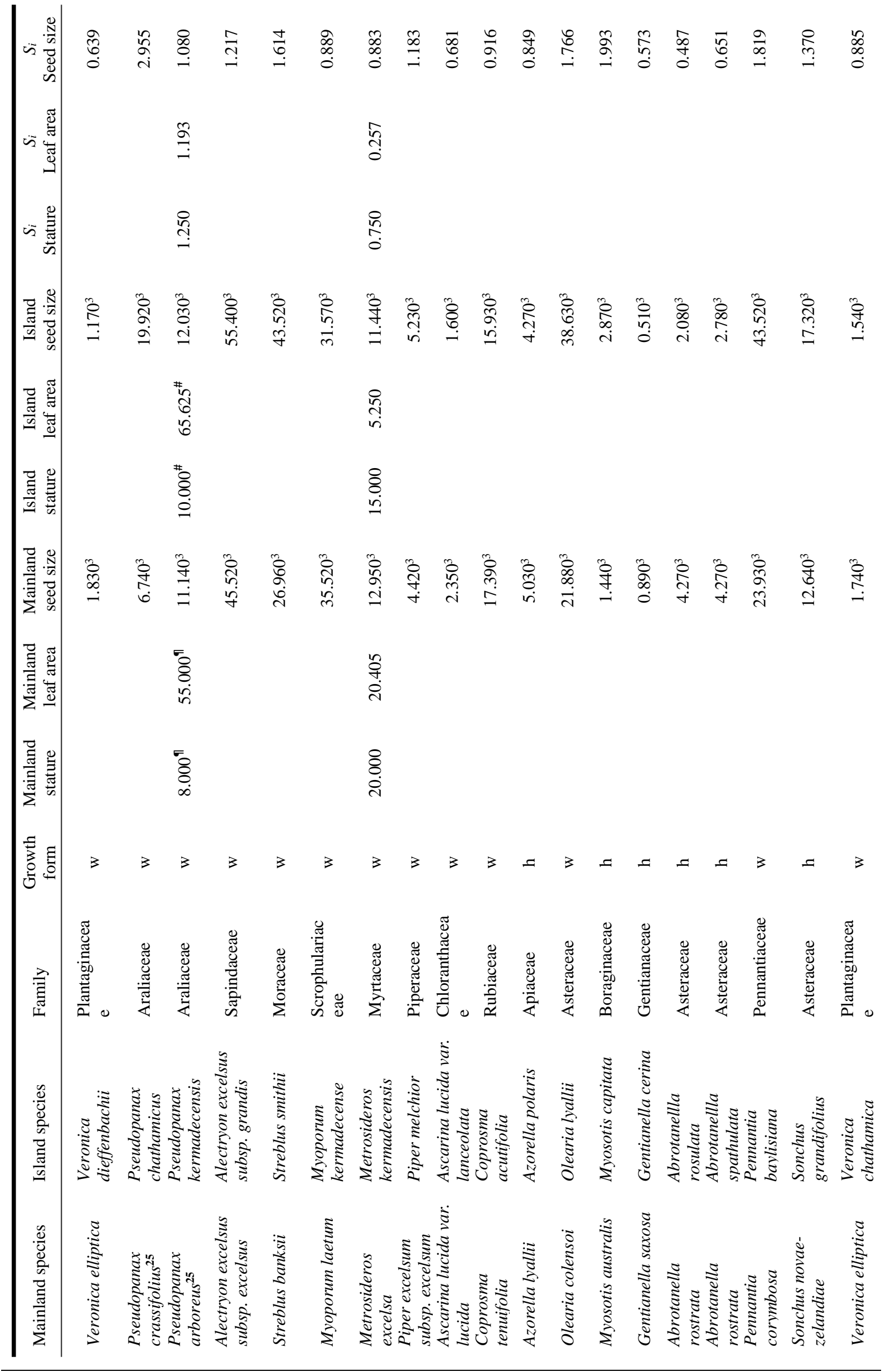




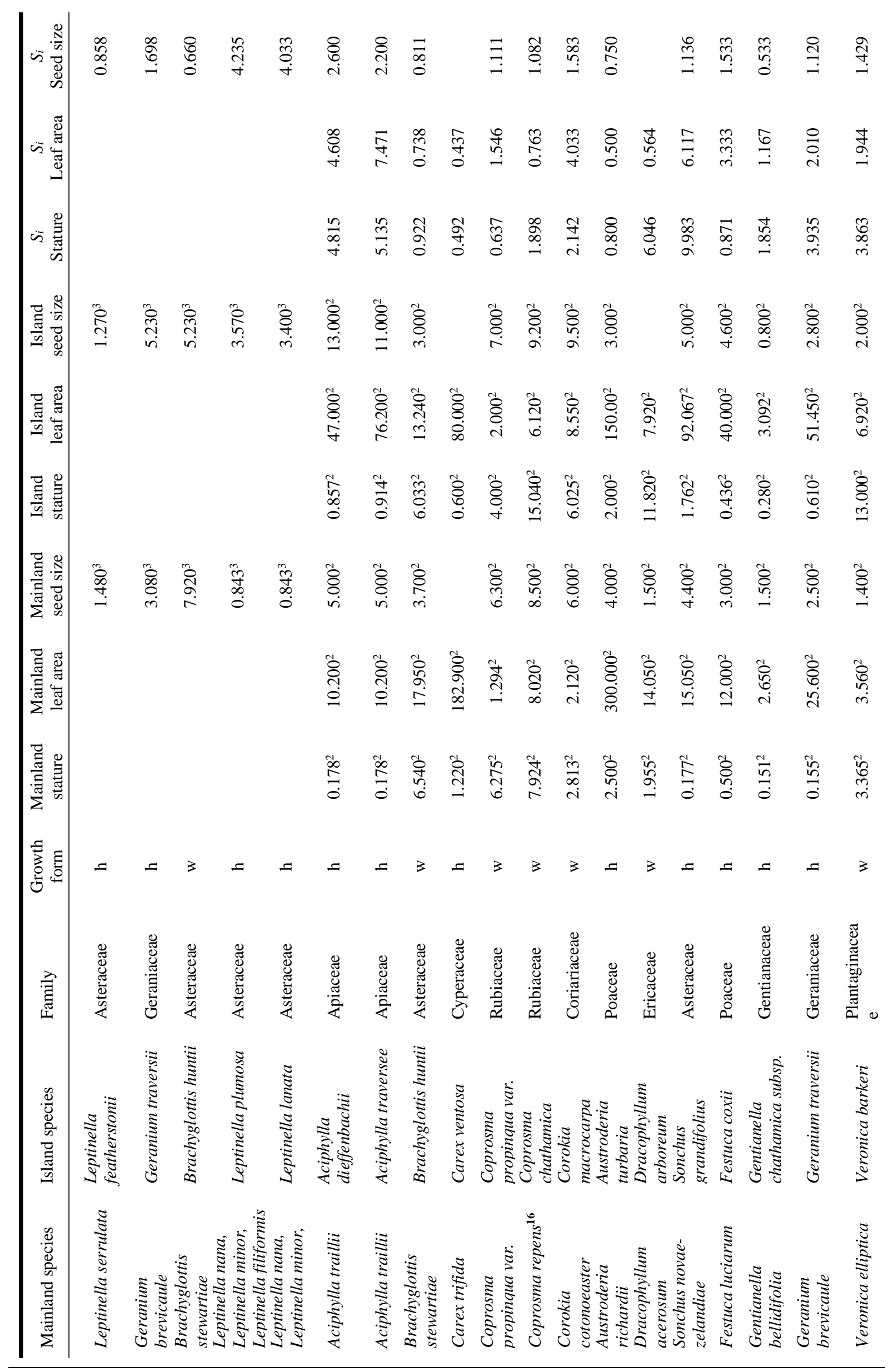




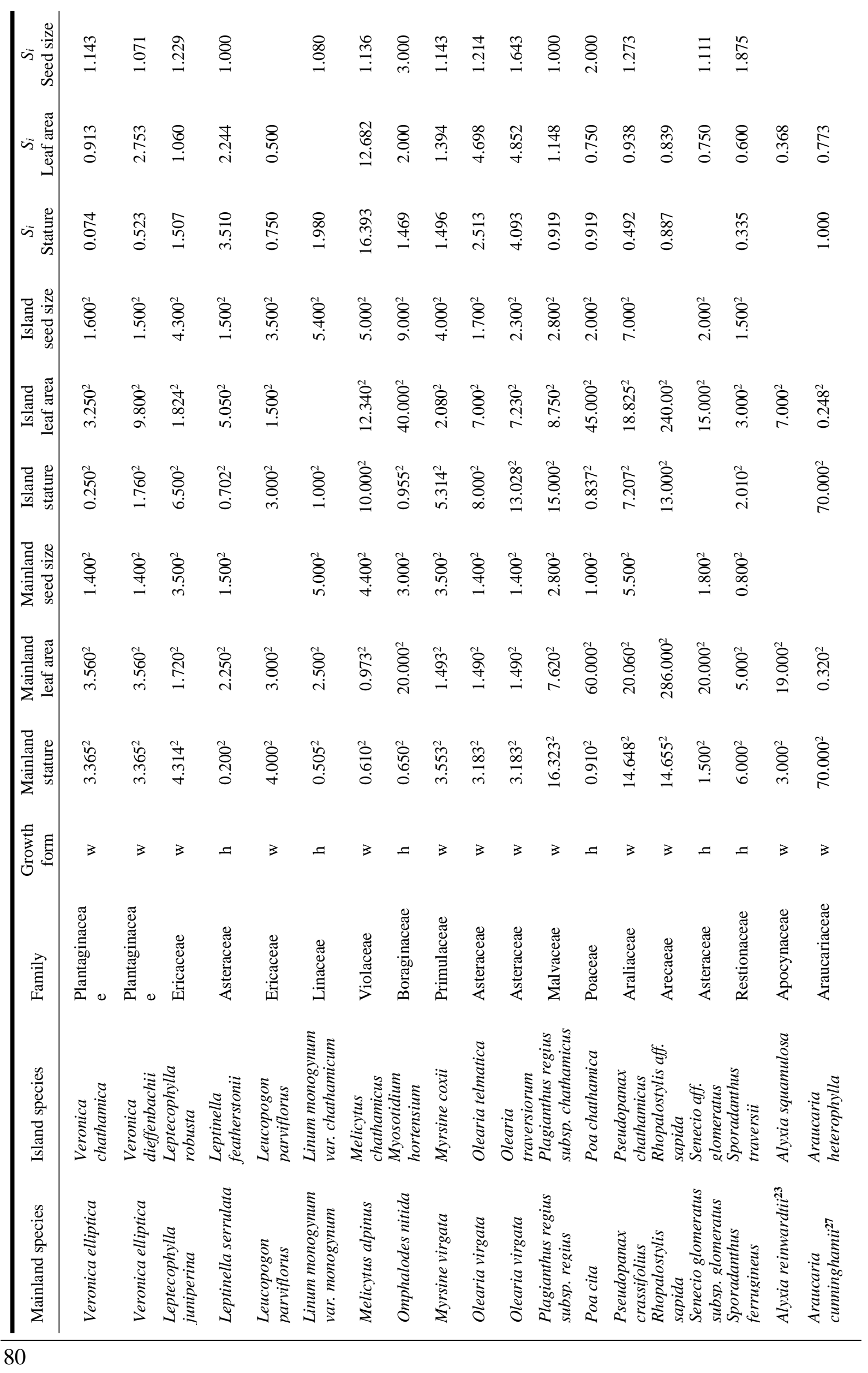




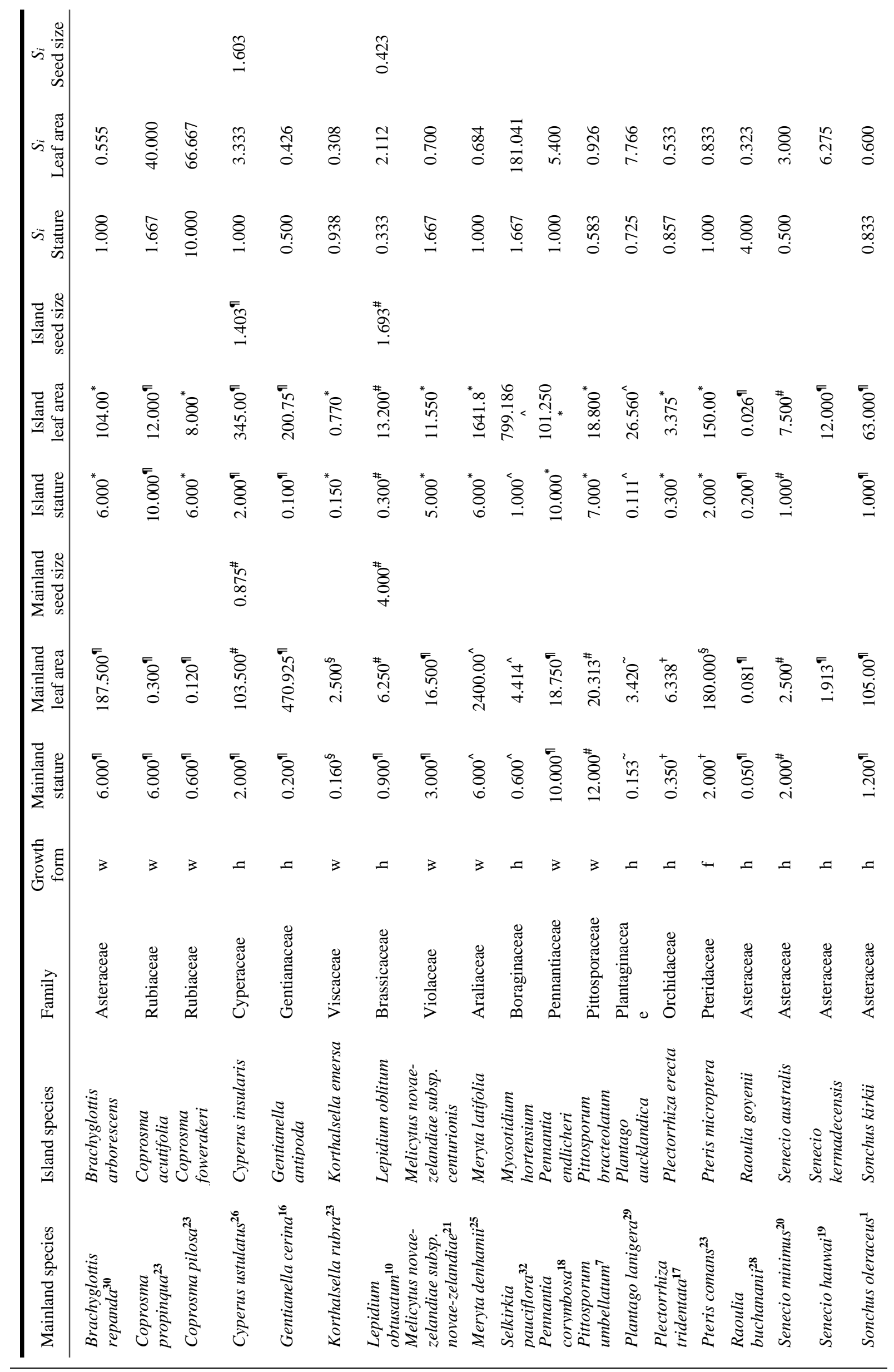




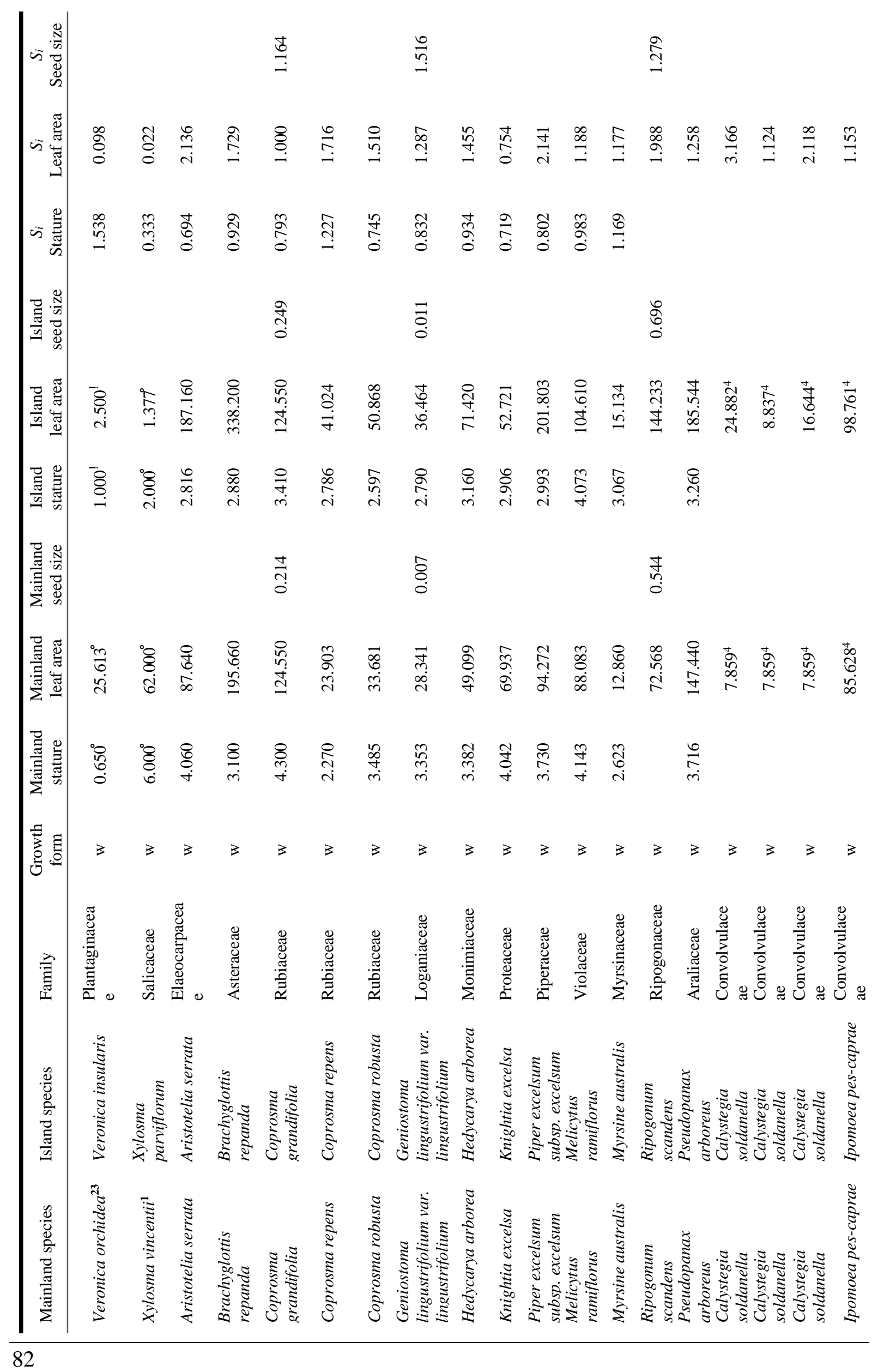




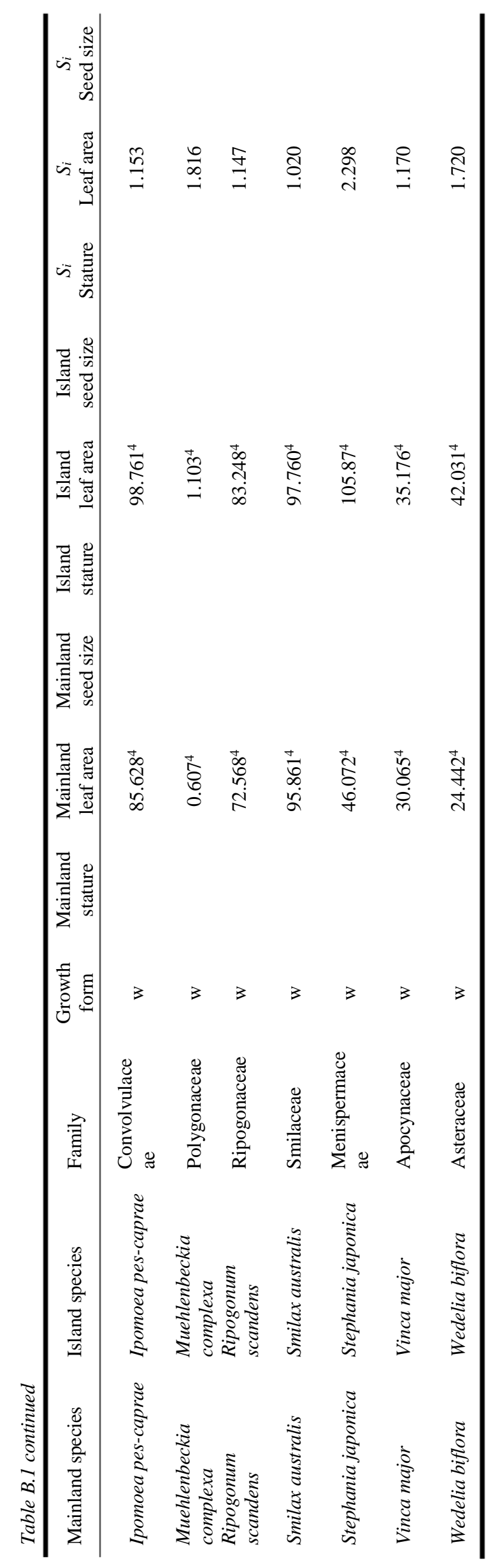




\section{Collection method key:}

${ }^{1}$ Burns, K. C., Herold, N., \& Wallace, B. (2012). Evolutionary size changes in plants of the south-west Pacific. Global Ecology and Biogeography, 21(8), 819-828.

${ }^{2}$ Cox, B. T. M., \& Burns, K. C. (2017). Convergent evolution of gigantism in the flora of an isolated archipelago. Evolutionary Ecology, 31(5), 741-752.

${ }^{3}$ Kavanagh, P. H., \& Burns, K. C. (2014). The repeated evolution of large seeds on islands. Proceedings of the Royal Society B: Biological Sciences, 281(1786), 20140675.

${ }^{4}$ Biddick, M., Hutton, I., \& Burns, K. C. (2018). Independent evolution of allometric traits: a test of the allometric constraint hypothesis in island vines. Biological Journal of the Linnean Society, 126(1), 203-211.

\section{Trait source key:}

* Australian Flora, volume 49

$\dagger$ PlantNET (plantnet.org)

$\$$ eFloras (efloras.org)

$\S$ VicFlora (vicflora.rgb.vic.gov.au)

II NZFlora (www.nzflora.info)

\# New Zealand Plant Conservation Network (www.ncpcn.org.nz)

$\wedge$ Royal Kew Garden Herbarium (www.gbif.org/dataset/cd6e21c8-9e8a-493a-8a76fbf7862069e5)

! Missouri Botanic Gardens

'Auckland War Memorial Museum Herbarium (www.aucklandmuseum.com)

Te Papa Museum Herbarium, Wellington

${ }^{+}$Montpellier University Herbarium

\section{Phylogeny reference key:}

1. Albach, D.C. \& Greilhuber, J. (2004). Genome size variation and evolution in Veronica. Annals of Botany, 94, 897-911.

2. Appelhans, M.S., Wen, J. \& Wagner, W.L. (2014). A molecular phylogeny of Acronychia, Euodia, Melicope and relatives (Rutaceae) reveals polyphyletic genera and key innovations for species richness. Molecular Phylogenetics and Evolution, 79, 54-68.

3. Asmarayani, R. \& Pancoro, A. (2016). Phylogenetic study of Piper L.(Piperaceae) based on ITS regions of nrDNA. Floribunda, 2.

4. Brouillet, L., Anderberg, A.A., Nesom, G.L., Lowrey, T.K. \& Urbatsch, L.E. (2009). Welwitschiella is a member of the African subtribe Grangeinae (Asteraceae Astereae): a new phylogenetic position based on ndhF and ITS sequence data. Kew Bulletin, 64, 645-660. 
5. Burke, J.M., Bayly, M.J., Adams, P.B. \& Ladiges, P.Y. (2008). Molecular phylogenetic analysis of Dendrobium (Orchidaceae), with emphasis on the Australian section Dendrocoryne, and implications for generic classification. Australian Systematic Botany, 21, 1-14.

6. Cantley, J.T., Swenson, N.G., Markey, A. \& Keeley, S.C. (2014). Biogeographic insights on Pacific Coprosma (Rubiaceae) indicate two colonizations to the Hawaiian Islands. Botanical Journal of the Linnean Society, 174, 412-424.

7. Carrodus, S.K. (2009). Identification and the role of hybridisation in Pittosporum. The University of Waikato.

8. Clements, M.A. (2006). Molecular phylogentics systematics in dendrobieae (Orchidaceae). Aliso: A Journal of Systematic and Evolutionary Botany, 22, 465-480.

9. Cross, E., Quinn, C. \& Wagstaff, S. (2002). Molecular evidence for the polyphyly of Olearia (Astereae: Asteraceae). Plant Systematics and Evolution, 235, 99-120.

10. De Lange, P.J., Heenan, P.B., Houliston, G., Rolfe, J.R. \& Mitchell, A. (2013). New lepidium (Brassicaceae) from New Zealand. PhytoKeys, 1.

11. Edwards, K. \& Gadek, P. (2001). Evolution and biogeography of Alectryon (Sapindaceae). Molecular Phylogenetics and Evolution, 20, 14-26.

12. Edwards, R.D., Craven, L.A., Crisp, M.D. \& Cook, L.G. (2010). Melaleuca revisited: cpDNA and morphological data confirm that Melaleuca L.(Myrtaceae) is not monophyletic. Taxon, 59, 744-754.

13. Gallaher, T., Callmander, M.W., Buerki, S. \& Keeley, S.C. (2015). A long distance dispersal hypothesis for the Pandanaceae and the origins of the Pandanus tectorius complex. Molecular Phylogenetics and Evolution, 83, 20-32.

14. Gardner, R.O. \& de Lange, P.J. (2002). Revision of Pennantia (Icacinaceae), a small isolated genus of Southern Hemisphere trees. Journal of the Royal Society of New Zealand, 32, 669-695.

15. Heenan, P. (1998). Phylogenetic analysis of the Carmichaelia complex, Clianthus, and Swainsona (Fabaceae), from Australia and New Zealand. New Zealand Journal of Botany, 36, 21-40.

16. Heenan, P., Mitchell, A., De Lange, P., Keeling, J. \& Paterson, A. (2010). Late-Cenozoic origin and diversification of Chatham Islands endemic plant species revealed by analyses of DNA sequence data. New Zealand Journal of Botany, 48, 83-136.

17. Hidayat, T., Weston, P.H., Yukawa, T., Ito, M. \& Rice, R. (2012). Phylogeny of subtribe Aeridinae (Orchidaceae) inferred from DNA sequences data: Advanced analyses including Australasian genera. Jurnal Teknologi, 59.

18. Keeling, D., Gardner, R. \& de Lange, P. (2004). An inferred molecular phylogeny from nrDNA ITS sequences for Pennantia (Pennantiaceae). New Zealand Botanical Society Newsletter, 76, 24-27.

19. Kim, S.-C., Chunghee, L. \& Mejías, J.A. (2007). Phylogenetic analysis of chloroplast DNA matK gene and ITS of nrDNA sequences reveals polyphyly of the genus Sonchus and new relationships among the subtribe Sonchinae (Asteraceae: Cichorieae). Molecular Phylogenetics and Evolution, 44, 578-597. 
20. Liew, C.-S., Memory, A.E., Ortiz-Barrientos, D., Lange, P.J.d. \& Pelser, P.B. (2018). The delimitation and evolutionary history of the Australasian Lautusoid group of Senecio (Asteraceae: Senecioneae). Taxon, 67, 130-148.

21. Mitchell, A., Heenan, P., Murray, B., Molloy, B. \& De Lange, P. (2009). Evolution of the south-western Pacific genus Melicytus (Violaceae): evidence from DNA sequence data, cytology and sex expression. Australian Systematic Botany, 22, 143-157.

22. Nepal, M.P. \& Ferguson, C.J. (2012). Phylogenetics of Morus (Moraceae) inferred from ITS and trnL-trnF sequence data. Systematic Botany, 37, 442-450.

23. Papadopulos, A.S., Baker, W.J., Crayn, D., Butlin, R.K., Kynast, R.G., Hutton, I. et al. (2011). Speciation with gene flow on Lord Howe Island. Proceedings of the National Academy of Sciences, 108, 13188-13193.

24. Pelser, P.B., Kennedy, A.H., Tepe, E.J., Shidler, J.B., Nordenstam, B., Kadereit, J.W. et al. (2010). Patterns and causes of incongruence between plastid and nuclear Senecioneae (Asteraceae) phylogenies. American Journal of Botany, 97, 856-873.

25. Perrie, L.R. \& Shepherd, L.D. (2009). Reconstructing the species phylogeny of Pseudopanax (Araliaceae), a genus of hybridising trees. Molecular Phylogenetics and Evolution, 52, 774-783.

26. Reid, C.S., Carter, R. \& Urbatsch, L.E. (2014). Phylogenetic insights into New World Cyperus (Cyperaceae) using nuclear ITS sequences. Brittonia, 66, 292-305.

27. Ruhsam, M., Rai, H.S., Mathews, S., Ross, T.G., Graham, S.W., Raubeson, L.A. et al. (2015). Does complete plastid genome sequencing improve species discrimination and phylogenetic resolution in Araucaria? Molecular Ecology Resources, 15, 1067-1078.

28. Smissen, R.D., Galbany-Casals, M. \& Breitwieser, I. (2011). Ancient allopolyploidy in the everlasting daisies (Asteraceae: Gnaphalieae): complex relationships among extant clades. Taxon, 60, 649-662.

29. Tay, M.L., Meudt, H.M., Garnock-Jones, P.J. \& Ritchie, P.A. (2010). DNA sequences from three genomes reveal multiple long-distance dispersals and non-monophyly of sections in Australasian Plantago (Plantaginaceae). Australian Systematic Botany, 23, 47-68.

30. Wagstaff, S.J. \& Breitwieser, I. (2004). Phylogeny and classification of Brachyglottis (Senecioneae, Asteraceae): an example of a rapid species radiation in New Zealand. Systematic Botany, 29, 1003-1010.

31. Wagstaff, S.J. \& Tate, J.A. (2011). Phylogeny and character evolution in the New Zealand endemic genus Plagianthus (Malveae, Malvaceae). Systematic Botany, 36, 405-418.

32. Weigend, M., Luebert, F., Selvi, F., Brokamp, G. \& Hilger, H.H. (2013). Multiple origins for Hound's tongues (Cynoglossum L.) and Navel seeds (Omphalodes Mill.)-The phylogeny of the borage family (Boraginaceae s. str.). Molecular Phylogenetics and Evolution, 68, 604-618.

33. Woo, V.L., Funke, M.M., Smith, J.F., Lockhart, P.J. \& Garnock-Jones, P.J. (2011). New World origins of southwest Pacific Gesneriaceae: multiple movements across and within the South Pacific. International Journal of Plant Sciences, 172, 434-457. 


\section{APPENDIX C}

Table C1 - Dataset used to test evolutionary drift model of insular size changes. Dataset modified from Biddick et al. (2019) (i.e. graminoids and potential instances of cladogenesis removed). 


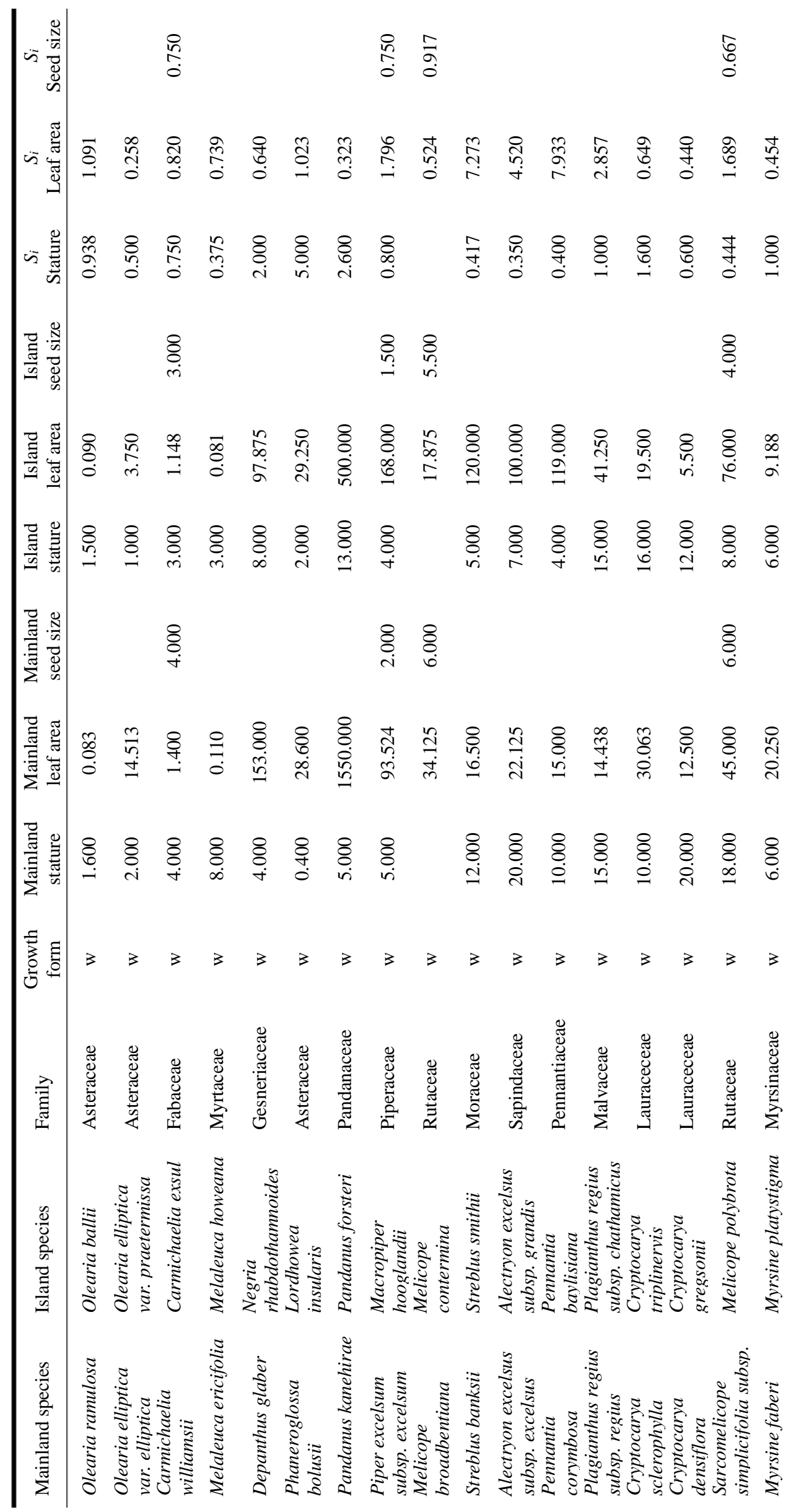




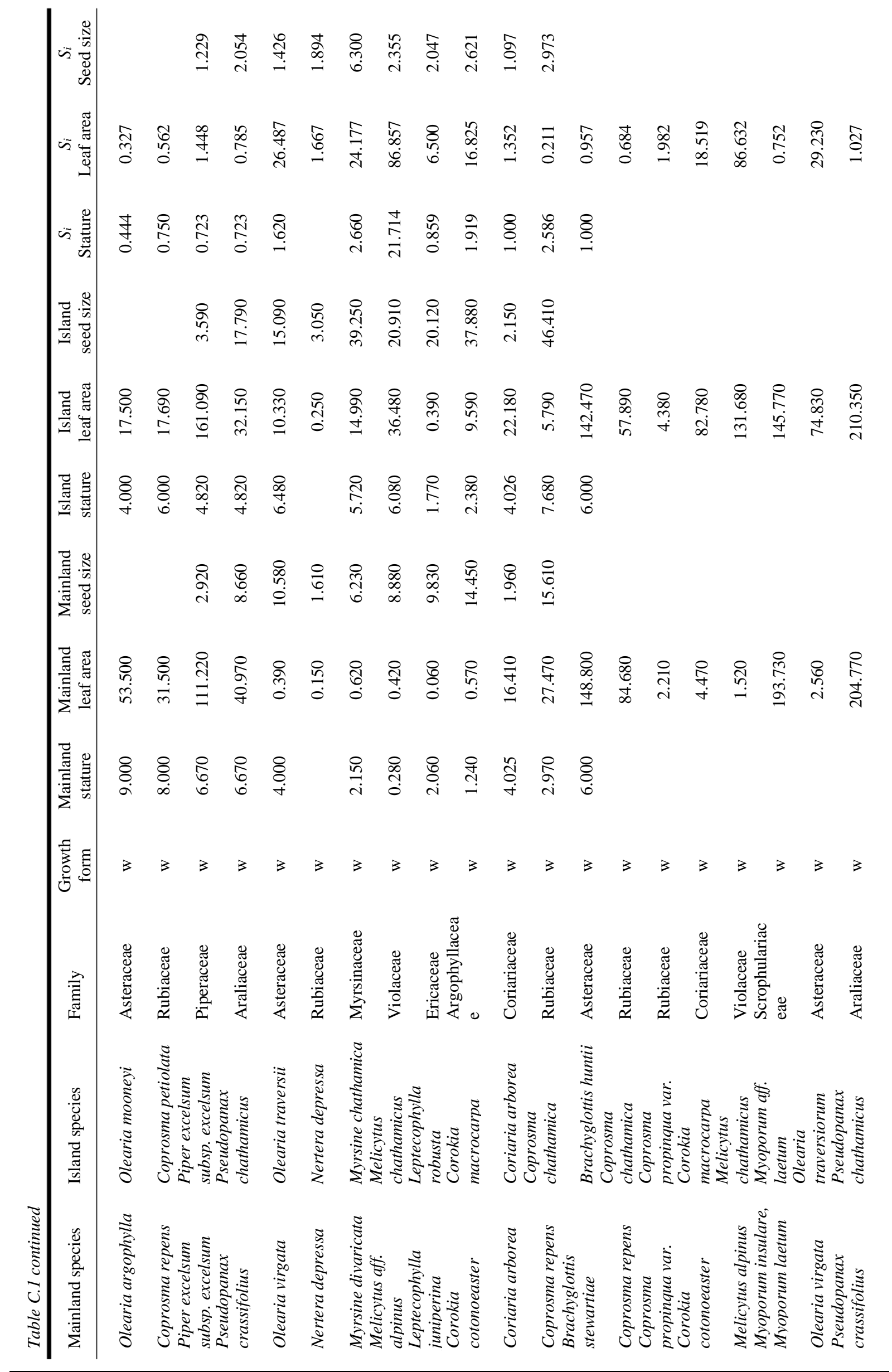




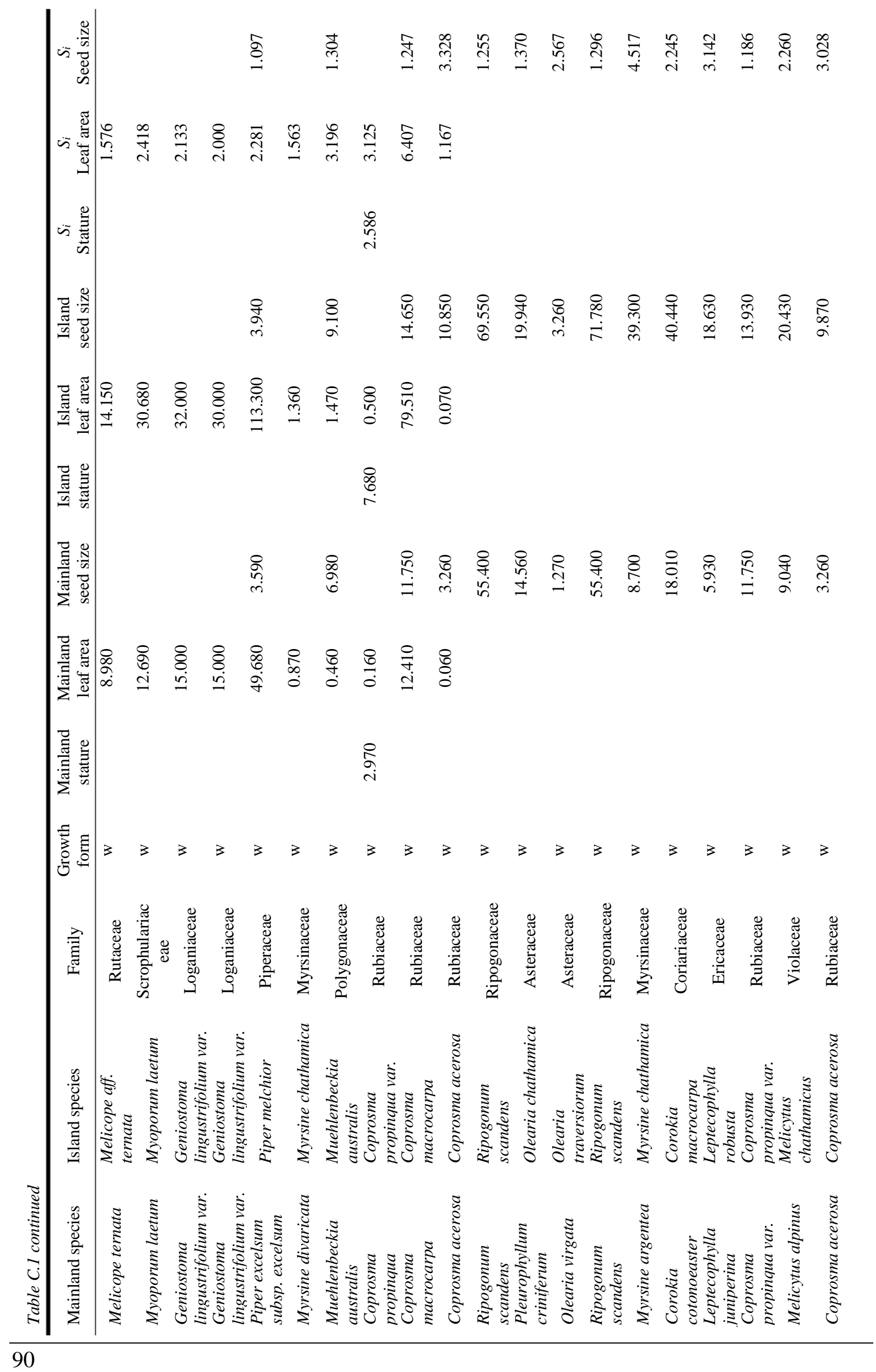




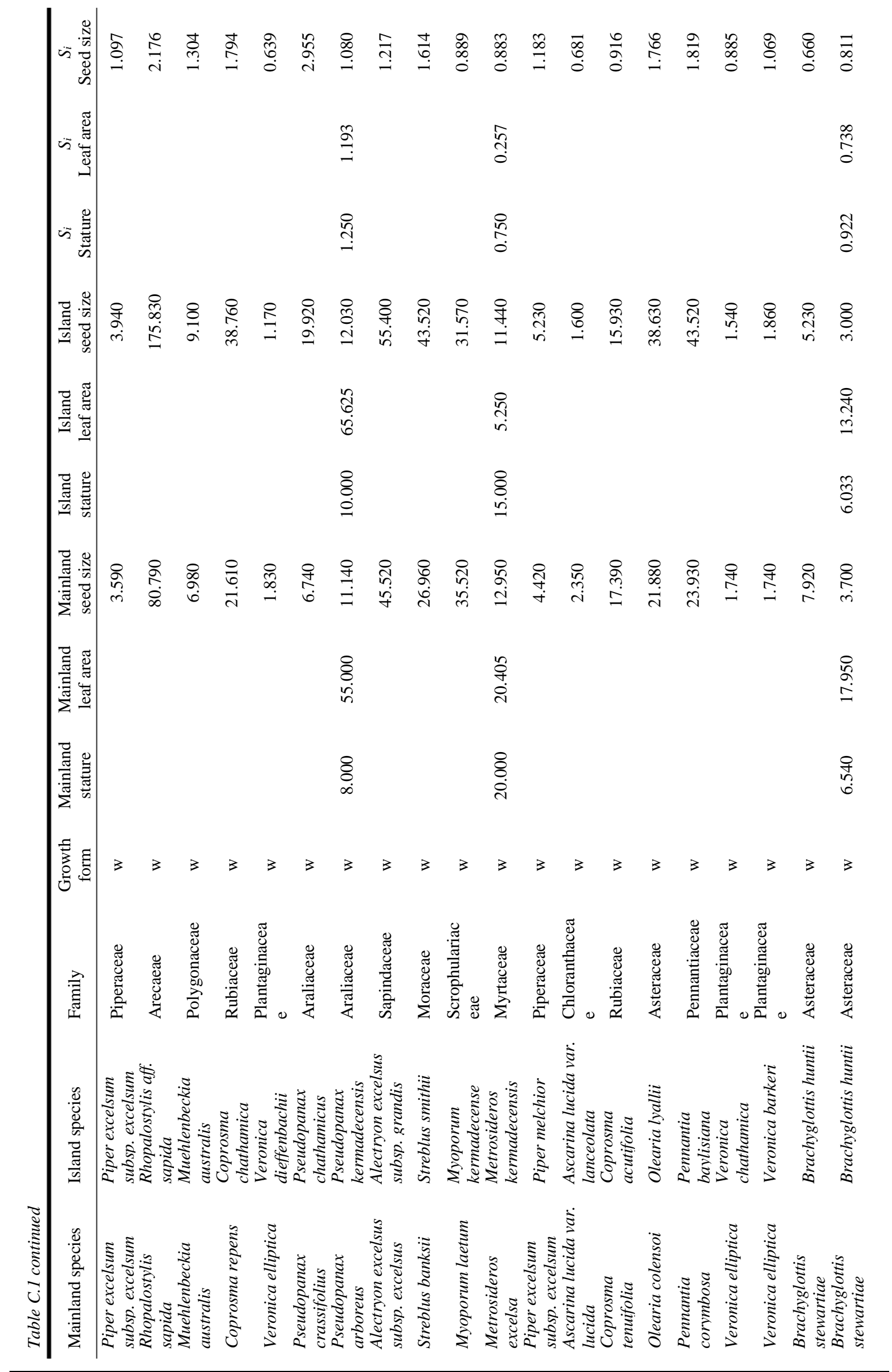




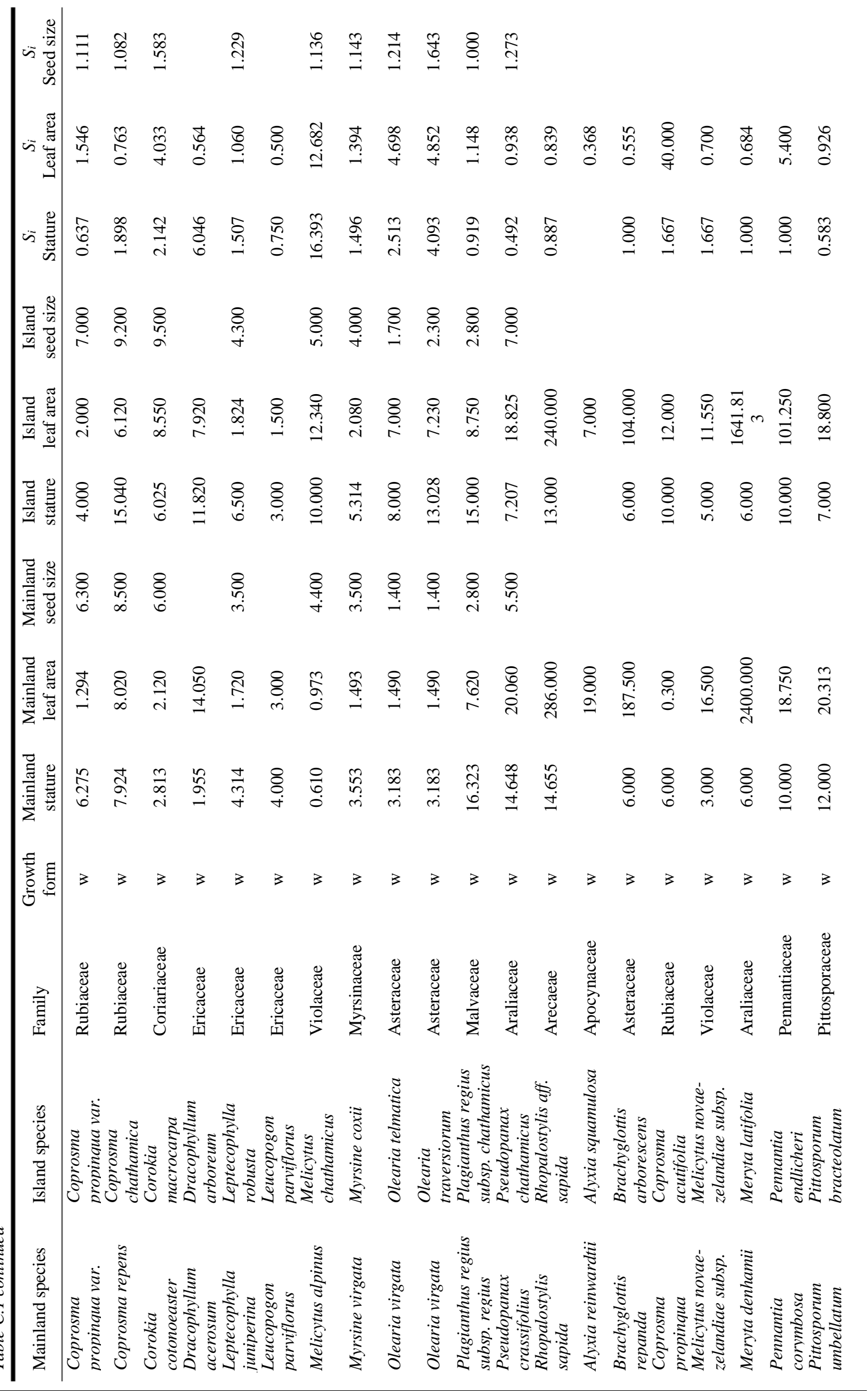




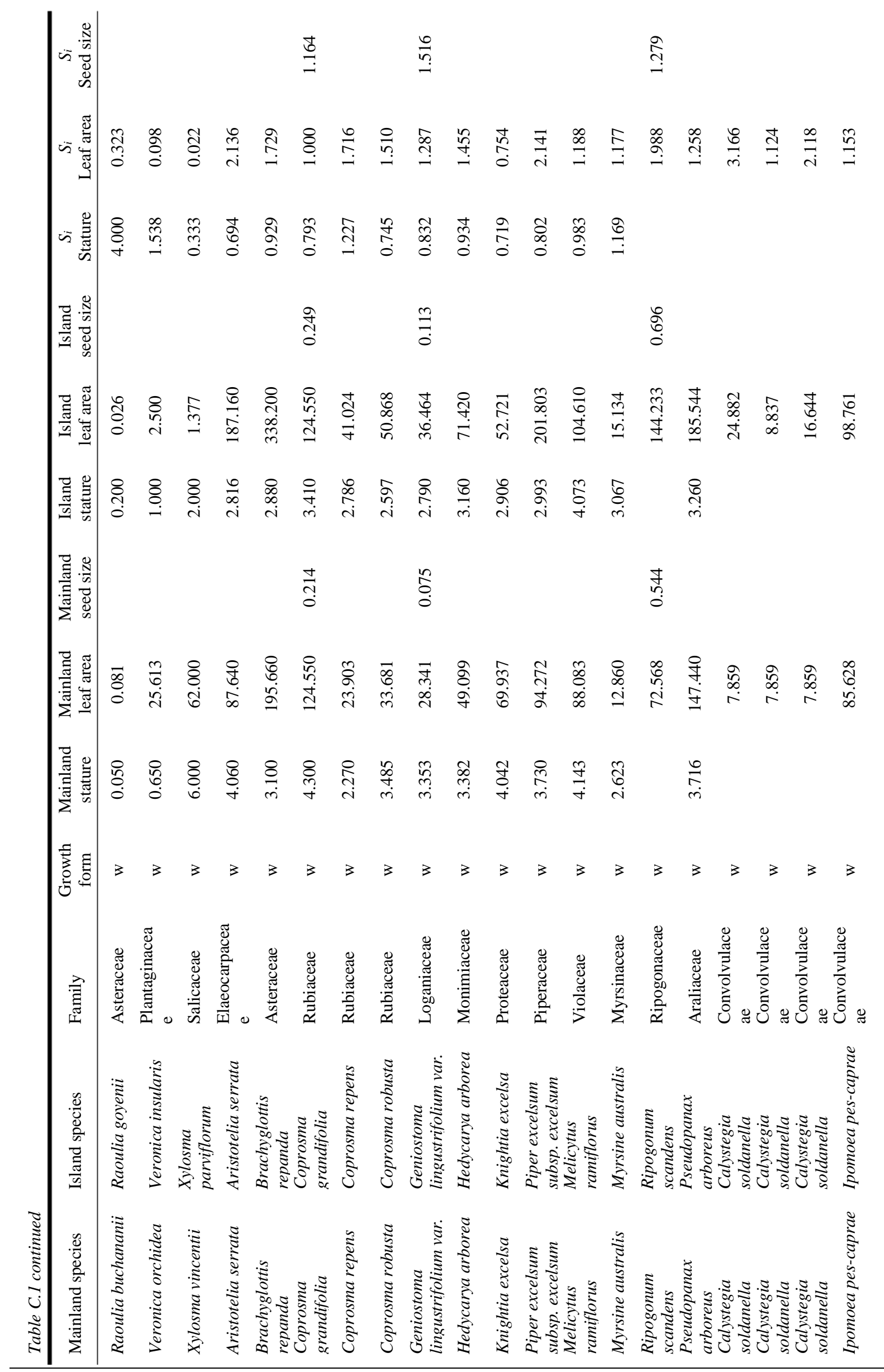




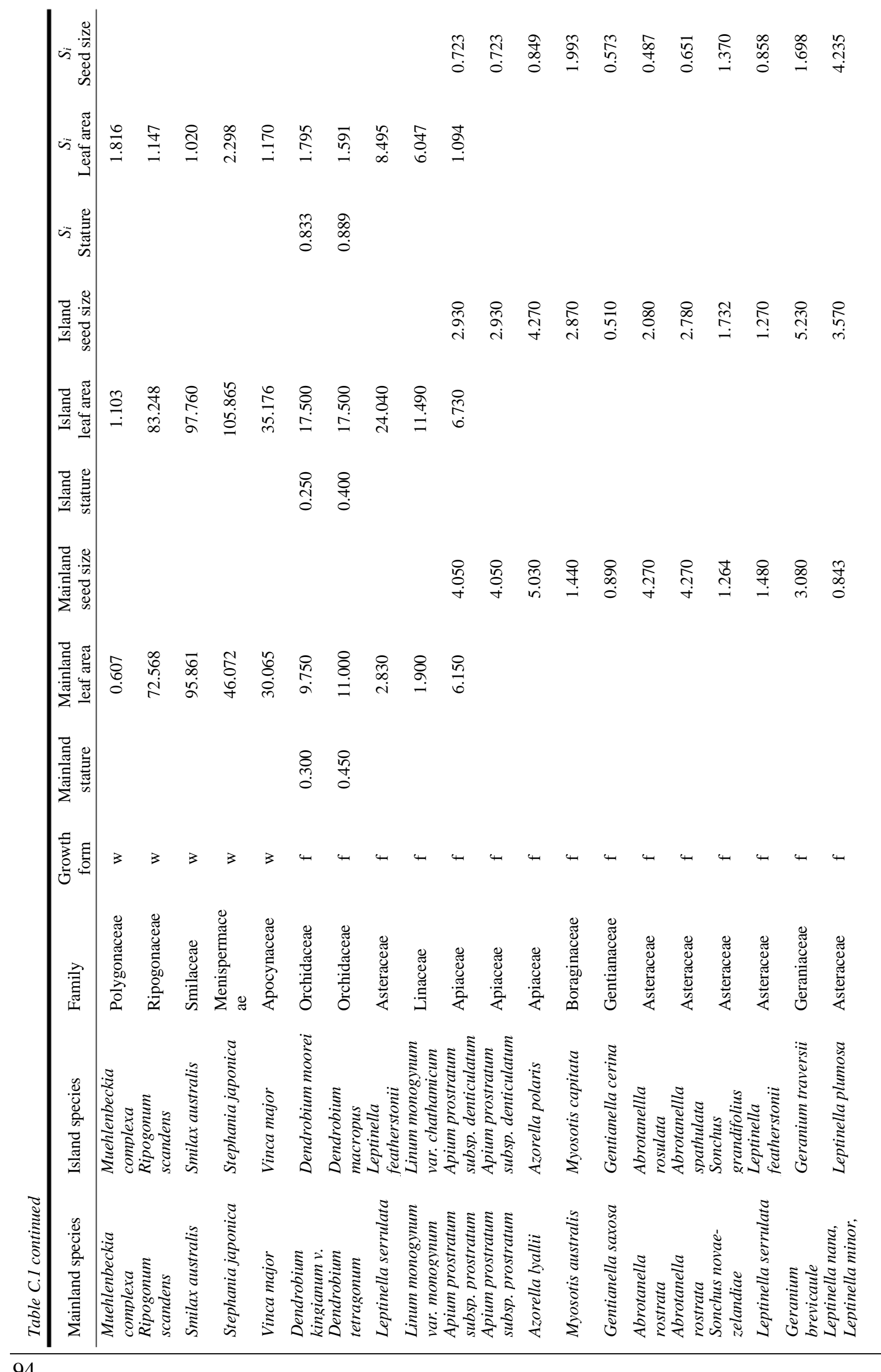




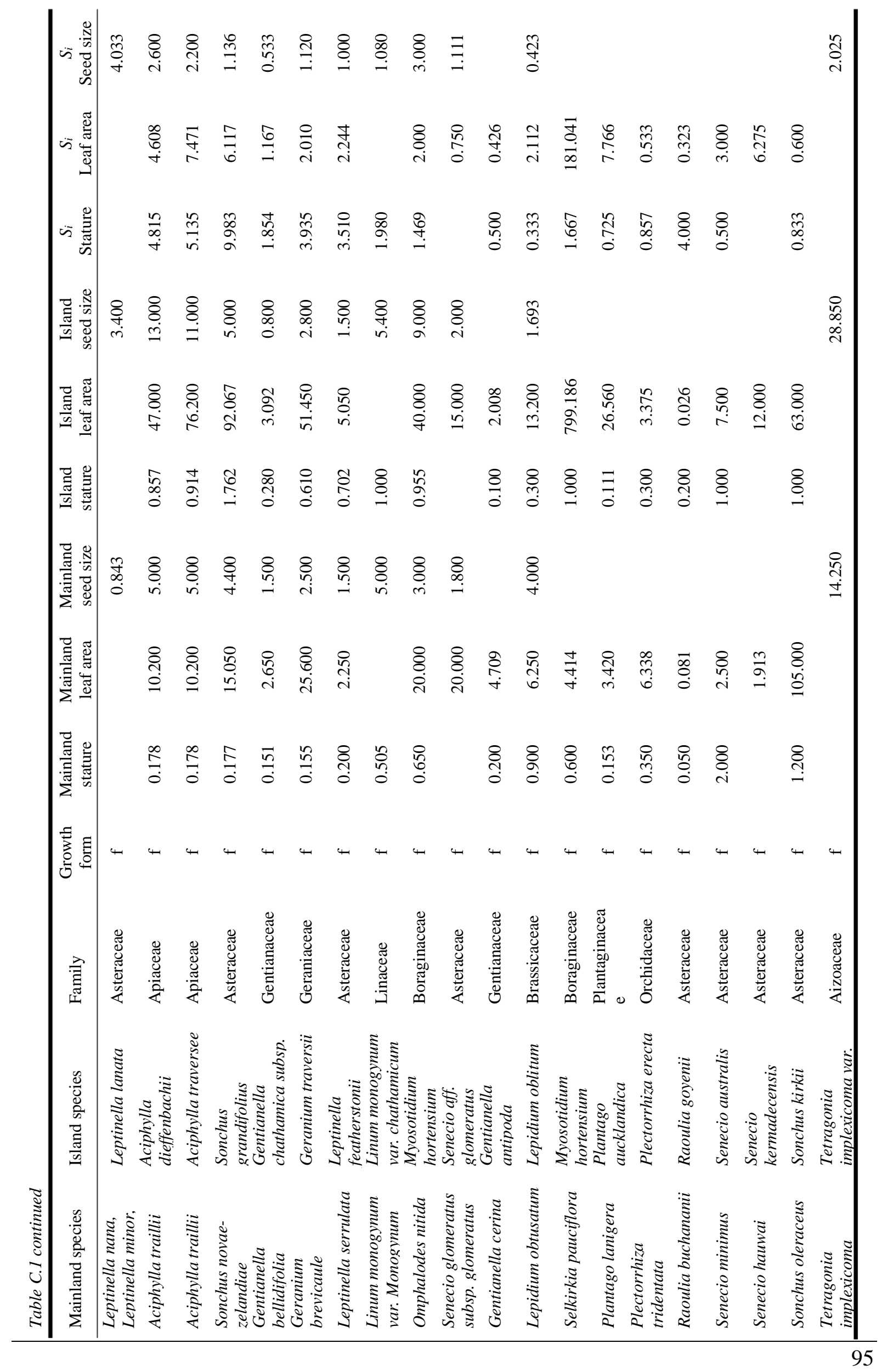


APPENDIX D 


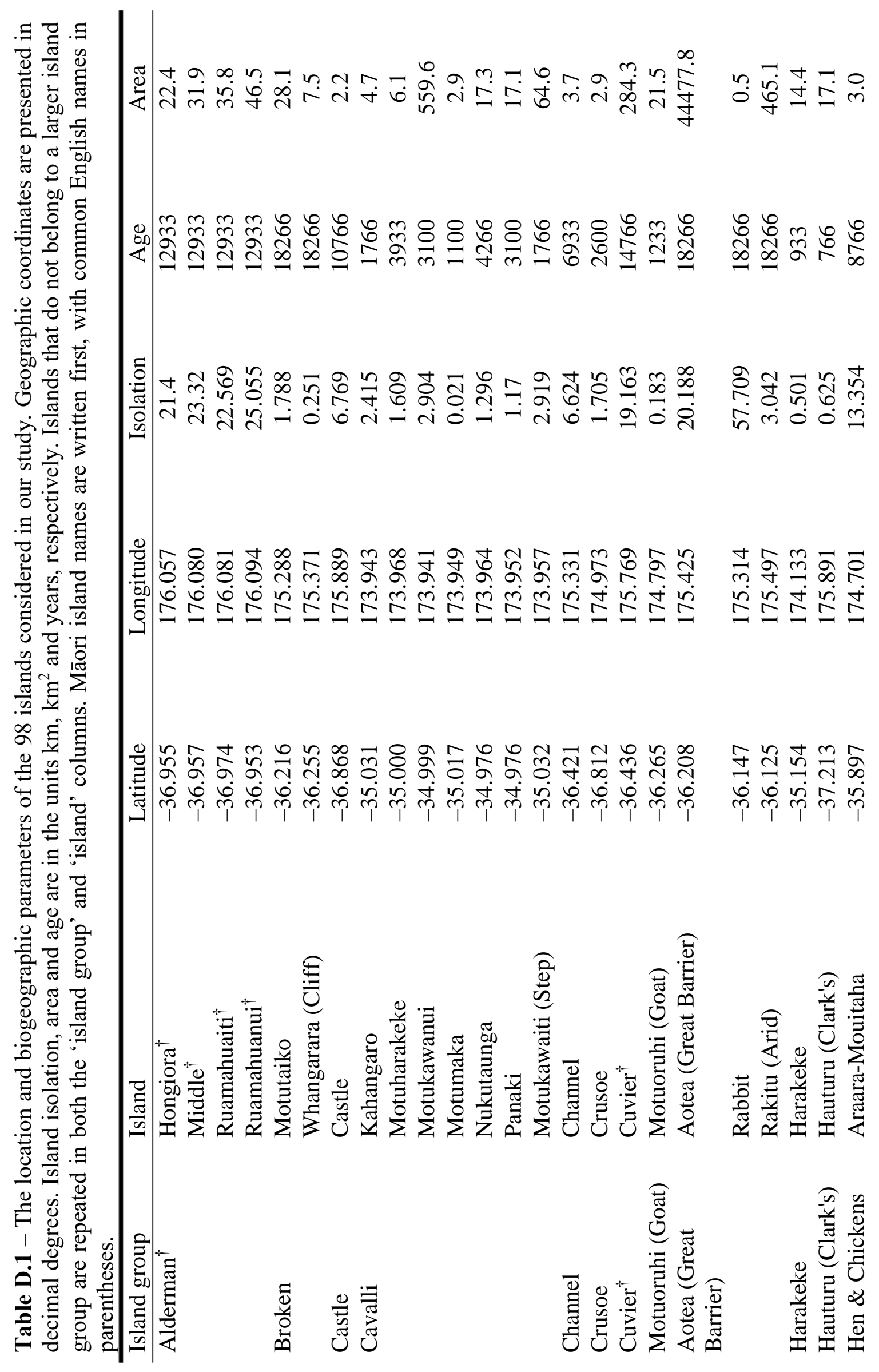




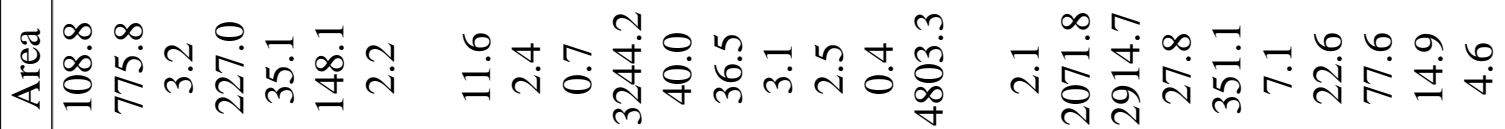
닝ㅇㅇㅇㅇㅇㅇㅇㅇㅇㅠ

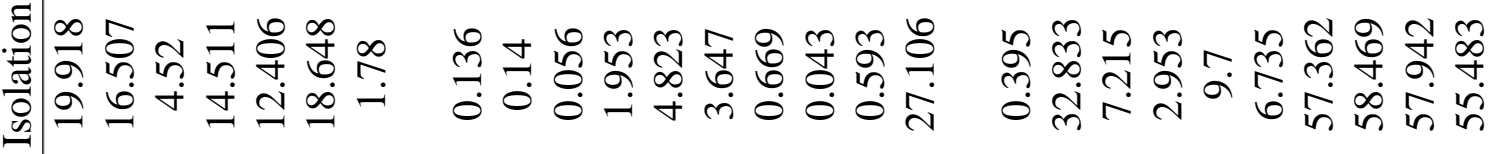

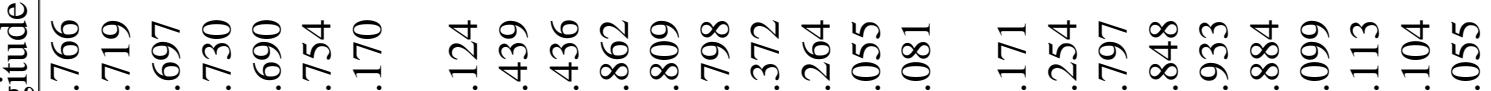

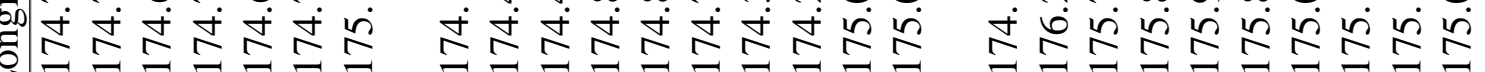

चु

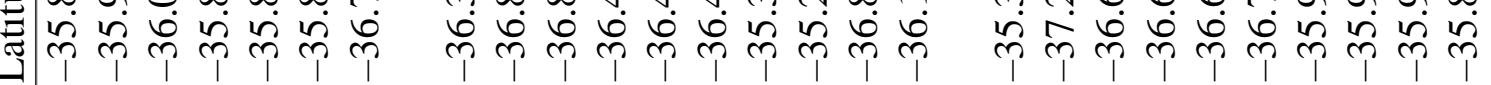

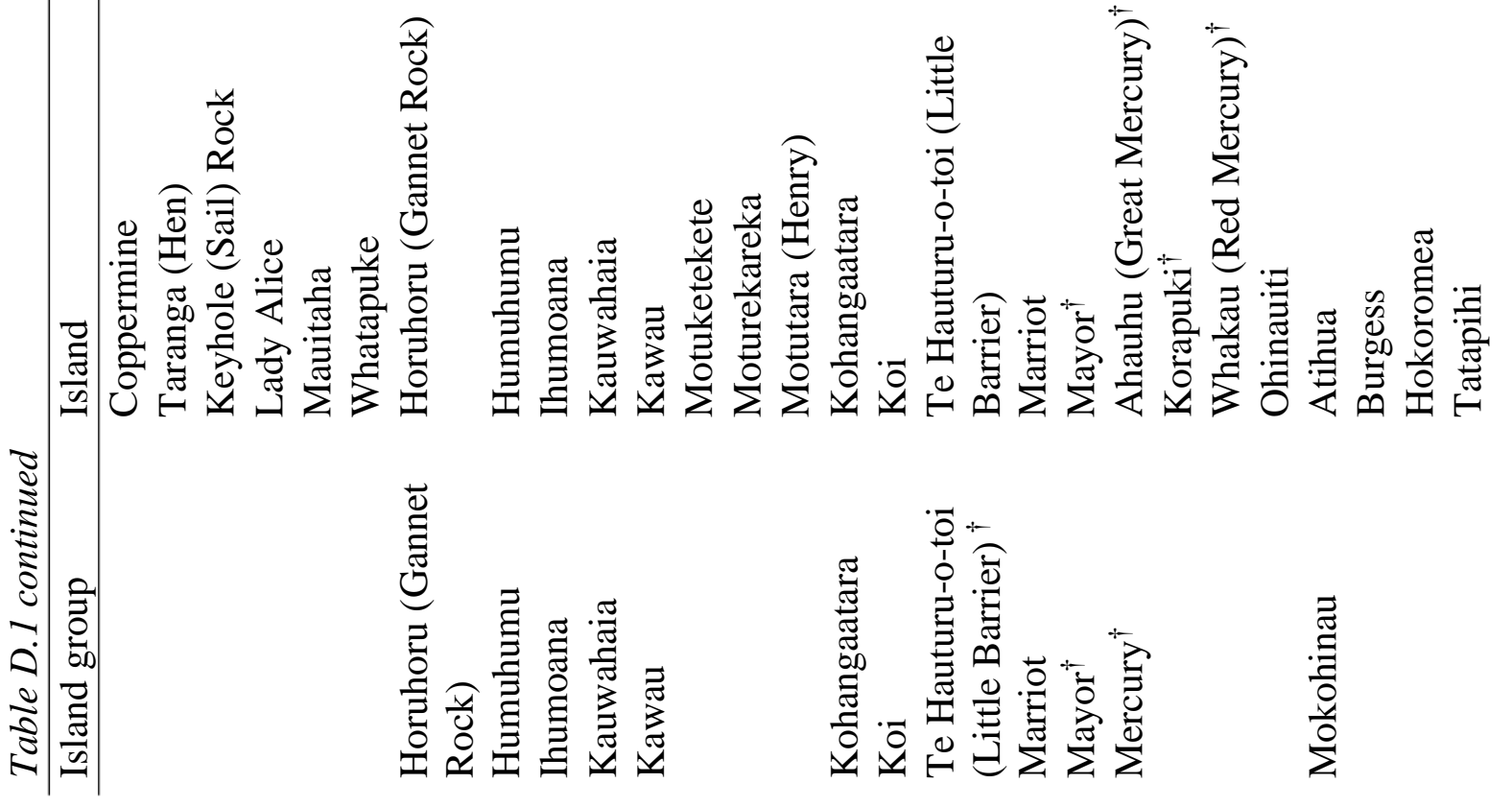




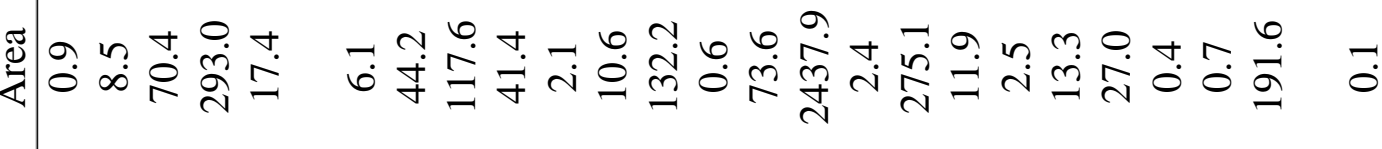

\&্র

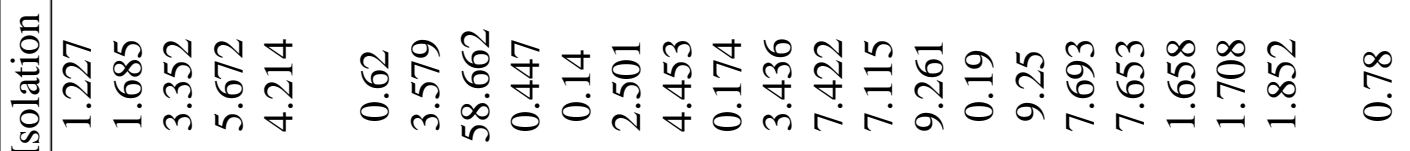

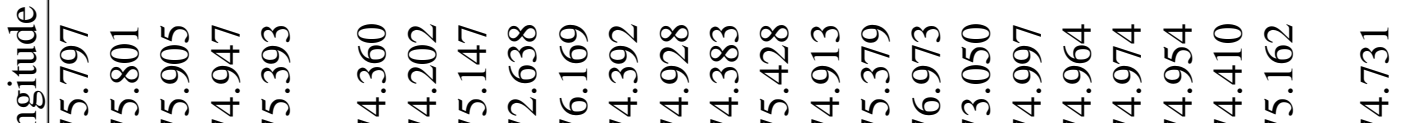

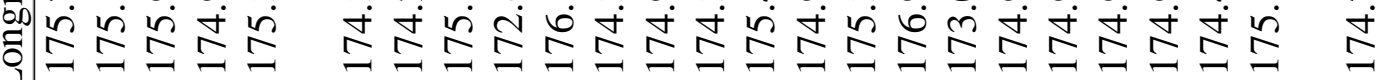

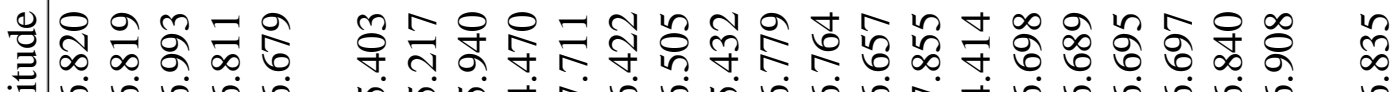

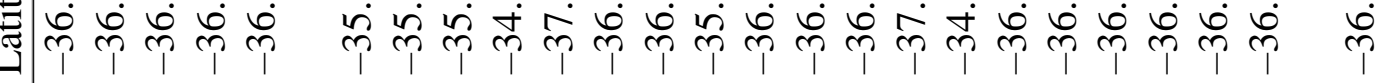

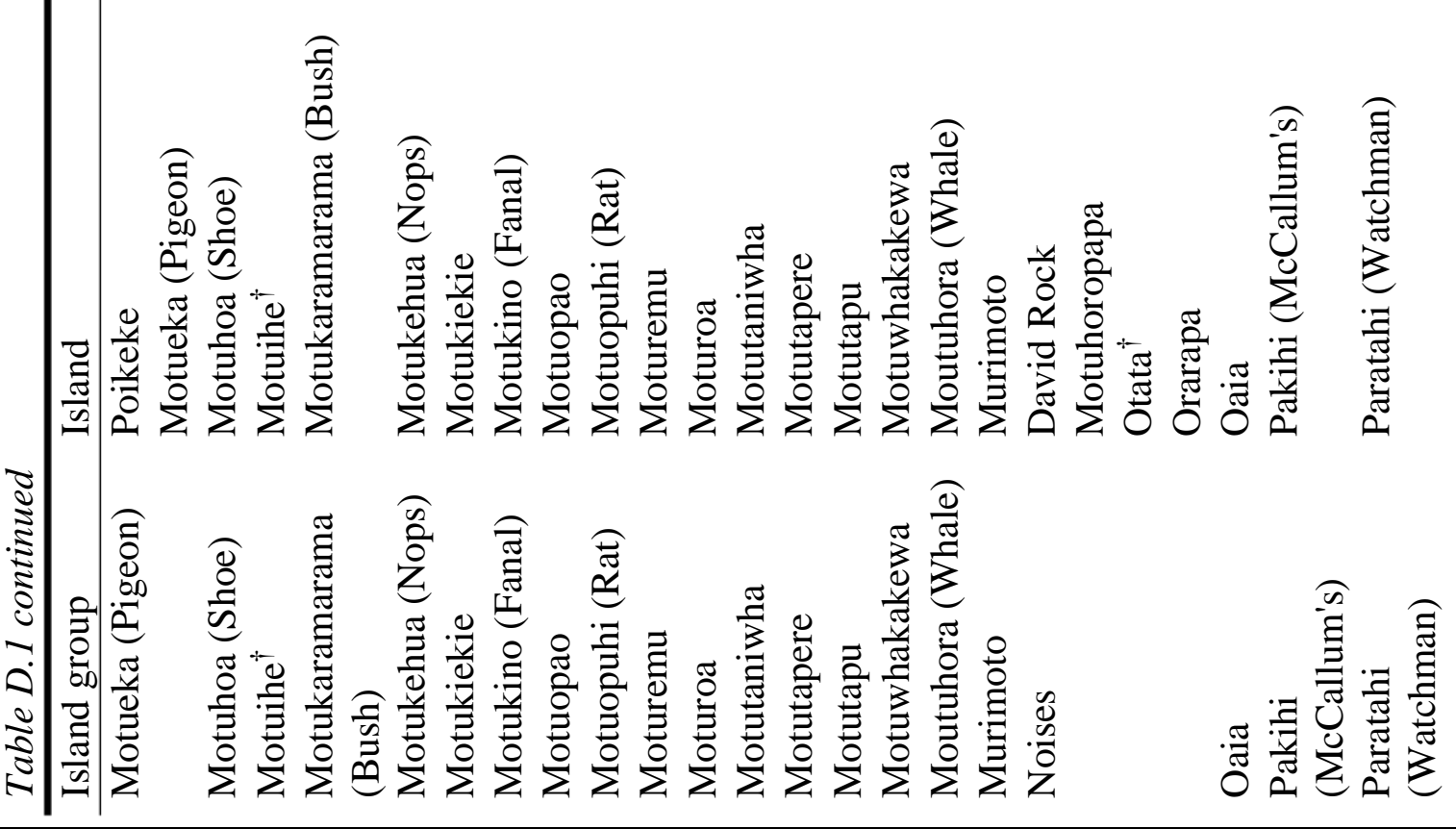




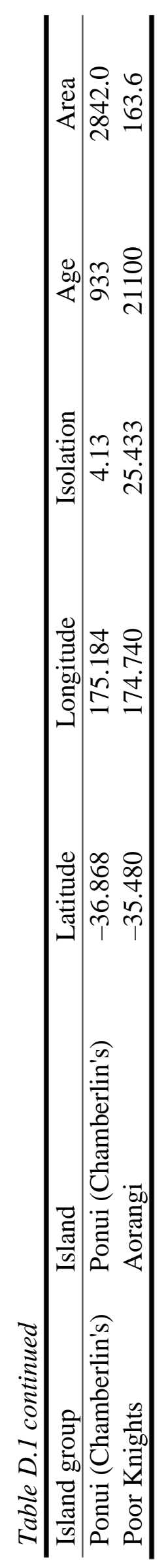

100 